\title{
Spontaneous motor behaviour in full-term small for gestational age and appropriate for gestational age newborn infants
}

Citation for published version (APA):

van Kranen-Mastenbroek, V. H. J. M. (1993). Spontaneous motor behaviour in full-term small for gestational age and appropriate for gestational age newborn infants. [Doctoral Thesis, Maastricht University]. Datawyse / Universitaire Pers Maastricht. https://doi.org/10.26481/dis.19931022vk

\section{Document status and date:}

Published: 01/01/1993

DOI:

10.26481/dis.19931022vk

Document Version:

Publisher's PDF, also known as Version of record

\section{Please check the document version of this publication:}

- A submitted manuscript is the version of the article upon submission and before peer-review. There can be important differences between the submitted version and the official published version of record. People interested in the research are advised to contact the author for the final version of the publication, or visit the DOI to the publisher's website.

- The final author version and the galley proof are versions of the publication after peer review.

- The final published version features the final layout of the paper including the volume, issue and page numbers.

Link to publication

\footnotetext{
General rights rights.

- You may freely distribute the URL identifying the publication in the public portal. please follow below link for the End User Agreement:

www.umlib.nl/taverne-license

Take down policy

If you believe that this document breaches copyright please contact us at:

repository@maastrichtuniversity.nl

providing details and we will investigate your claim.
}

Copyright and moral rights for the publications made accessible in the public portal are retained by the authors and/or other copyright owners and it is a condition of accessing publications that users recognise and abide by the legal requirements associated with these

- Users may download and print one copy of any publication from the public portal for the purpose of private study or research.

- You may not further distribute the material or use it for any profit-making activity or commercial gain

If the publication is distributed under the terms of Article $25 \mathrm{fa}$ of the Dutch Copyright Act, indicated by the "Taverne" license above, 
Spontaneous motor behaviour in full-term small for gestational age and appropriate for gestational age newborn infants 


\section{CIP DATA KONINKLIJKE BIBLIOTHEEK, DEN HAAG}

Kranen-Mastenbroek, Vivianne Henriëtte Johanna Maria van

Spontaneous motor behaviour in full-term small for gestational age and appropriate for gestational age newborn infants / Vivianne Henriëtte Johanna Maria van Kranen-Mastenbroek - Maastricht : Universitaire Pers Maastricht. - III. Thesis Maastricht. - With ref. - With summary in Dutch. ISBN 90-5278-094-3

Subject headings: motor behaviour ; full-term infants / SGA infants. 


\section{Spontaneous motor behaviour in full-term small for gestational age and appropriate for gestational age newborn infants}

\section{PROEFSCHRIFT}

ter verkrijging van de graad van doctor aan de Rijksuniversiteit Limburg te Maastricht, op gezag van de Pro-Rector, Prof. dr. L. Boon, volgens het besluit van het College van Dekanen, in het openbaar te verdedigen

op vrijdag, 22 oktober 1993 om 14.00 uur

door

Vivianne Henriëtte Johanna Maria van Kranen-Mastenbroek geboren op 6 november 1962 te Geleen

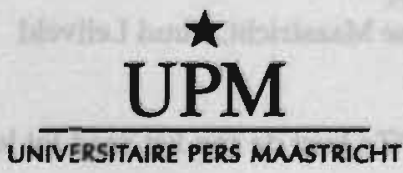




\section{Promotores}

Prof. dr. C.E. Blanco

Prof. dr. J. Troost

Co-promotores

Dr. J.S.H. Vles

Dr. T.H.M. Hasaart

Beoordelingscommissie

Prof. dr. J. de Haan (voorzitter)

Dr. M. Hadders-Algra (Rijksuniversiteit Groningen)

Dr. J. Lodder

Dr. O. van Nieuwenhuizen (Rijksuniversiteit Utrecht)

Prof. dr. F. Spaans

Produktie en lay-out: Datawyse Maastricht, Ruud Leliveld

Druk: Krips Repro, Meppel

Omslag ontwerp: Jos Caelen. "Zo kust de zon het zaad tot leven"

The publication of this thesis was financially supported by:

Ciba-Geigy BV, Glaxo BV, Katwijk Farma BV, Sanofi Winthrop VOF and Sandoz BV 
If I were to prescribe one process in the training of men which is fundamental to succes in any direction, it would be thoroughgoing training in the habit of observation. It is a habit which every one of us should be seeking ever more to perfect.

Eugene G. Grace

Aan mijn vader en moeder Voor Wouter 


\section{Contents}

List of abbreviations $\quad 8$

Chapter 1 General introduction 9

Chapter 2 Review of the literature 13

Chapter 3 Infants and methods 29

Chapter 4 Inter- and intra-observer agreement in the assessment of the quality of spontaneous movements in the newborn 39

Chapter 5 Spontaneous motor behaviour in full-term appropriate for gestational age newborn infants $\quad 47$

Chapter 6 Spontaneous motor behaviour in full-term small for gestational age newborn infants $\quad 67$

Chapter 7 Comparison between spontaneous motor behaviour of fullterm small for gestational age and appropriate for gestational age newborn infants $\quad 87$

Chapter 8 General discussion 97

Chapter 9 Summary and conclusions $\quad 107$

Samenvatting en conclusies $\quad 111$

References $\quad 115$

Appendices $\quad 121$

Publications $\quad 127$

Dankwoord $\quad 128$

Curriculum Vitae 131 


\section{List of abbreviations}

AGA Appropriate for Gestational Age

ATNP Asymmetric Tonic Neck Posture

ATNR Asymmetric Tonic Neck Reflex

BP Blood Pressure

CNS Central Nervous System

$\mathrm{CP} \quad$ Cerebral Palsy

COPD Chronic Obstructive Pulmonary Disease

GM General Movement

HELLP Hemolysis, Elevated Liver function tests, Low Platelet counts

ICH Intracranial Hemorrhage

IQ Intelligence Quotient

IUGR Intrauterine Growth Retardation

MDI Mental Developmental Index

PDI Psychomotor Developmental Index

PI Ponderal Index

PIH Pregnancy-Induced Hypertension

PVL Periventricular Leucomalacia

SGA Small for Gestational Age 
Chapter 1

General introduction 
Several conditions in the pre- and perinatal periods, such as intrauterine growth retardation, fetal distress, asphyxia and peri-/intraventricular haemorrhage, may disturb the structural and functional integrity of the central nervous system (CNS) of the fetus/infant. Infants who have suffered from these adverse conditions are therefore at risk of developing neurological and neurodevelopmental disturbances. Information on CNS function in these infants is of substantial importance, since the early detection of neurological and neurodevelopmental problems may help to predict prognosis, allows possible interventions to stimulate future neurological development and forms the basis for adequate support of the family at early stages.

Over the past 30 years, several examination schemes for the neurological and neurobehavioural assessment of the full-term neonate have been developed (Brazelton 1973; Saint-Anne Dargassies 1977; Prechtl 1979; Dubowitz and Dubowitz 1981). However, various factors limit the clinical value of this neonatal neurological examination:

- the neurological examination, based on the assessment of the responses to certain stimuli, mainly evaluates the integrity of subcortical neuroanatomic structures, especially of the brainstem (Graziani et al. 1977). Nowadays, the infant's nervous system is recognized as a primarily active organ system, being too complex to be explained merely on the basis of reflexes and reactions (Touwen 1984);

- neurological abnormalities in the neonatal period are usually unspecific with respect to etiology and furthermore non-localizing with respect to neuroanatomic structures (Graziani et al. 1977);

- the infant's reflex and behavioural responses are influenced by other factors such as behavioural state, environmental stimulation, prior handling and postural position (Beintema 1968; Graziani et al. 1977);

- the clinical situation (incubator, monitoring, minimal handling etc) may limit the possibility to carry out a complete neurological examination.

Therefore, from a clinical point of view, the relationship between brain activity, as reflected by the neurological examination, and brain structures is difficult to assess in the neonatal period.

Over the past decade, a growing interest has arisen in spontaneous motility as an indicator of central nervous system function in the fetus and the newborn infant. The complex and variable display of infant motor behaviour demonstrates the involvement of large parts of the nervous system and reflects the integration of the two main properties of the infant's brain: the generation of motor patterns and the reaction to stimulation (Touwen 1984).

It is known from studies on spontaneous motility of the fetus (de Vries et al. 1982, 1985; Bekedam et al. 1985; Prechtl 1985, 1988; Visser et al. 1985) and the preterm infant (Gesell and Amatruda 1945; Prechtl et al. 1979; Vles 1988; Vles et al. 1988a, 1988b, 1988c, 1989; Cioni et al. 1990; Ferrari et al. 1990) that 
observation of posture and of quantitative and especially qualitative aspects of spontaneous motor behaviour is a non-invasive procedure which, in addition to the neurological examination, may yield extra information on the condition of the nervous system in the newborn. Although spontaneous motility of the fetus and the preterm infant has been investigated thoroughly, information on spontaneous motor behaviour in healthy full-term infants is limited (Hopkins and Prechtl 1984; Prechtl and Hopkins 1989; Erkinjuntti 1988; Cioni et al. 1988; Hadders-Algra et al. 1992).

One of the conditions which may influence CNS development is intrauterine growth retardation, a frequent complication of pregnancy (Chiswick 1985). Intrauterine malnutrition has been demonstrated to modify several processes in the development of the brain, such as neuronal and glial cell multiplication, myelination, synaptogenesis and dendritic branching (Dobbing and Sands 1971, 1973; Dobbing 1974; Sarma and Rao 1974; Chase 1972, 1976), leading to diffuse quantitative deficits and distortion of quantitative relationships between CNS structures (Dobbing 1979).

The neurological and developmental consequences of these changes in brain development for the infant have been subject to extensive study. Followup studies have shown an increased risk for minor neurological dysfunction and neurodevelopmental and behavioural problems at school age in full-term small for gestational age (SGA) infants (Fitzhardinge and Steven 1972; Low et al. 1978; Walther and Ramaekers 1982; Harvey et al. 1982; Villar et al. 1984; Hill et al. 1984; Ounsted et al. 1988; Hadders-Algra et al. 1988).

Significant differences in neonatal neurological and neurobehavioural performance between full-term SGA and appropriate for gestational age (AGA) infants have been described by several authors (Michaelis et al. 1970; Als et al. 1976; Low et al. 1978; Jurgens-van der Zee et al. 1979; Frederickson and Brown 1980; Ounsted et al. 1988). According to Als et al. (1976), the SGA infant appears in general to be more stressed on handling than his AGA counterpart. This could influence the results of a neurological examination which involves frequent manipulations. Such a disadvantage is not encountered in observational studies of spontaneous motor behaviour.

The aim of the present investigation was:

1. to provide an accurate description of spontaneous motor behaviour in healthy full-term infants;

2. to investigate the influence of intrauterine growth retardation on spontaneous motor behaviour;

3. to investigate whether spontaneous motor behaviour in the newborn is related to future neurological development. 


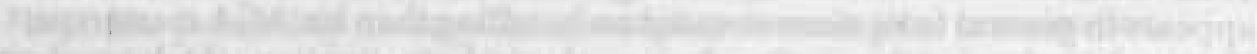

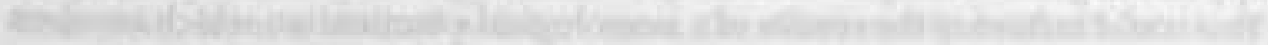

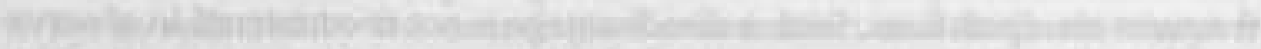

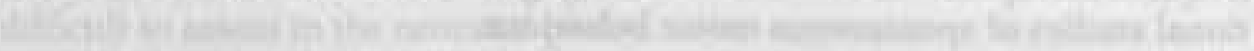

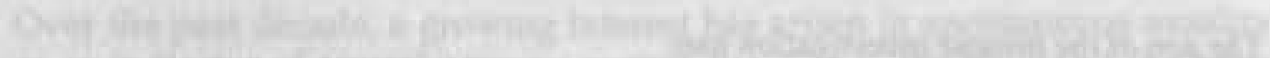

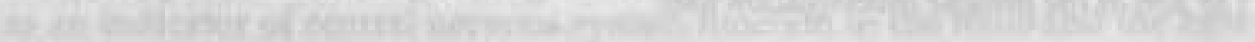

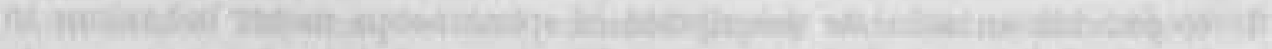

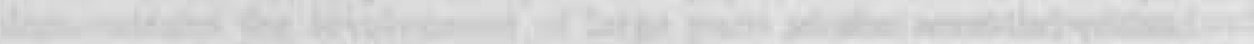

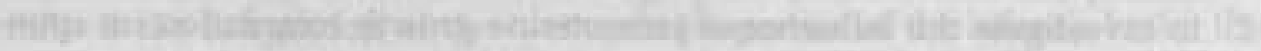

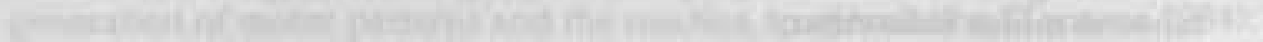

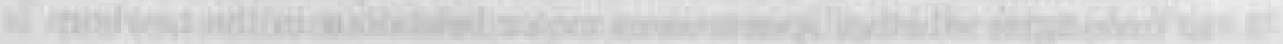

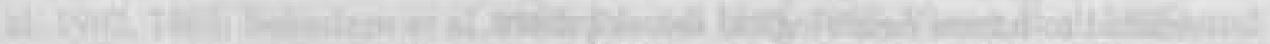

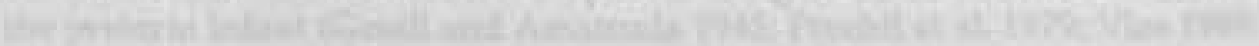

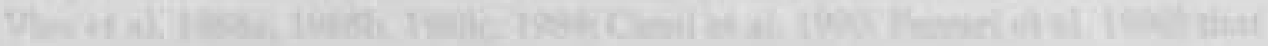




\section{Chapter 2}

\section{Review of the literature}

2.1 Spontaneous motility and posture in the full-term newborn

2.1.1 Quantitative aspects of spontaneous motility

2.1.2 Posture

2.1.3 Asymmetric tonic neck reflex (ATNR)

2.1.4 Quality of movement

2.2 The full-term small for gestational age infant

2.2.1 Introduction

2.2.2 Aetiology of intrauterine growth retardation

2.2.3 Identification of the intrauterine growth retarded infant

2.2.4 Influence of prenatal malnutrition on brain development

2.2.5 Neonatal neurological and behavioural development of small for gestational age newborns

2.2.6 Outcome of full-term small-for gestational age infants

2.3 Conclusions 


\subsection{Spontaneous motility and posture in the full-term newborn}

In the past 30 years several authors have developed and tested methods for the neurological and neurobehavioural assessment of the full-term neonate (Prechtl 1979; Dubowitz and Dubowitz 1981; Brazelton 1973; Saint-Anne Dargassies 1977). The majority of the studies on neurological development and motor behaviour of full-term newborns have used one of these examination methods. Studies of spontaneous motor behaviour in healthy full-term infants are scarce.

To study spontaneous motor behaviour, the following features can be observed: quantitative aspects of motility, posture, the influence of head position on posture, and quality of movement.

\subsubsection{Quantitative aspects of spontaneous motility}

A description of quantitative aspects of motility in 10 healthy full-term infants observed during an one hour video recording on the first and fourth day of postnatal life was published by Cioni et al. (1989). These authors found large inter-individual differences in the rates of specific motor patterns, but observed an intra-individual consistency of these rates on day one and four. Erkinjuntti (1988) studied duration and number of body movements during sleep in healthy and neurologically damaged infants using the static charge sensitive bed at the ages of 1 week, 1 month and 3 months. He found no significant differences between healthy and neurologically damaged infants. None of the authors mentioned above, studied the influence of head position on the distribution of limb movements.

In conclusion:

Information on quantitative aspects of motility in healthy full-term newborn infants is scarce.

\subsubsection{Posture}

Resting posture, as a reflection of muscle tone, can be used for the evaluation of central nervous system maturation in the neonate (Amiel-Tison 1968; Prechtl 1979). Several authors (Andre-Thomas and Saint-Anne Dargassies 1952; Amiel-Tison 1968; Saint-Anne Dargassies 1977; Prechtl 1979; Dubowitz and Dubowitz 1981; Touwen 1984) have described a preference posture in full-term infants which consisted of a full flexed position of all limbs. Cioni et al. (1989) could not confirm this preference posture in a study on spontaneous posture and motility in healthy full-term infants. They observed a large interand intra-individual variability in postural repertoire. Muhiudeen et al. (1984) described the above-mentioned full flexion posture in 3-day old full-term infants as a neutral position to which all infants returned before another posture was assumed. 
Amiel-Tison $(1968,1986)$ described an increase of muscle tone in flexor muscles in caudocephalic progression from 28 to 40 weeks gestational age, as a reflection of CNS maturation, resulting in a full flexion posture of all limbs at term age. Later, within the first year of life, there is a decrease in flexor tone in a cephalocaudal direction, starting with the upper extremities and proceeding to the lower extremities. Prechtl et al. (1979) and Vles et al. (1989) could not demonstrate a correlation between preference posture and gestational age.

Head position preference to the right was observed by Gesell and Halverson (1942), Turkewitz and Creighton (1974), Casaer (1979) and Hopkins et al. (1987). Cioni et al. (1989) and Vles et al. (1991) could not confirm this head position preference.

In conclusion:

There is no consensus in the literature with regard to the existence of a preference position for head and limbs in healthy full-term neonates.

\subsubsection{Asymmetric Tonic Neck Reflex (ATNR)}

This reflex was first described by Magnus and de Kleyn (1912). They investigated the influence of head position on the extremities in decerebrated animals, and demonstrated an increase in tone of the extension muscles on the side that the head was turned to and a decrease in tone of the extension muscles on the opposite side. The animals were decerebrated to prevent voluntary movements. Furthermore, both labyrinths were removed to prevent the occurrence of labyrinth reflexes.

According to Beyers et al. (1938) spontaneous active rotation of the head is often a better way of demonstrating tonic reflexes than a passive head turning. This concurs with Magnus and de Kleyn (1912) who could not demonstrate the ATNR in full-term newborns. According to the authors this was due to the presence of active resistance and voluntary movements.

Gesell (1938) found the reflex present in the spontaneous waking postures as a dominating characteristic of normal infancy in the first 3 months of life in healthy infants. He stated that the persistence of the ATNR after the age of 6 months was pathological and indicative of retarded, arrested or defective development. Pacella and Barrera (1940) found a consistent ATNR in 16 out of 30 full-term newborn infants. In the remaining 14 infants the reflex was variable and inconsistent.

Several authors have demonstrated a peak incidence of the reflex at 2 months of age, and a decrease in incidence from this age onwards (Paine et al. 1964; Capute et al. 1984). Capute et al. (1984) reported the presence of the reflex at birth in the majority of 381 full-term infants, with a peak incidence at 2 months. They concluded that: 1) a complete absence of the ATNR at birth is 
abnormal; 2) an obligatory ATNR is abnormal; 3) a persistent ATNR after the age of 1 year is abnormal.

In contrast, Magnus (1924), Vasella and Karlsson (1962), Paine et al. (1964) and Prechtl and Beintema (1976) found the ATNR to be rare in newborn infants. Cioni et al. (1989) investigated the occurrence of asymmetric tonic neck postures (ATNP) in the most frequently occurring postures in full-term newborns. Their results indicated that an ATNP is rare and, if present, inconsistent in normal full-term newborns.

The discrepancy between the percentages of occurrence of the ATNR reported in the literature may be explained by the variable definition and scoring of the ATNR and the different methods used to study the ATNR (passively elicited versus spontaneous patterns).

In conclusion:

There is no consensus in the literature concerning the influence of head position and head position change on body posture in healthy full-term neonates.

\subsubsection{Quality of movement}

Hopkins and Prechtl were the first to describe the developmental changes in the quality of spontaneous movements in full-term infants (Hopkins and Prechtl 1984; Prechtl and Hopkins 1986). They analyzed the qualitative aspects of general movements (GM), based mainly on Gestalt-perception, from 3 to 18 weeks in 12 healthy full-term infants. In addition to these 12 infants, 11 healthy awake newborn infants were videorecorded during the first hour after birth. All newborn infants in the first hour after birth showed GM with a writhing quality ("squirming, cramped movements which spread, with waxing and waning, throughout the whole body"). All infants observed at the age of three weeks also showed general movements with a writhing movement quality, but they were of higher speed and less languid in appearance than those of the newborn infants in the first hour after birth. At the age of six weeks, most infants displayed a "wiggling-oscillating" movement quality ("irregular, oscillatory, waving-like movements, which are most noticeable in partially or fully extended arms, with a frequency of 2 to $3 \mathrm{~Hz}^{\prime \prime}$ ). The most striking change however, occurred at 9 weeks when a fidgety quality appeared in most infants ("restless but elegant rounded movements which are seen throughout the whole body. They are smooth in appearance and may go on continually during wakefulness"). Later movements became more voluntary-like and goal-directed. The occurrence of the fidgety quality of GM is considered by the authors to be the first major transition in postnatal neurological development. In a recent publication Hadders-Algra et al. (1992) described the existence of 'tight' and 'oose' writhing movements in healthy full-term infants from 2 to 10 weeks of age. At 4 weeks fidgety movements 
became apparent. They were almost constantly present between 8 and 12 weeks of age. The authors found no relationship between general movement development and birth weight. However, all infants studied had a birth weight within the normal full-term range (2560-4930, median $3600 \mathrm{gm})$. Wiggling-oscillating movements occurred at 4 weeks. Saccadic, 'swiping' and 'swatting' movements originated at 8 weeks. This development showed no relation with gestational age at birth. Furthermore, no associations were found between the development of the form of the GM and the items of the neurological examination. They found no sex differences at the ages at which the developmental changes in the form of movements and other aspects of the neurological repertoire occurred. However, none of those studies accurately describe the method by which the classification of the movements was developed. In the publication of Hopkins and Prechtl (1984) a pilot-study was described in which two observers commented on the general movements of six infants. Similar comments in the transcripts of both observers were used as a basis for the classification system. From the description however, it is not clear whether the observers had been given instructions concerning the items which had to be observed, how many general movements were studied, and in what percentage of the general movements the comments were similar. Furthermore, in the studies mentioned, neither the number of general movements judged per infant, nor the percentage of general movements per infant showing the particular quality of movement, was mentioned. Furthermore, the definitions of the observed movement qualities (e.g. 'tight and loose writhing') are very difficult to interpret for people unfamiliar with this method of observation.

Shirataki et al. (1987) studied the developmental changes of quality of movements as described by Hopkins and Prechtl in 5 high-risk and 5 low-risk infants of varying postmenstrual age. They described an abnormally slow development of the different general movement qualities in the high-risk infants.

According to Ferrari and co-workers, the assessment of quality of GM as normal or abnormal, is a sensitive and specific diagnostic procedure concerning the prediction of absence or presence of a brain lesion in preterm infants (Ferrari et al. 1990). According to these authors, the existence of certain developmental trajectories of abnormal aspects of quality of movement is a predictor of neurological outcome.

In conclusion:

Qualitative aspects of spontaneous motor behaviour have been described in full-term infants from 2 to 18 weeks of age. Only one description of quality of movement of healthy full-term infants during the first postnatal week is reported in the literature. However, this is a description of quality of movement in the first hour after birth, when the infant is still recovering from birth (Escardo and de Coriat 1960). 


\subsection{The full-term small for gestational age infant}

\subsubsection{Introduction}

The full-term small for gestational age (SGA) infant is born with a low birth weight due to intrauterine growth retardation (IUGR) and has to be distinguished from preterm infants born with a low birth weight due to a short gestation. Apart from the difference in the process leading to the observed low birth weight, these groups also present different perinatal and postnatal problems which may influence outcome (van Gils 1971).

\subsubsection{Aetiology of intrauterine growth retardation}

Full-term SGA infants constitute a heterogenous group with respect to aetiology, onset and duration of the growth restriction. The factors associated with reduced fetal growth can be of fetal, maternal or placental origin (table 2.1).

Fetal growth is determined by the intrinsic growth potential of the fetus and by an extrinsic factor, namely the support it receives through the placenta from the mother (Cassady 1981). Therefore, impaired fetal growth can be caused by factors affecting the intrinsic growth potential or by factors which reduce nutrition. Most of the fetal causes impair the intrinsic growth potential of the fetus, whereas maternal and placental causes often lead to intrauterine malnutrition on the basis of reduced uteroplacental blood flow and/or reduction of the supply of energy and nutrients across the placenta (Allen 1984; Gross and Sokol 1989).

The severity of the growth retardation does not only depend on the aetiology, but also on the time of onset and duration of the growth retarding insult. On this basis two types of growth retardation can be distinguished. Terms as chronic versus subacute fetal distress, proportionate versus disproportionate growth retardation, symmetrical versus asymmetrical growth retardation and soft tissue type versus skeletal type growth retardation are most frequently used (Warshaw 1985; Miller and Hassanein 1973; Jones and Roberton 1984; Winick 1983; Keirse 1984; Adair 1989). In this review we will use the terms proportionate and dispropertionate growth retardation.

Proportionate growth retardation is described as a symmetric reduction in birth weight, length and skull circumference. It is caused by factors acting early in pregnancy (before the third trimester), for instance fetal factors such as chromosornal anomalies, genetic syndromes, congenital infections or maternal factors like malnutrition, smoking and abuse of alcohol and drugs (Pearce and Campbell 1985). Short stature of the parents (particularly of the mother) can also result in proportionate growth retardation. The infant who is significantly SGA (birth weight below the 2.3 percentile) on the basis of parenta! short stature alone is thought to be rare (Allen 1984; Lubchenco 1976; Usher 1970; Scott and Usher 1966). 
Table 2.1 Factors associated with IUGR

(Adapted from Allen 1984, Gross and Sokoll 1989, Sijmons 1989)

Fetal conditions:

Genetic:

- Parental size

- Chromosomal disorders

- Syndromes

- Inborn errors of metabolism

Congenital infections:

- Toxoplasmosis

- Rubella

- Cytomegalovirus

- Herpes virus

Maternal conditions: Malnutrition

Low socio-economic status

Chronic hypertension

Chronic renal vascular disease

Collagen vascular disease

Hemoglobinopathies

Cyanotic congenital heart disease

Thyrotoxicosis

Preeclampsia

Metabolic abnormalities in maternal blood

Uterine structural abnormalities

Cigarette, alcohol or drug abuse

Therapeutic drugs

Radiation

Placental disorders: Chorioangioma

Hydatiform degeneration

Single umbilical artery

Twin-to-twin transfusion syndrome

Idiopathic

Disproportionate growth retardation is characterized by low birth weight, normal length and skull circumference but loss of subcutaneous tissue. It is associated with factors acting predominantly in the third trimester of pregnancy, such as pregnancy induced hypertension (PIH), which leads to reduced uteroplacental blood flow (Pearce and Campbell 1985; Warshaw 1985).

These two groups often overlap because asymmetry due to influences in later pregnancy may be superimposed on pathologies in early pregnancy 
which produce a symmetrically small fetus (Pearce and Campbell 1985). Recently, Kramer et al. (1989) suggested that proportionality amongst intrauterine growth-retarded infants is a continuum, with progressive disproportionality as severity of growth retardation increases. In an important percentage (34-50\%) of all SGA infants no obvious cause for their growth retardation can be identified (Allen 1984; Gross and Sokol 1989).

\subsubsection{Identification of the IUGR infant}

\section{Intrauterine growth curves}

In the studies reviewed, different growth curves are used, for instance, those of Lubchenco (1963), Usher-McLean (1969), Kloosterman (1969) and Babson (1970). In the Netherlands the Dutch Neonatal Society suggested the use of the Kloosterman intrauterine growth curves, making allowance for sex and parity, as a reference standard for intrauterine growth (Versluys 1980).

\section{Birth weight centiles}

Using an intrauterine growth curve, different birth weight centiles (2.3, 3, 5 and 10) are arbitrarily chosen as a cut-off point for normal fetal growth. Most authors prefer to define SGA as birth weight that is more than 2 standard deviations below the mean for gestational age and sex, corresponding with the 2.3 birth weight centile (Gruenwald 1963; Fitzhardinge and Steven 1972; Leijon et al. 1980; Ounsted et al. 1981; Hawdon et al. 1990).

Whatever centile or other definition is taken as a cutoff point for normal fetal growth, there will always be some infants malnourished in utero who on the basis of their large skeletal sizes will not fit into this limit and will therefore not be recognised as intrauterine growth-retarded (Pearce and Campbell 1985).

\section{Ponderal index}

Rhorer's Ponderal index can be used to define subgroups of intrauterine growth-retarded infants according to their clinical appearance (proportional versus disproportional).

Ponderal index $=\frac{\text { weigth in } \text { grams } \times 100}{\text { length in centimeters }}{ }^{3}$

Infants with a low ponderal index (PI) for their gestational age e.g. below the third (Miller and Hassanein 1973) or 10th (Walther 1982) percentile, are identified as disproportionate or wasted IUGR infants.

According to Miller and Hassanein (1973), the PI is not significantly affected by sex, race, fetal age or parity. Another advantage is that it also identifies those infants who are not identified as growth-retarded on the basis of birth weight for gestational age, because their skeletal sizes are large and their birth weights are consequently well above the cutoff levels generally 
used in diagnosing IUGR, but who are severely malnourished as is expressed by a loss of subcutaneous fat (Miller and Hassanein 1973).

However, if the PI is the only criterium used to screen for intrauterine growth-retarded infants, without taking into account birth weight for gestational age, infants with severe prolonged (proportional) intrauterine growth retardation (and thus a normal PI) are not identified as such.

Another disadvantage of using the PI as the only criterium for growth retardation is that it is subject to error because of methodological difficulties in neonatal length assessment. As length is cubed in the PI, a small error may cause a large difference (Gross and Sokol 1989).

\subsubsection{Influence of prenatal malnutrition on brain development}

The influence of nutrition, especially undernutrition, on brain development has been the subject of extensive research in the past 20 years.

An important issue to consider is the vulnerable period in brain development. The brain seems to be especially vulnerable to nutritional deprivation during the brain growth spurt (Dobbing 1974; Dobbing and Sands 1970, 1971, 1973).

The brain growth spurt is defined as a transient period of growth when the brain is growing most rapidly, extending from 18 weeks gestational age to the end of the second postnatal year (Dobbing 1974).

Some important processes in brain development are: neuroblast multiplication, proliferation of glial cells, migration of neuroblasts and glial cells, differentiation of neurons and glial cells, especially dendritic branching and synaptogenesis, cell death and selective elimination of neuronal processes, and myelination (table 2.2).

\section{Neuroblast multiplication}

Rapid neuroblast multiplication takes place from 10 to 18 weeks gestational age in most parts of the brain. This period is not usually subject to growth restriction, as the nutritional requirements of the fetus are still negligible this early in gestation (Dobbing 1974; Dobbing and Sands 1973). In the cerebellum there are granular neurons which start dividing later, during the brain growth spurt, and therefore could be numerically affected by intrauterine malnutrition. This may have consequences for the development of motor coordination and therefore may be responsible for the later "clumsy child" (Brandt 1981).

However, many other factors may influence neuronal multiplication in all parts of the brain, e.g. X-radiation, infection, therapeutic drugs and chromosomal anomalies. 
Table 2.2 Timing of different processes in brain development

Developmental process

Neuroblast multiplication

Glial cell proliferation

Neuronal migration

Dendritic branching and synaptogenesis

Cell death and selective elimination

of neuronal processes

Myelination
Peak time period

10 - 18 weeks g.a.

18 weeks g.a. -2 years

12 - 20 weeks g.a.

18 weeks g.a. -80 years

24 weeks g.a. - several years

25 weeks g.a. - 20 years

$8^{a}=g_{\text {estational age }}$

Proliferation of glial cells

Glial multiplication is the process occupying the first part of the brain growth spurt starting at 18 weeks gestational age extending well into the second postnatal year (Dobbing 1974).

Two sorts of glial cells can be distinguished: astrocytes and oligodendrocytes. Astrocytes play a nutritive and supportive role in neuronal homeostasis and in the reaction to metabolic and structural insults. They originate from radial glial cells which serve as guides for migration of neuroblasts. Later in pregnancy these radial glial cells proliferate and are transformed into astrocytes (Volpe 1986). Oligodendrocytes are responsible for the synthesis of myelin lipids and formation of myelin sheaths. As prenatal malnutrition influences oligodendrocyte multiplication, it will also influence myelination indirectly.

Chase (1976) demonstrated that total DNA (i.e. DNA in neurons as well as in glial cells) of SGA newborn brain is approximately $81 \%$ of total DNA of AGA newborn brain for cerebrum/brainstem fractions, and only $65 \%$ for cerebellar DNA. In contrast, Sarma and Rao (1974) found a decreased cellularity only in the cerebrum, not in the cerebellum. However, the differences in bodyweight in their study groups were less marked than in the infants studied by Chase.

\section{Migration}

Neurons migrate from their site of origin in the ventricular and subventricular zones to the loci within the CNS where they will stay for life. The peak time for migration is in the third to fifth months of gestation. At 20 to 24 weeks gestation, the cerebral cortex has essentially its full complement of neurons (Volpe 1986). Rees et al. (1988) demonstrated that neuronal migration was not significantly affected by intrauterine growth retardation in fetal sheep brain. In the literature no data were available concerning the effect of intrauterine malnutrition on neuronal migration in human brain. 


\section{Dendritic branching and synaptogenesis}

These two processes which are very important to normal brain development also coincide with the brain growth spurt, commencing at 18 weeks gestational age and according to Herschkowitz (1989) persisting up to 80 years.

According to Dobbing (1979) even moderate fetal malnutrition during the brain growth spurt period can reduce the number of synapses per neuron by $40 \%$. Thomas et al. (1979) demonstrated a $37 \%$ and $31 \%$ deficit in synaps-toneuron ratio in respectively frontal cortex and cerebellar granular layer of rats undernourished from birth to 30 days of age. Bedi (1986) found no significant difference in synaps-to-neuron ratio between rats undernourished in early life and control rats at 160 days of age. He concluded that the deficits in synapsto-neuron ratios, produced as a result of undernutrition in early life, were reversible. Rees et al. (1988) demonstrated a significant reduction in the growth of the neuropil (which is the space between neuronal cell bodies and includes axons, dendrites, synapses and glial cell processes) in fetal sheep affected by intrauterine growth retardation. The functional consequences of such a reduction are still unknown (Brandt 1981).

\section{Cell death and selective elimination of neuronal processes}

These are two "regressive events" that are of major importance in brain development.

Cell death serves to adjust the size of each neuronal population to the size or functional need of its projection field. Furthermore, it eliminates neurons which axons have grown towards the wrong target or an inappropriate region within the target range.

The selective elimination of neuronal processes results in the removal of terminal axcnal branches and their synapses. The two "regressive events" are restricted to the organisational period of brain development from 6 months gestational age to several postnatal years. It is likely that they are modified when the brain is injured. Therefore, after this period the plasticity of developing brain decreases (Volpe 1986).

\section{Myelination}

The phase of glial multiplication is followed by a period of rapid myelination. This period occupies the second half of the brain growth spurt. The brain growth spurt ends as myelination is completed towards the end of the second postnatal year. The peak velocity of myelination is around birth when only a small fraction of adult myelin is present, turning into slow myelination at the age of 1 year. In some areas of the brain myelination goes on for over two decades (Herschkowitz 1988).

Chase et al (1972) and Sarma and Rao (1974) demonstrated a lower myelin lipid content of SGA newborn brain compared to AGA newborn brain. 
In conclusion:

There seems to be no doubt that prenatal malnutrition can influence brain development. Its consequences are dependent on timing and duration of the insult. Nutritional deprivation in early pregnancy (before 18 weeks gestational age) will merely influence neuroblast proliferation whereas nutritional deprivation in later pregnancy will influence glial cell multiplication, neuronal differentiation and migration, and myelination. However, the functional consequences of these alterations in brain development still remain to be resolved.

\subsubsection{Neonatal neurological and behavioural development of SGA newborns}

The neonatal period is the only period in which we can assess the influence of intrauterine malnutrition on the function of the CNS and its development, before the extrauterine environment can exert its influence. Several authors studied neonatal neurological and neurobehavioural performance in fullterm SGA newborns (Michaelis et al. 1970; Als et al. 1976; Low et al. 1978; Jurgens-van der Zee et al. 1979; Frederickson and Brown 1980; Ounsted et al. 1988). The results are summarized in table 2.3 .

Significant differences between full-term SGA and AGA newborns were found, not only in reflex behaviour (Moro, ATNR, crawling, sucking, rooting, stepping, gripping and placing responses), but also in tone, quality of movement, activity, visual activity and responsiveness. Als et al. (1976) described the typical underweight newborn as showing poor responsiveness to social stimuli and as giving an overall impression of stress when handled.

On the other hand, Ounsted et al. (1988) did not find any differences between full-term SGA and AGA infants until the age of 2 months, when SGA infants became noticeably retarded.

In conclusion:

Marked differences in neonatal neurological and behavioural development between full-term SGA and AGA newborns have been described by several authors. They all used neurological and/or behavioural examination methods. However, as SGA newborns seem to be more stressed on handling (Als et al. 1976), this could also influence the results of those examinations in which frequent manipulations are necessary. Therefore, it is important to investigate whether these differences also exist in spontaneous motor behaviour. To our knowledge no studies on spontaneous motor behaviour in full-term SGA newborns, have been published until now.

\subsubsection{Outcome of full-term SGA infants}

Despite the numercus follow-up studies of SGA infants published in the past 20 years, there is no unequivocal answer to the question considering the effect 
Table 2.3 Studies on neonatal behaviour of full-term SGA newborns.

\begin{tabular}{|c|c|c|c|c|}
\hline Author & $\begin{array}{l}\text { Study group } \\
\text { SGA-criteria }\end{array}$ & $\begin{array}{l}\text { Control group } \\
\text { criteria }\end{array}$ & Assessment & Findings SGA \\
\hline Michaelis of al. 1970 & $\begin{array}{l}22 \mathrm{FT} \cdot \mathrm{SGA} \\
<\mathrm{P} 10\end{array}$ & $\begin{array}{l}25 F \\
\text { P10- }\end{array}$ & N.E. & $\begin{array}{l}\text { different Moro } \\
\text { sustained ATNR } \\
\text { frequent wind-mill motions } \\
\text { infrequent head lifting } \\
\text { loss rhythmic head turning } \\
\text { poor standing response } \\
\text { poor stepping movements }\end{array}$ \\
\hline Ns et al. 1976 & $\begin{array}{l}10 \mathrm{FT} \text {. } \\
\text { undenweight } \\
\mathrm{PI}<\mathrm{P} 10\end{array}$ & $\begin{array}{l}\text { 10 FT-hull-weight } \\
\text { PI > P10 }\end{array}$ & BNBAS & $\begin{array}{l}\text { poor tone } \\
\text { low activity levels: } \\
\text { poor hand-b-mouth coordination } \\
\text { jorky movements } \\
\text { poor crawling and walking } \\
\text { poor sucking and rooting } \\
\text { poor responsiveness } \\
\text { poor delensive reactions }\end{array}$ \\
\hline Low ot al. 1978 & $\begin{array}{l}86 \mathrm{FT}-S G A \\
<P 10\end{array}$ & $\begin{array}{l}\text { 97FT-AGA } \\
\text { P10-P90 }\end{array}$ & Bohavioural studies & $\begin{array}{l}\text { lower activity score } \\
\text { less visual activity }\end{array}$ \\
\hline $\begin{array}{l}\text { Jurgens-van der Zee ot } \\
\text { al. } 1979\end{array}$ & $\begin{array}{l}\text { 184 FT-SGA } \\
15 \text { PT-SGA } \\
\text { <P10 }\end{array}$ & $\begin{array}{l}1247 \text { FT-AGA } \\
61 \text { PT-AGA } \\
\text { P10-P90 }\end{array}$ & N.E. & $\begin{array}{l}\text { more neurological abnomalities, } \\
\text { especially in acidemic SGA infants }\end{array}$ \\
\hline $\begin{array}{l}\text { Frederickson and } \\
\text { Brown } 1980\end{array}$ & $\begin{array}{l}\text { 9FT-SGA } \\
<P 10\end{array}$ & $\begin{array}{l}16 F T-A G A \\
>P 10\end{array}$ & $\begin{array}{l}\text { Moro } \\
\text { Grip-response }\end{array}$ & $\begin{array}{l}\text { waker 2nd phase of Moro } \\
\text { longer 2nd phase of grip response }\end{array}$ \\
\hline Ounsted et al. 1988 & $\begin{array}{l}137 \text { FT-SGA } \\
<-2 \text { sd }\end{array}$ & $\begin{array}{l}170 \mathrm{FT} \cdot A G A \\
>-2 \mathrm{sd}\end{array}$ & $\begin{array}{l}\text { neuro-behavioural } \\
\text { assessment }\end{array}$ & no differences with AGA Inlants \\
\hline
\end{tabular}

FT=Full-term; $P T=$ Preterm; $S G A=$ Small for gestational age; $A G A=$ Appropriate for gestational age; N.E.=Neurological examination; $B N B A S=B$ razelton Neonatal Behavioural Assessment Scale; $P I=$ Ponderal Index; sd=standard deviations

of intrauterine growth retardation on neurodevelopmental outcome in small for gestational age infants.

As the population of SGA infants is not a homogeneous one, and the follow-up studies show a great variation in design, it is not surprising that they do not all get the same results.

In tables 2.4a and 2.4b follow-up studies of full-term SGA infants published in the past two decades are summarized. The results of the studies show considerable discrepancies.

In a short-term follow-up study Low et al. (1978), as well as Ounsted et al. (1988), found significantly lower mental and psychomotor developmentall indices (MDI and PDI) at the postnatal age of 12 months in the intrauterine growth retarded infants as compared to the infants in the control group. No significant neurological differences were observed. 
Table 2.4a Follow-up studies of full-term SGA infants.

\begin{tabular}{|c|c|c|c|c|c|}
\hline Authors & Year of birth & $\begin{array}{l}\text { Study group } \\
\text { SGA criteria }\end{array}$ & $\begin{array}{l}\text { Control group } \\
\text { crieria }\end{array}$ & $\begin{array}{l}\text { Follow-up assessrnent } \\
\text { method and age }\end{array}$ & Results \\
\hline $\begin{array}{l}\text { Fitzhard- } \\
\text { inge and } \\
\text { Steven } \\
1972\end{array}$ & $1960-1966$ & $\begin{array}{l}96 \text { FT-SGA } \\
<P 3\end{array}$ & 36 FT-AGA & $\begin{array}{l}\text { Neurological exam. } \\
\text { Speech assessment } \\
\text { EEG } \\
\text { Developmental tost } \\
\text { School evaluation } \\
46 \text { years }\end{array}$ & $\begin{array}{l}\text { SGA group: } 1 \% \text { CP, } 6 \% \\
\text { convulsions. } 25 \% \text { minor } \\
\text { neurological dystunction. EEG } \\
\text { abnormalites in } 59 \% \text { of the } \\
\text { boys and } 69 \% \text { of the girls. } \\
\text { Speech defects in } 33 \% \text { of the } \\
\text { boys and } 26 \% \text { of the girls. } \\
\text { Average } 1095 \text { for boys and } \\
101 \text { for girls but poor school } \\
\text { pertormance in } 50 \% \text { of the } \\
\text { boys and } 36 \% \text { of the girls. }\end{array}$ \\
\hline
\end{tabular}

\begin{tabular}{|c|c|c|c|c|c|}
\hline $\begin{array}{l}\text { Low of al. } \\
1978\end{array}$ & early 1970's & $\begin{array}{l}86 \mathrm{FT}-\mathrm{SGA} \\
<\mathrm{P} 10\end{array}$ & $\begin{array}{l}97 \text { FT.AGA } \\
>P 25\end{array}$ & $\begin{array}{l}\text { Nour. examination } \\
\text { Developmental lost } \\
1 \text { year }\end{array}$ & $\begin{array}{l}\text { No neurological differences. } \\
\text { Significantly lower MDI and } \\
\text { PDI for SGA infants. }\end{array}$ \\
\hline $\begin{array}{l}\text { Walther } \\
\text { and } \\
\text { Ramaekers } \\
1982\end{array}$ & $1976-1977$ & $\begin{array}{l}25 \text { FT-SGA } \\
8 W<P 10 \\
P I<P 10\end{array}$ & $\begin{array}{l}25 F T-A G A \\
B W>P 10 \\
P 1>P 25\end{array}$ & $\begin{array}{l}\text { Neurological exam. } \\
\text { BSQ and BOR } \\
3 \text { years }\end{array}$ & $\begin{array}{l}\text { No major neurological defects, } \\
\text { but significantly more } \\
\text { neurological dystunction and } \\
\text { behavioural problems in the } \\
\text { SGA group. }\end{array}$ \\
\hline $\begin{array}{l}\text { Harvey ot } \\
\text { al. } 1982\end{array}$ & $?$ & $\begin{array}{l}\text { 51 FT-SGA } \\
<P 10\end{array}$ & $\begin{array}{l}51 \text { FT-AGA } \\
>P 10\end{array}$ & $\begin{array}{l}\text { Developmental } \\
3-7 \text { years }\end{array}$ & $\begin{array}{l}\text { Lower scores only in SGA } \\
\text { infants whose head growth } \\
\text { began to slow before } 26 \\
\text { woeks gestation, not in other } \\
\text { SGA infants. }\end{array}$ \\
\hline $\begin{array}{l}\text { Low of al. } \\
1982\end{array}$ & oarly 1970's & $\begin{array}{l}76 \text { FT.SGA } \\
<P 10\end{array}$ & $\begin{array}{l}\text { 88 FT-AGA } \\
>\text { P25 }\end{array}$ & $\begin{array}{l}\text { Neurological exam. } \\
\text { Developmental lost } \\
\text { Language assessment } \\
\text { School evaluation } \\
6 \text { years }\end{array}$ & $\begin{array}{l}\text { No significant differences } \\
\text { between SGA and control } \\
\text { group }\end{array}$ \\
\hline $\begin{array}{l}\text { Westwood } \\
\text { of al. } 1983\end{array}$ & $1960-1966$ & $\begin{array}{l}33 \mathrm{FT}-\mathrm{SGA} \\
<\mathrm{PB}\end{array}$ & $\begin{array}{l}\text { 33 FT-AGA } \\
\text { P25-P75 }\end{array}$ & $\begin{array}{l}\text { Neurological exam. } \\
\text { Developmental tost } \\
13-19 \text { years }\end{array}$ & $\begin{array}{l}\text { No significant differences } \\
\text { between SGA and control } \\
\text { group }\end{array}$ \\
\hline $\begin{array}{l}\text { Hill ot al. } \\
1984\end{array}$ & 1964-1965 & $\begin{array}{l}\text { 33 FT-CIMN } \\
\text { loss of } \\
\text { subcut.tissue }\end{array}$ & $\begin{array}{l}\text { 13FT-CIWN } \\
\text { abundance of } \\
\text { subcut tissue }\end{array}$ & $\begin{array}{l}\text { Neurological exam. } \\
\text { Developmental test } \\
12-14 \text { yoars }\end{array}$ & $\begin{array}{l}\text { No major neurological } \\
\text { impaiment. } 42 \% \text { of CIMN } \\
\text { infants were mentally retarded } \\
\text { of had a leaming disability }\end{array}$ \\
\hline
\end{tabular}

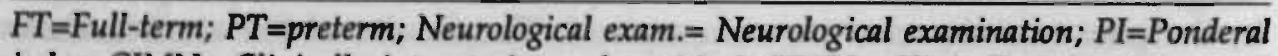
index; $C I M N=$ Clinically intrauterine malnourished; $C I W N=$ Clinically intrauterine well nourished; $B W=b i r t h$ weight; Developmental test includes every neurodevelopmental test including intelligence tests. $B S Q=$ behaviour screening questionnaire; $B O R=$ Behaviour observation report; $M D I=$ mental developmental index; $P D I=$ Phychomoter developmental index 
Table 2.4b More follow-up studies of full-term SGA infants.

\begin{tabular}{|c|c|c|c|c|c|}
\hline Authors & Year of bith & $\begin{array}{l}\text { Sudy group } \\
\text { SGA criteria }\end{array}$ & $\begin{array}{l}\text { Control group } \\
\text { criteria }\end{array}$ & $\begin{array}{l}\text { Follow-up assessment } \\
\text { method and agg }\end{array}$ & Results \\
\hline $\begin{array}{l}\text { Villar et al. } \\
1984\end{array}$ & $1969-1977$ & $\begin{array}{l}59 \mathrm{FT} \text {-SGA } \\
<P 10\end{array}$ & $\begin{array}{l}146 \text { FT-AGA } \\
\text { P10-P90 }\end{array}$ & $\begin{array}{l}\text { Devolopmental tast } \\
3 \text { years }\end{array}$ & $\begin{array}{l}\text { SGA infants scored lower than } \\
\text { AGA infants.SGA infants with } \\
\text { a PI < P10 scored lower than } \\
\text { SGA infants with a PI > P10 }\end{array}$ \\
\hline $\begin{array}{l}\text { Hadders- } \\
\text { Agra el al. } \\
1988\end{array}$ & $1977-1978$ & $\begin{array}{l}166 \mathrm{FT}-\mathrm{SGA} \\
<\mathrm{P} 10\end{array}$ & $\begin{array}{l}206 \mathrm{FT} \cdot \mathrm{AGA} \\
>\mathrm{P} 10\end{array}$ & $\begin{array}{l}\text { Neurological exam. } \\
\text { Behavioural } \\
\text { questionnaires } \\
6 \text { yoars }\end{array}$ & $\begin{array}{l}\text { More neumological } \\
\text { abnormalities in } S G A \text { group, } \\
\text { esp. in infants with } B W<P 2,3 \text {. } \\
\text { No behavioural difterences }\end{array}$ \\
\hline $\begin{array}{l}\text { Ounsted et } \\
\text { al. } \\
1988\end{array}$ & $1973-1977$ & $\begin{array}{l}137 \text { SGA } \\
<-2 \text { sd }\end{array}$ & $\begin{array}{l}170 \text { SGA } \\
>-2 \text { sd }\end{array}$ & $\begin{array}{l}\text { Neurobehavioural } \\
\text { assessment } \\
2,6 \text { and } 12 \text { months }\end{array}$ & $\begin{array}{l}\text { significantly lower } \\
\text { neurobehavioural scores in } \\
\text { SGA inlants from } 2 \text { months } \\
\text { onwards. }\end{array}$ \\
\hline 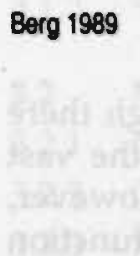 & 1960 's & $\begin{array}{l}\text { 467FT-SGA } \\
<\text { P10 }\end{array}$ & $\begin{array}{l}4068 F T \cdot A G A \\
>P 10\end{array}$ & $\begin{array}{l}\text { Neurological exam. } \\
7 \text { years }\end{array}$ & $\begin{array}{l}\text { No significant differences in } \\
\text { absence ol hypoxia-related } \\
\text { lactors. In presence of } \\
\text { hypoxia-reated facters more } \\
\text { neurological abnornalites in } \\
\text { the SGA infants, esp. In } \\
\text { infants with eymmetric IUGR }\end{array}$ \\
\hline $\begin{array}{l}\text { Hawdon ot } \\
\text { al. } 1990\end{array}$ & $1973-1974$ & $\begin{array}{l}30 \mathrm{FT}-\mathrm{SGA} \\
<\mathrm{P2} \\
\text { (only boys) }\end{array}$ & $\begin{array}{l}30 \mathrm{FT}-\mathrm{AGA} \\
>\mathrm{P2} \\
\text { (only boys) }\end{array}$ & $\begin{array}{l}\text { Neurological exam. } \\
\text { Developmental test } \\
10-11 \text { years }\end{array}$ & $\begin{array}{l}2 \text { cases in SGA group } \\
\text { profoundly disabled and } \\
\text { excluded from lesting. No } \\
\text { differences in intelligence and } \\
\text { school achievement. More } \\
\text { behavioural abnormallies } \\
\text { (esp. features of "attention } \\
\text { deficit disorder") in SGA group }\end{array}$ \\
\hline
\end{tabular}

$P I=$ Ponderal index; FT=Full-term; Neurological exam. $=$ Neurological examination; $B W=$ birth weight; sd=standard deviation; IUGR=Intrauterine Growth Retardation

In their long-term follow-up studies Villar et al. (1984) and Hill et al. (1984) found significant differences in neurodevelopmental scores and IQ, SGA infants scoring lower than the AGA infants. Harvey et al. (1982) only found this difference in infants whose head growth began to slow down before 26 weeks gestation, whereas SGA infants whose head growth began to slow down later in gestation scored comparable to AGA infants. Fitzhardinge and Steven (1972) found an increased risk of major neurological abnormalities such as cerebral palsy (CP) and seizures in SGA infants. Minor neurological dysfunction (e.g hyperactivity, short attention span, learning problems, poor fine coordination, and hyperreflexia) was found by several authors (Fitzhardinge and Steven 1972; Hadders-Algra et al. 1988; Walther and Ramaekers 1981). Berg (1989) found an increased risk of neurological abnormalities in 
IUGR infants only in the presence of hypoxia-related factors, especially in those infants with symmetrical IUGR. No distinction was made between major and minor neurological abnormalities. Villar et al. (1984) observed that SGA infants with an appropriate PI (symmetrical IUGR) scored lower than SGA infants with a low PI (asymmetrical IUGR), while both groups scored lower than the AGA infants. Walther and Ramaekers (1982) compared SGA infants who suffered asymmetrical IUGR with AGA infants and found significantly more neurological dysfunction and behavioural problems in the SGA infants.

In contrast to the studies mentioned above neither Low et al. (1982) nor Westwood et al. (1983) and Hawdon et al. (1990) found significant differences between SGA and AGA infants. The studygroup of Westwood et al. consisted of part of the cohort studied by Fitzhardinge and Steven at an earlier age.

For an extensive review of the follow-up studies of SGA infants see the review articles of Allen (1984) and Teberg et al. (1988).

\section{In conclusion:}

From the studies mentioned above it can be concluded that although there may be a slightly increased risk of major neurological problems, the vast majority of the full-term SGA infants will have no major handicap. However, there is clear evidence of an increased risk of minor neurological dysfunction and neurodevelopmental and behavioural problems at around school age in term SGA infants who suffered from symmetrical IUGR as well as in those who suffered from asymmetrical IUGR. The risk increases in the presence of neonatal problems (Berg 1989; Hadders-Algra et al. 1988).

\subsection{Conclusions}

1. Many factors may cause or are associated with intrauterine growth retardation, but in an important percentage of SGA infants no cause for the growth retardation can be identified.

2. Prenatal malnutrition can influence many processes in brain growth and development.

3. From follow-up studies of full-term SGA infants it can be concluded that symmetrically as well as asymmetrically growth retarded SGA infants are at an increased risk for minor neurological dysfunction, behavioural and school problems at later age, and that the risk increases in the presence of neonatal problems.

4. Marked differences in neonatal neurological and behavioural development between SGA and AGA infants have been described, but knowledge of spontaneous motor behaviour in full-term SGA and AGA infants is very limited. 


\section{Chapter 3}

\section{Infants and methods}

3.1 Infants

3.1.1 Inclusion criteria

3.1.2 Exclusion criteria

3.1.3 Study population

\subsection{Methods}

3.2.1 Neonatal neurological examination

3.2.2 Observation session

3.2.3 Playback

3.2.4 Follow-up

3.2.5 Statistical analysis 


\subsection{Infants}

\subsubsection{Inclusion criteria}

\section{AGA infants:}

- postmenstrual age at birth $37-42$ weeks;

- birth weight between the 10 th and 97.7 centile of the Dutch Kloosterman intrauterine growth curves (Kloosterman 1970).

\section{SGA infants:}

- postmenstrual age at birth 37-42 weeks;

- birth weight below the 2.3 centile of the Dutch Kloosterman intrauterine growth curves (Kloosterman 1970).

By definition, postmenstrual age is the interval between the first day of the last menstrual period and the day of birth. If the last menstrual period was uncertain, postmenstrual age was corrected by using the fetal biparietal diameter, measured by means of ultrasound before the 20th week of pregnancy.

\subsubsection{Exclusion criteria}

1. non-Caucasian parents;

2. no spontaneous vaginal delivery;

3. apgar score at 1 or 5 minutes $<6$;

4. umbilical artery $\mathrm{pH} \leq 7.10$;

5. congenital malformations, infections or chromosomal abnormalities;

6. abnormal cranial ultrasound scan;

7. intensive care needed at the time of observation.

AGA infants born after a complicated pregnancy were excluded from the study. A complicated pregnancy was defined as:

- presence of criteria selected from Kloosterman (1983) as mentioned in appendix I;

- hypertension (maximum diastolic blood pressure $>90 \mathrm{mmHg}$, measured at 2 or more occasions);

- regular use of medication other than ferro-therapy or vitamins;

- presence of pregnancy-induced diabetes mellitus;

- alcohol- or drug abuse.

Furthermore, AGA infants were excluded from the study if they showed deviant neurological findings at the neonatal neurological examination . 


\subsubsection{Study population}

The infants were enrolled in the study after obtaining informed consent from the parents.

\section{Group I: 15 full-term AGA infants.}

Group II: 15 full-term SGA infants.

The infants were born between November 1989 and October 1991. Of the infants of group I, five were born at home, whereas ten infants were born in the hospital. In only one case a medical indication for clinical delivery existed (an ovarian cyst, removed a few days post partum). Fourteen of the infants of group II were born clinically, mostly because of a suspected intrauterine growth retardation. One of the infants was born at home and was transported to the hospital immediately after delivery.

A summary of neonatal parameters of the two groups is listed in table 3.1.

The $\mathrm{pH}$ of the umbilical artery was measured in $75 \%$ of the AGA infants and in $93 \%$ of the SGA infants. Most SGA infants were proportionally growth retarded as can be seen from the symmetrical reduction of birth weight, birth length and skull circumference.

Maternal and infant data are shown in Appendix Ila and IIb.

Table 3.1. Summary of clinical characteristics of both groups of infants. Median, range and p-value (Mann-Whitney $U$ test).

\begin{tabular}{|c|c|c|c|}
\hline Parameter & $\begin{array}{l}\text { AGA } \\
n=15\end{array}$ & $\begin{array}{l}\text { SGA } \\
n=15\end{array}$ & p-value \\
\hline Postmenstrual age (weeks) & $39.5(37.5-41)$ & $39.0(37.5-41)$ & n.s. \\
\hline birth weight (grams) & $3430(2750-4100)$ & $2240(1580-2480)$ & $p<0.01$ \\
\hline birth length $(\mathrm{cm})$ & $50.0(47.0-53.0)$ & $45.0(39.5-48.0)$ & $p<0.01$ \\
\hline skull circumference (cm) & $34.2(32.0-36.5)$ & $32.5(30.5-34.8)$ & $p<0.01$ \\
\hline Apgar $1^{\prime}$ & $9 \quad(7-10)$ & $9(6-9)$ & n.s. \\
\hline Apgar $5^{\prime}$ & $10 \quad(9-10)$ & $10 \quad(8-10)$ & n.s. \\
\hline pH umbilical artery & $7.23(7.15-7.48)$ & $7.28(7.14-7.34)$ & n.s. \\
\hline
\end{tabular}

n.s. = not significant

\subsection{Methods}

\subsubsection{Neonatal neurological examination}

An extensive neurological examination (Prechtl 1979) was performed between the 3rd and 8th postnatal day. The results of the examination were divided in the categories "normal", "suspect" and "abnormal". 


\subsubsection{Observation session}

The infants were observed between their third and eighth postnatal day. During the video recording session, the infants were lying supine in an incubator or radiant warmer at neutral temperature, wearing only a loose diaper. At the beginning of the observation session, the head was held in the midline until no lateral pressure was felt (Cioni et al. 1986). Each recording lasted 3 hours. Most of the observation sessions started one hour before a feed. The infants were videotaped with one camera, which was placed at the foot of the incubator. In this position the infants were seen from above. A time code signal was superimposed on the tape. The observer was able to see the infant from all sides. Spoken comments on opening and closing of the eyes and crying were recorded on the audio channel of the videocamera. All observations and videotapes were made by the same person (VvK-M).

\subsubsection{Playback}

After the observation session, the observer scored the various variables of spontaneous motor behaviour.

The results were analyzed with respect to the following items:

- quantitative aspects of motility

- posture

- the influence of change of head position on limb position

- quality of movement

\section{Quantitative aspects of motor behaviour}

During playback of the videotape, a series of items described below were scored and these data were fed into a personal computer, using an eventdetecting programme. For each item, incidence (in absolute number and in rate/10 minutes) or duration (in seconds and in percentage of total time) was determined. The following items were registered (definitions adapted from Cioni et al. 1989 and Vles 1988):

1. Eyes open or closed;

2. Heac position left, right or middle;

3. Dummy in or out;

4. General movements: series of gross movements of variable speed and amplitude which involve all parts of the body, without distinctive patterning or sequencing of body parts;

5. Stretches: complex movement patterns, consisting of overextension of the spine, retroflexion of the head, flexion of the arms or external rotation at the shoulder. The legs may or may not be extended;

6. Startles: brief generalized contraction of all muscles. They can incidentally be superimposed on a general movement;

7. Twitches: isclated, rapid movement of one limb. These movements were registered for each limb separately; 
8. Cloni: rhythmical movements in rapid succession $(3-5 \mathrm{~Hz})$ of moderate to large amplitude of one or more extremities. Duration of bouts may vary from a few beats to several seconds. They were registered for each limb separately;

9. Isolated arm and leg movements: movement of one arm or leg without movements of any other part of the body. Registered for each limb separately;

10. Hand-face contact left or right: left or right hand touching any part of the face other than the mouth;

11. Hand-mouth contact left or right: left or right hand touching the mouth;

12. Crying;

13. Manipulation.

The head position preference could be determined from the incidence and duration of the different head positions. After every manipulation the head was held in the midline until no lateral pressure was felt. Therefore, only spontaneous and no imposed head positions were analyzed.

States were defined as:

- State A (sleep state): eyes closed, no crying;

- State B (wakefulness): eyes open, no crying;

- State $C$ (crying state): crying.

Since no polygraphic registration of respiration was performed, regularity and irregularity of respiration were not taken into account when defining the state of the infant. The aim of this state classification was not to study the occurrence of states in the 2 groups of infants, but to define a frame of reference for the occurrence of the different movement patterns in the two groups. Therefore, a one-second window was used, to include as much data as possible. No differentiation was made between rest/activity periods during sleep and wakefulness (or quiet and active sleep/wakefulness), absence of general movements being considered as "rest" and presence of general movements as "activity" periods, for the following reason: since general movements do not occur simultaneously with other movement patterns, general movements would only occur in "active" states, all other movement patterns only in "quiet" states. Since the aim of this part of the study was to give a quantitative description of the occurrence of different movement patterns in several states, this definition would have been very artificial, leading to an a priori distribution of the movement patterns over the different states.

The influence of head position on limb movements was studied in two ways. Firstly, the frequency of occurrence of limb movements during a left-sided head position was compared to the frequency of occurrence of limb movements during a right-sided head position. Secondly, the frequency of occurrence of movements of left arm and leg was compared to the frequency of 
occurrence of movements of right arm and leg during a left- or right-sided head position.

\section{Posture}

During the observation session posture was assessed every minute and a sketch was made if the infant was not moving. After the observation session, sketches that were missed during the observation were drawn from the videotape.

For the purpose of analysis, each posture was described by a code consisting of 5 numbers, the first number indicating head position, manipulation or feeding, the next four numbers indicating the position of respectively the right arm, left arm, right leg and left leg (Vles 1989). The postures of the limbs were classified (using a graduated arc) in terms of abduction or adduction and internal or external rotation of the shoulder or hip and of flexion or extension of the elbow or knee.

The degree of abduction and adduction of the shoulder and hip was divided in 7 classes:
1. neutral
2. adduction
3. $0<$ abduction $<90$ degrees
4. 90 degrees abduction
$5.90<$ abduction $<180$ degrees
6. 180 degrees abduction
7. abduction $>180$ degrees

The position of the elbows and knees was classified in terms of degree of flexion and extension and of internal and external rotation of shoulder and hip. This also resulted in 7 classes:

1. fully extended ( $=180$ degrees)

2. partly extended ( $>90,<180$ degrees $)+$ external rotation

3. partly extended ( $>90,<180$ degrees) + internal rotation

4. partly flexed $(\geq 60, \leq 90)+$ external rotation

5. partly flexed $(\geq 60, \leq 90)+$ internal rotation

6. fully flexed $(<60)+$ external rotation

7. fully flexed $(<60)+$ internal rotation

The classification of the position of each limb therefore resulted in $7 \times 7=49$ (theoretical) categories. As the sketches were drawn in a two-dimensional plane, (ante-) flexion of shoulder and hip were not taken into account. The limb positions according to the above mentioned classification are therefore simplifications of the real three-dimensional positions.

All postures were classified and coded by the same person (KF).

The inter- and intra-observer agreement for sketching and scoring of the limb positions was determined for the two investigators involved. They simultaneously sketched and classified 120 randomly selected limb positions 
during the playback of one videotape. One hundred and fifteen sketches and classifications of both investigators were identical (inter-observer agreement $96 \%$ ). The same $120 \mathrm{limb}$ positions were sketched and coded again one week later. The intra-observer agreements were $95 \%$ and $98 \%$.

Posture was analyzed in several ways, considering:

1. the complete observed posture

2. abduction/adduction and flexion/extension

3. flexion/extension

4. abduction/adduction

Furthermore each limb position was analyzed separately, considering:

5. abduction/adduction

6. flexion/extension

During manipulation, feeding and movements of the infant, postures were not assessed. Furthermore, the postures occurring when the infant was sucking on a dummy (because of prolonged crying), were excluded from the final analysis, as they were not considered to reflect resting posture but rather posture during activity.

The total number of postural assessments $(\mathrm{M})$, the number of different postures $(\mathrm{N})$, the posture occurring most frequently and the longest uninterrupted posture were determined for every infant. If, due to manipulation and frequent movements, the postural assessments of an infant were considered to be insufficient ( $<10$ minutes) for an analysis of (preference) posture, the infant was excluded from the postural analysis.

A preference posture was defined as the posture occurring most frequently, provided that it occurred at least 5 times and at least 2 times as often as would be expected on the basis of chance. In formula:

$$
X \geq 5 \text { and } \geq 2 \frac{M}{N}
$$

$X=$ frequency of occurrence

$M=$ total number of postural data

$N=$ number of different postures of the infant

$M / N=$ frequency of occurrence as would be expected on the basis of chance

The influence of change of head position on limb position

The influence of a spontaneous head rotation on the position of the extremities was studied. For this purpose every head turning was registered during playback of the videotape. Only head turnings without lateral, dorsal or ventral flexion were analyzed. Head turnings occurring during a startle were excluded from the analysis. The body posture just before, immediately and one minute after a spontaneous head turning were noted. Postures were 
classified according to the method described before. The degree of flexion/extension was analyzed.

The positions of the limbs on the face side before and after a spontaneous head turning were compared with the positions of the limbs on the occiput side before and after the head turning. The analysis was performed for head turnings during sleep (state $A$ ), wakefulness (state $B$ ) and crying (state $C$ ). The occurrence of an asymmetric tonic neck posture (ATNP) in the resting postures was studied. As this posture is not considered in relation to a head turning, but to a head position, it is called ATNP instead of ATNR. An ATNP was defined as a posture in which the face-side extremities were relatively more extended than the occiput-side extremities. All postures were classified as ATNP, ATNP of arms, ATNP of legs or no ATNP. In the classification only the degree of flexion and extension as classified in the analysis of posture as described in the previous section (fully extended, partly extended, partly flexed, fully flexed) were considered.

\section{Quality of movement}

Since general movements (GM) are complex and have a high frequency of occurrence in the newborn, they are the best suitable movement pattern for the assessment of movement quality (Prechtl 1990).

The quality of movement can be judged by observation of the following items: onset and end of movement, speed, variability in speed, speed of arms compared to speed of legs, force against gravity, amplitude, variability in amplitude, amplitude of arms compared to amplitude of legs, fluency, variability in the overall pattern of the movement, variability in the movement patterns of arms and legs, participation of head and trunk, participation of all four extremities, and the presence of fine distal movements.

However, the value of an assessment of these qualitative aspects of movement depends on the consistency of this assessment. The inter- and intra-observer agreement is a measure for the objectivity and reliability of such a judgement. The intra- and inter-observer agreement for the judgement of several aspects of quality of GM in full-term infants was determined in a separate study. Since a different group of infants was used, this study is described separately in chapter 4.

Quality of movement was studied in both groups by observation of the above mentioned items. Furthermore, a global judgment of the movement quality as normal or abnorrnal was given. All GM with a minimal duration of 20 seconds were collected from the videotapes of each individual infant. The exact timing of beginning and end of the movement was noted, as well as the state of the child during this GM.

Since the quality of movement might be influenced by vigorous crying, the $\mathrm{GM}$ in state $\mathrm{C}$ were excluded from the qualitative analysis. Furthermore, GM during sucking and during hiccups were excluded. 
All GM were judged by the same observer. The scoring form used for this analysis is shown in Appendix III. The definitions of the items used are given in Appendix IV.

The judgements of the different GM of every infant were coded and fed into a personal computer. A computer database program was developed for storage of the data. The number of GM, the mean duration of the GM and the frequency of occurrence (\% of total number of GM) of the different categories of every item, were calculated for both states (A, B) in every infant. The degree of correlation between the different items was determined by calculation of the Spearman rank-order correlation coefficient. The items showing significant mutual correlation were used to extract dominant patterns of quality of movement from the GM in each group (pattern analysis).

\subsubsection{Follow-up}

All infants were seen by a child neurologist and a medical psychologist at 9 months of age. A neurological examination and the Bayley Scales of Infant Development with Psychomotor (PDI) and Mental (MDI) developmental indexes (normal range $100 \pm 16$ ) were performed. We have used the Dutch adaptation (van der Meulen and Smirkovsky 1982) of the Bayley Scales of Infant Development (Bayley 1969), which is commonly being used in the Netherlands.

\subsubsection{Statistical analysis}

All data were analyzed using non-parametric statistics.

For analyzing differences within one group, the Friedman two way analysis of variance followed by the Wilcoxon matched-pairs signed-ranks test, or the Wilcoxon matched-pairs signed-ranks test with Bonferroni correction for multiple testing were used.

For analyzing differences between the two groups the 2-tailed Mann-Whitney $U$ test was used. Correlations between variables in each group were determined by calculating the Spearman rank-order correlation coefficient.

Statistical significance was defined by a p-value $<0.05$. 


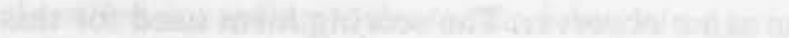

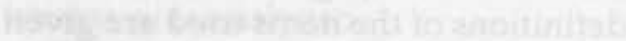

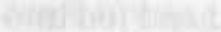

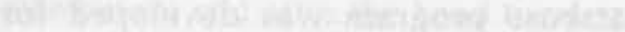

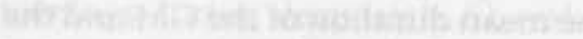

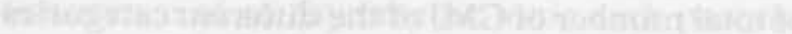

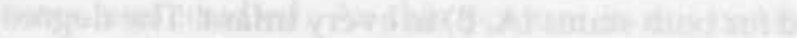

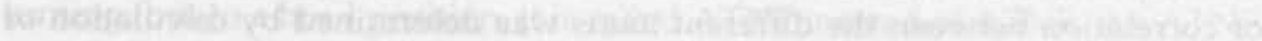

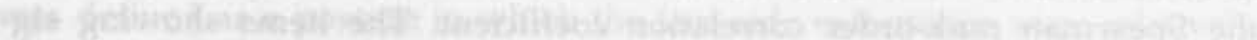

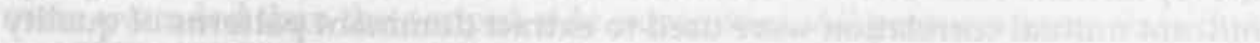

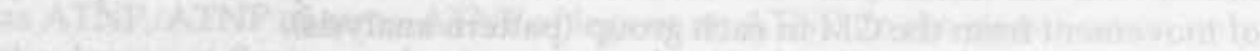

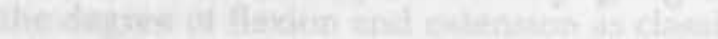

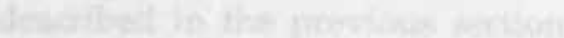

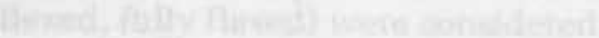

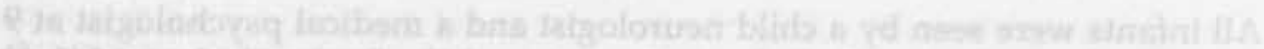

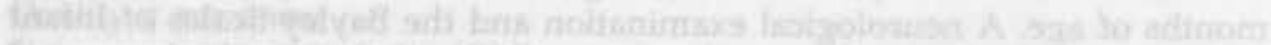
ILAH

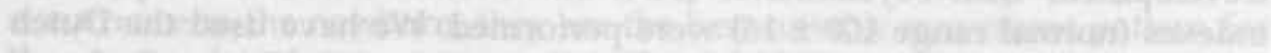

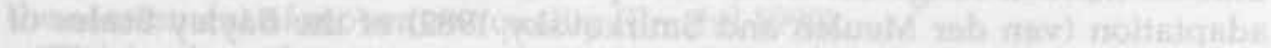

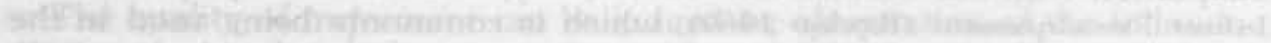

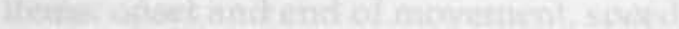

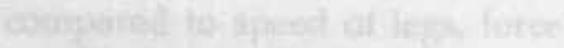

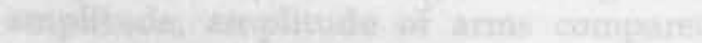

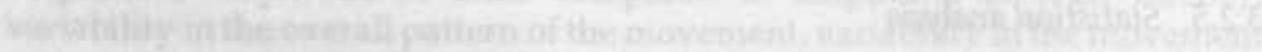

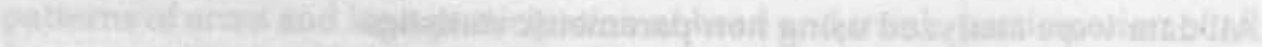

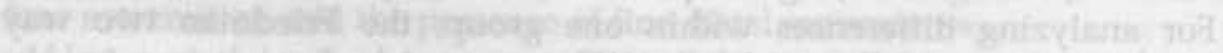

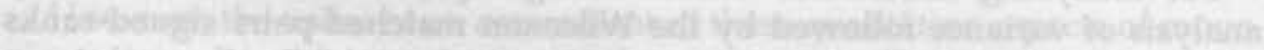

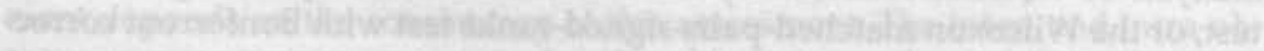

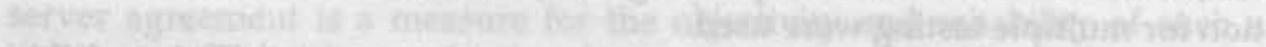

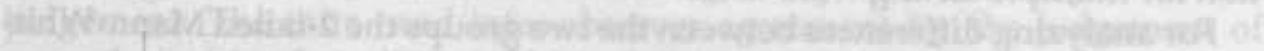
5agwe

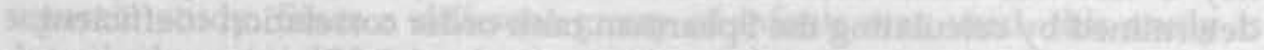

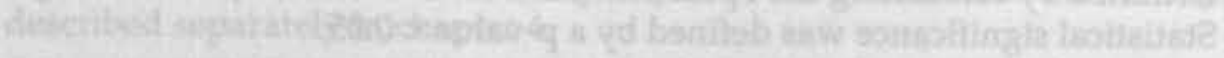

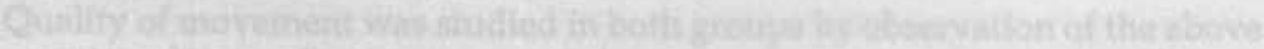

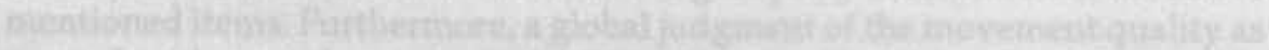

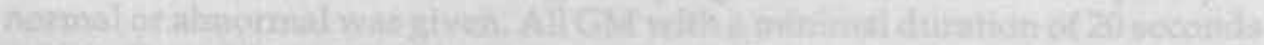

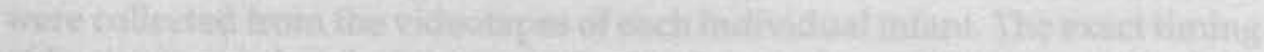

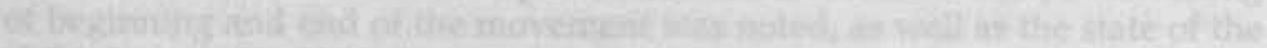

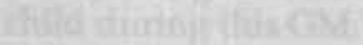

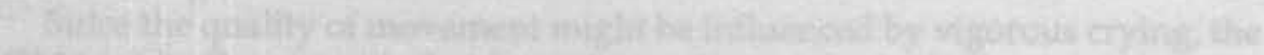

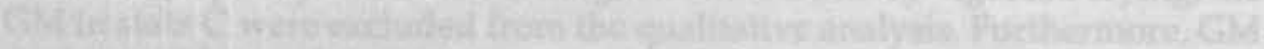

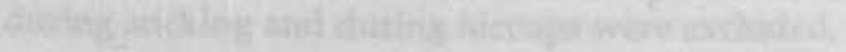




\section{Chapter 4}

Inter- and intra-observer agreement in the assessment of the quality of spontaneous movements in the newborn

4.1 Introduction

4.2 Material and methods

4.3 Results

4.4 Discussion 


\subsection{Introduction}

In the past decade, a growing interest has risen regarding the analysis of qualitative aspects of spontaneous movements as an assessment for normality or abnormality of central nervous system function in the newborn (Hopkins and Prechtl 1984; Prechtl and Hopkins 1986; Shirataki 1987; Prechtl 1990; Ferrari et al. 1990). In a recent study from Ferrari et al. (1990), it was shown that the assessment of the quality of spontaneous movements had a high sensitivity and specificity for the prediction of brain lesions in preterm infants of 26-36 weeks gestational age.

The quality of movement can be assessed by the observation of several aspects of a particular movement, such as the onset and end of the movement, variability in speed and amplitude, overall speed, overall amplitude, speed and amplitude of the arms compared to speed and amplitude of the legs, fluency, variability (or stereotypy) in the overall pattern of the movement, variability in the movement patterns of arms and legs, participation of head and trunk, participation of all four extremities, and the presence of fine distal movements.

However, the value of an assessment of these qualitative aspects of movement depends on the consistency of this assessment. Before the assessment of the quality of movement can be used for diagnostic or prognostic purposes, an objective and reliable judgement of the quality of movement should be obtained. The inter- and intra-observer agreement is a measure for the objectivity and reliability of such a judgement. In the literature, data on inter- and intra-observer agreement in the assessment of qualitative aspects of movement in newborn infants are scarce (Prechtl 1990). Agreement rates corrected for chance are not available in the literature.

The aim of this study was to determine the inter- and intra-observer agreement with a correction for chance agreement (kappa statistics) for the judgement of several aspects of the quality of general movements in healthy and high-risk full-term newborns.

\subsection{Materials and methods}

As part of a study concerning spontaneous motor behaviour in healthy and high-risk full-term infants, 3-hour lasting videotape recordings were made of 50 infants between the 3rd and 9th postnatal day. All general movements lasting more than 20 seconds were collected from the videotapes. The interand intra-observer agreement for the assessment of several items (table 4.1) related to the quality of general movements, was studied.

The degree of inter- and intra-observer agreement was analyzed by kappa statistics $(\kappa)$. Kappa $(\kappa)$ is a statistic tool, developed to calculate the agreement between two observers (pairwise agreement), with a correction for agreement by chance. 
Kappa $(\kappa)=\mathrm{Po}-\mathrm{Pe} / 1-\mathrm{Pe}$ in which $\mathrm{Po}$ is the observed agreement and $\mathrm{Pe}$ is the agreement that is to be expected by chance when judgements are statistically independent (Cohen 1960). Kappa values vary between 0 and 1 . If kappa is 0 , there is only chance agreement, whereas with a kappa value of 1 , perfect agreement exists between the observations of the 2 observers, none of which is determined by chance.

It should be mentioned, however, that high kappa values only relate to the degree of agreement between observers, but they do not prove the validity of the observations.

As the items were judged by 4 observers to determine inter-observer agreement, we also calculated the group kappa (Schouten 1982) for each item. The group kappa is a group measure of pairwise inter-observer agreement and is calculated from the average Po and Pe determined for paired observers.

The value of kappa is influenced by the proportion of subjects in each category (Altman 1990). If two studies are compared, one with equal and one with unequal proportions in each category, kappa will be lower in the study with an unequal prevalence of the categories, even if the observed agreement is the same. The reason for this difference is that the chance expected frequencies of agreement $(\mathrm{Pe})$ are very different. The kappa values from these two studies are therefore not comparable. In order to obtain optimal kappa values, which are a real reflection of inter-observer agreement, it is therefore desirable that within each item the different categories are present in an equal percentage of the movements to be analyzed.

Therefore, for every item (table 4.1) a test tape was constructed, consisting of 20-30 general movements with a proportional distribution over its categories. For instance, the test tape for the item onset of movement (item 1) consisted of 15 general movements showing an abrupt onset and 15 general movements showing a smooth onset.

Table 4.1 Qualitative aspects of motor behaviour for which inter-and intra-observer agreement could be determined.

Item

Categories

1. Onset of movement

2. Speed

3. Speed of arms compared to legs

4. Amplitude

5. Amplitude of arms compared to legs

6. Fluency

7. Variability in movement pattern

8. Variability in arm patterns

9. Variability in leg patterns

10. Global judgement of the movement smooth / abrupt

predominantly fast / predominantly slow equal / lower

predominantly large / predominantly small equal/ larger / smaller

fluent / not fluent

present / absent

present / absent

present / absent

normal / abnormal 
For construction of the test tapes, all general movements, which were collected from the 50 videotapes, were analyzed by the author (VvK-M). The occurrence of the different categories of the items was listed for every movement. Fifteen general movements were randomly selected for every category of each item and copied to the test tape. These first judgements of the movements given by the first author (observer 1), were used in the determination of the inter-observer agreement with the three other observers.

Kappa values cannot be calculated if all subjects are allocated to one category. As the category absent of the items "end of the movement", "variability in speed and amplitude", "participation of head and trunk", "participation of the limbs" and "presence of fine distal movements", did not occur in our material, these items were excluded from the analysis. For the item "speed of arms compared to speed of legs", the category "speed of arms higher than speed of legs" did not occur in our material and was therefore excluded from analysis.

The test tapes were independently analyzed by 3 observers: 2 physiotherapists (observer 2 and 3 ) and 1 research fellow involved in studies on preterm infant motor behaviour (observer 4). The observers were not aware of the patient history, nor were they aware that the categories of the items were expected to occur with an approximately equal distribution. As the observers were not trained in the judgement of the different items, a list of definitions of the items was handed out to them before the first observation session (Appendix IV).

Inter-observer agreement was calculated for the group of 4 observers (group I). As observer 1 was the only person who was experienced in the judgment of the different items and had constructed the test tapes, group kappa values for observers 2, 3 and 4 (group II) were calculated separately.

For the assessment of the intra-observer agreement, 3 observers judged the general movements on the test tapes a second time (observers 1-3). The interval between the two observation sessions was 2 months or longer. Kappa values were calculated to determine the chance corrected degree of agreement between the first and the second judgement.

\subsection{Results}

Pairwise and group inter-observer agreement corrected for chance, calculated for the ten items is summarized in table 4.2. When comparing the kappa values for paired observers it is clear that for some items, especially items 4 and 8 , considerable variability in kappa values between the observer pairs exists. However, no combination of observers scored consistently better or worse than the other pairs. Therefore, the estimation of the group kappa does not alter the information as obtained from the kappa values for pairwise agreement, but gives an impression of the overall degree of agreement within the group. 
Table 4.2 Pairwise (A-F) and group inter-observer agreement for ten aspects of movement quality. $P o=$ observed agreement, $P \varepsilon=$ agreement to be expected by chance when judgements are statistically independent, $k=k a p p a$ value. A-F are the possible combinations of observers 1,2,3 and 4. Group $I$ is the group inter-observer agreement for observers 1,2,3 and 4. Group Il is the group inter-observer agreement for observers 2, 3 and 4.

\begin{tabular}{|c|c|c|c|c|c|c|c|c|c|}
\hline Item & $\begin{array}{l}\text { Pair } \\
\text { observers }\end{array}$ & $\begin{array}{l}A \\
1-2\end{array}$ & $\begin{array}{l}\text { B } \\
1-3\end{array}$ & $\begin{array}{l}C \\
1-4\end{array}$ & $\begin{array}{l}D \\
2-3\end{array}$ & $\begin{array}{l}E \\
2-4\end{array}$ & $\begin{array}{l}F \\
3-4\end{array}$ & $\mathrm{i}^{\text {group }}$ & $\begin{array}{l}\text { group } \\
\text { II }\end{array}$ \\
\hline 1 & $\begin{array}{l}\text { Po } \\
\text { Pe } \\
\text { k }\end{array}$ & $\begin{array}{l}0.87 \\
0.52 \\
0.72\end{array}$ & $\begin{array}{l}0.90 \\
0.50 \\
0.80\end{array}$ & $\begin{array}{l}0.90 \\
0.50 \\
0.80\end{array}$ & $\begin{array}{l}0.90 \\
0.51 \\
0.79\end{array}$ & $\begin{array}{l}0.83 \\
0.51 \\
0.65\end{array}$ & $\begin{array}{l}0.87 \\
0.49 \\
0.75\end{array}$ & $\begin{array}{l}0.88 \\
0.51 \\
0.76\end{array}$ & $\begin{array}{l}0.87 \\
0.50 \\
0.74\end{array}$ \\
\hline 2 & $\begin{array}{l}\text { Po } \\
\text { Pe } \\
\text { k }\end{array}$ & $\begin{array}{l}0.87 \\
0.49 \\
0.74\end{array}$ & $\begin{array}{l}0.83 \\
0.50 \\
0.67\end{array}$ & $\begin{array}{l}0.67 \\
0.50 \\
0.80\end{array}$ & $\begin{array}{l}0.90 \\
0.51 \\
0.79\end{array}$ & $\begin{array}{l}0.90 \\
0.51 \\
0.80\end{array}$ & $\begin{array}{l}0.87 \\
0.51 \\
0.73\end{array}$ & $\begin{array}{l}0.88 \\
0.50 \\
0.76\end{array}$ & $\begin{array}{l}0.89 \\
0.51 \\
0.78\end{array}$ \\
\hline 3 & $\begin{array}{l}\text { Po } \\
\text { Pe } \\
\text { k }\end{array}$ & $\begin{array}{l}0.75 \\
0.53 \\
0.47\end{array}$ & $\begin{array}{l}0.75 \\
0.53 \\
0.47\end{array}$ & $\begin{array}{l}0.80 \\
0.54 \\
0.57\end{array}$ & $\begin{array}{l}0.80 \\
0.55 \\
0.56\end{array}$ & $\begin{array}{l}0.85 \\
0.56 \\
0.66\end{array}$ & $\begin{array}{l}0.75 \\
0.56 \\
0.43\end{array}$ & $\begin{array}{l}0.78 \\
0.55 \\
0.51\end{array}$ & $\begin{array}{l}0.80 \\
0.56 \\
0.55\end{array}$ \\
\hline 4 & $\begin{array}{l}\text { Po } \\
\text { Pe } \\
\text { k }\end{array}$ & $\begin{array}{l}0.73 \\
0.51 \\
0.45\end{array}$ & $\begin{array}{l}0.77 \\
0.52 \\
0.52\end{array}$ & $\begin{array}{l}0.77 \\
0.50 \\
0.54\end{array}$ & $\begin{array}{l}0.65 \\
0.58 \\
0.17\end{array}$ & $\begin{array}{l}0.65 \\
0.49 \\
0.31\end{array}$ & $\begin{array}{l}0.62 \\
0.48 \\
0.27\end{array}$ & $\begin{array}{l}0.70 \\
0.51 \\
0.39\end{array}$ & $\begin{array}{l}0.64 \\
0.52 \\
0.25\end{array}$ \\
\hline 5 & $\begin{array}{l}\mathrm{Po} \\
\mathrm{Pe} \\
\mathrm{k}\end{array}$ & $\begin{array}{l}0.88 \\
0.38 \\
0.81\end{array}$ & $\begin{array}{l}0.73 \\
0.37 \\
0.57\end{array}$ & $\begin{array}{l}0.73 \\
0.37 \\
0.57\end{array}$ & $\begin{array}{l}0.69 \\
0.37 \\
0.51\end{array}$ & $\begin{array}{l}0.77 \\
0.40 \\
0.62\end{array}$ & $\begin{array}{l}0.69 \\
0.38 \\
0.50\end{array}$ & $\begin{array}{l}0.75 \\
0.38 \\
0.60\end{array}$ & $\begin{array}{l}0.72 \\
0.38 \\
0.55\end{array}$ \\
\hline 6 & $\begin{array}{l}\mathrm{Po} \\
\mathrm{Pe} \\
\mathrm{k}\end{array}$ & $\begin{array}{l}0.87 \\
0.50 \\
0.74\end{array}$ & $\begin{array}{l}0.90 \\
0.50 \\
0.80\end{array}$ & $\begin{array}{l}0.80 \\
0.51 \\
0.59\end{array}$ & $\begin{array}{l}0.90 \\
0.50 \\
0.80\end{array}$ & $\begin{array}{l}0.77 \\
0.50 \\
0.54\end{array}$ & $\begin{array}{l}0.80 \\
0.51 \\
0.59\end{array}$ & $\begin{array}{l}0.84 \\
0.50 \\
0.68\end{array}$ & $\begin{array}{l}0.82 \\
0.50 \\
0.64\end{array}$ \\
\hline 7 & $\begin{array}{l}\text { Po } \\
\text { Pe } \\
\text { k }\end{array}$ & $\begin{array}{l}0.78 \\
0.50 \\
0.56\end{array}$ & $\begin{array}{l}0.67 \\
0.50 \\
0.34\end{array}$ & $\begin{array}{l}0.67 \\
0.50 \\
0.34\end{array}$ & $\begin{array}{l}0.78 \\
0.57 \\
0.49\end{array}$ & $\begin{array}{l}0.67 \\
0.55 \\
0.27\end{array}$ & $\begin{array}{l}0.78 \\
0.65 \\
0.37\end{array}$ & $\begin{array}{l}0.73 \\
0.55 \\
0.40\end{array}$ & $\begin{array}{l}0.74 \\
0.59 \\
0.37\end{array}$ \\
\hline 8 & $\begin{array}{l}\text { Po } \\
\text { Pe } \\
\text { k }\end{array}$ & $\begin{array}{l}0.86 \\
0.50 \\
0.72\end{array}$ & $\begin{array}{l}0.64 \\
0.50 \\
0.28\end{array}$ & $\begin{array}{l}0.82 \\
0.50 \\
0.64\end{array}$ & $\begin{array}{l}0.68 \\
0.52 \\
0.33\end{array}$ & $\begin{array}{l}0.86 \\
0.52 \\
0.71\end{array}$ & $\begin{array}{l}0.73 \\
0.60 \\
0.33\end{array}$ & $\begin{array}{l}0.77 \\
0.52 \\
0.52\end{array}$ & $\begin{array}{l}0.76 \\
0.55 \\
0.47\end{array}$ \\
\hline 9 & $\begin{array}{l}\text { Po } \\
\text { Pe } \\
\text { k }\end{array}$ & $\begin{array}{l}0.65 \\
0.50 \\
0.30\end{array}$ & $\begin{array}{l}0.73 \\
0.49 \\
0.47\end{array}$ & $\begin{array}{l}0.73 \\
0.50 \\
0.46\end{array}$ & $\begin{array}{l}0.76 \\
0.60 \\
0.40\end{array}$ & $\begin{array}{l}0.77 \\
0.64 \\
0.36\end{array}$ & $\begin{array}{l}0.69 \\
0.60 \\
0.23\end{array}$ & $\begin{array}{l}0.72 \\
0.56 \\
0.36\end{array}$ & $\begin{array}{l}0.74 \\
0.61 \\
0.33\end{array}$ \\
\hline 10 & $\begin{array}{l}\text { Po } \\
\text { Pe } \\
k\end{array}$ & $\begin{array}{l}0.89 \\
0.50 \\
0.78\end{array}$ & $\begin{array}{l}0.93 \\
0.50 \\
0.86\end{array}$ & $\begin{array}{l}0.93 \\
0.50 \\
0.86\end{array}$ & $\begin{array}{l}0.96 \\
0.52 \\
0.92\end{array}$ & $\begin{array}{l}0.89 \\
0.46 \\
0.80\end{array}$ & $\begin{array}{l}0.93 \\
0.52 \\
0.85\end{array}$ & $\begin{array}{l}0.92 \\
0.50 \\
0.84\end{array}$ & $\begin{array}{l}0.93 \\
0.50 \\
0.86\end{array}$ \\
\hline
\end{tabular}


Table 4.3 Intra-observer agreement for observers 1,2 and 3. $P o=$ observed agreement; $P_{e=}$ agreement to be expected by chance when judgements are statistically independent; $k=k a p p a$.

\begin{tabular}{|c|c|c|c|c|}
\hline Item & Observer & 1 & 2 & 3 \\
\hline 1 & $\begin{array}{l}\mathrm{Po} \\
\mathrm{Pe} \\
\mathrm{k}\end{array}$ & $\begin{array}{l}0.97 \\
0.50 \\
0.94\end{array}$ & $\begin{array}{l}0.86 \\
0.49 \\
0.73\end{array}$ & $\begin{array}{l}0.90 \\
0.51 \\
0.80\end{array}$ \\
\hline the & $\begin{array}{l}\text { Po } \\
\text { Pe } \\
\mathbf{k}\end{array}$ & $\begin{array}{l}0.90 \\
0.50 \\
0.80\end{array}$ & $\begin{array}{l}0.77 \\
0.50 \\
0.54\end{array}$ & $\begin{array}{l}0.93 \\
0.53 \\
0.85\end{array}$ \\
\hline 3 & $\begin{array}{l}\text { Po } \\
\text { Pe } \\
\text { k }\end{array}$ & $\begin{array}{l}0.95 \\
0.51 \\
0.90\end{array}$ & $\begin{array}{l}0.75 \\
0.56 \\
0.43\end{array}$ & $\begin{array}{l}0.80 \\
0.61 \\
0.49\end{array}$ \\
\hline 4 & $\begin{array}{l}\mathrm{Po} \\
\mathrm{Pe} \\
\mathrm{k}\end{array}$ & $\begin{array}{l}0.85 \\
0.50 \\
0.70\end{array}$ & $\begin{array}{l}0.58 \\
0.50 \\
0.16\end{array}$ & $\begin{array}{l}0.69 \\
0.57 \\
0.30\end{array}$ \\
\hline 5 & $\begin{array}{l}\text { Po } \\
\text { Pe } \\
\text { k }\end{array}$ & $\begin{array}{l}0.96 \\
0.37 \\
0.94\end{array}$ & $\begin{array}{l}0.62 \\
0.41 \\
0.36\end{array}$ & $\begin{array}{l}0.69 \\
0.35 \\
0.52\end{array}$ \\
\hline 6 & $\begin{array}{l}\mathrm{Po} \\
\mathrm{Pe} \\
\mathrm{k}\end{array}$ & $\begin{array}{l}0.97 \\
0.50 \\
0.94\end{array}$ & $\begin{array}{l}0.93 \\
0.50 \\
0.86\end{array}$ & $\begin{array}{l}0.80 \\
0.50 \\
0.60\end{array}$ \\
\hline 7 & $\begin{array}{l}\mathrm{Po} \\
\mathrm{Pe} \\
\mathrm{k}\end{array}$ & $\begin{array}{l}0.94 \\
0.50 \\
0.88\end{array}$ & $\begin{array}{l}0.78 \\
0.57 \\
0.49\end{array}$ & $\begin{array}{l}0.72 \\
0.56 \\
0.36\end{array}$ \\
\hline SEO) & $\begin{array}{l}\text { Po } \\
\text { Pe } \\
k\end{array}$ & $\begin{array}{l}0.82 \\
0.50 \\
0.64\end{array}$ & $\begin{array}{l}0.77 \\
0.57 \\
0.47\end{array}$ & $\begin{array}{l}0.86 \\
0.52 \\
0.71\end{array}$ \\
\hline 9 & $\begin{array}{l}\text { Po } \\
\text { Pe } \\
\text { k }\end{array}$ & $\begin{array}{l}0.85 \\
0.50 \\
0.70\end{array}$ & $\begin{array}{l}0.81 \\
0.62 \\
0.50\end{array}$ & $\begin{array}{l}0.85 \\
0.60 \\
0.63\end{array}$ \\
\hline 10 & $\begin{array}{l}\text { Po } \\
\text { Pe } \\
\text { k }\end{array}$ & $\begin{array}{l}1.00 \\
0.50 \\
1.00\end{array}$ & $\begin{array}{l}0.89 \\
0.52 \\
0.77\end{array}$ & $\begin{array}{l}0.85 \\
0.51 \\
0.69\end{array}$ \\
\hline
\end{tabular}


Considering the group kappas (group I) for individual parameters (i.e. item 1-9), kappa values varied between 0.36 and 0.76 with the lowest value for the item "variability in leg patterns" and the highest value for the items "onset of movement" and "speed". For the global judgement of the movement (normal/abnormal) we calculated a kappa value of 0.84 . Although the observed agreement $(\mathrm{Po})$ for every item seems satisfactory, the agreement after correction for chance agreement is substantially lower for some of the items (e.g. items 4,7 , and 9). This confirms the importance of a correction for chance agreement, because otherwise the inter-observer agreement and thus the value of a judgement might be overestimated.

Comparing the group kappa values of group I and II, it appears that there is only a very small difference in the kappa values. The fact that observer 1 is experienced in the judgement of the different items whereas the others are not, does not appear to make any difference in the inter-observer agreement.

In table 4.3 the intra-observer agreement of observer 1,2 and 3 is given. Concerning the intra-observer agreement there is considerable variability, not only between the 3 observers, but also between the different items that were tested.

Observer 1 had the highest kappa values for 8 of the 10 items, although she had the longest time interval between the observations (approximately 4 months). This is probably due to the fact that she was more experienced.

\subsection{Discussion}

Although absolute definitions for the interpretation of kappa values are not available, Altman (1992) and Landis and Koch (1977) gave the following indications for the level of inter-observer agreement: the strength of agreement is poor for $\kappa$ values $<0.20$, fair for $\kappa$ values between 0.21 and 0.40 ( 3 items), moderate for $\kappa$ values between 0.41 and 0.60 ( 3 items), good for $\kappa$ values between 0.61 and 0.80 ( 3 items) and very good for $K$ values $>0.81$ ( 1 item). Therefore, the results of this study confirm that several qualitative aspects of motility in the newborn can be reliably assessed by observers of different disciplines with experience in observing infant motor behaviour (group $\mathrm{K}$ values $0.51-1.0$ ). However, the items "amplitude", "variability in movement pattern" and "variability in leg patterns" appeared to be quite difficult to judge.

The inter- and intra-observer agreement on the global judgement of the movement corrected for chance turned out to be high (group I kappa $=0.84$; kappa values for intra-observer agreement 1.00, 0.77 and 0.69). Prechtl (1990), in a study on spontaneous motor behaviour in newborn infants, also found a very high inter-observer agreement for the global judgement of the movement as normal or abnormal (average $90 \%$, range $75-100 \%$ ). However, no correction was made for the percentage of agreement that could be expected by chance. 
The inter-observer agreement for the detailed judgement of different qualitative aspects of movement was not determined.

From our results it would seem to be easier to give a general judgement on normality or abnormality of a movement than to judge the different qualitative aspects separately. This may be ascribed to the fact that the global judgement is not merely a linear summation of the judgement of the separate items, but a complex partly unconscious integration. Furthermore, the categories of the more detailed aspects of quality of movement are difficult to define and the inter- and intra-observer agreement would therefore be sensitive to the observational experience of the observer.

However, although the global judgement appears to be the most reliable, most of the more detailed qualitative aspects can also be reliably assessed and they can give important additional information on the character of the quality of the movement.

In general, low inter-observer agreement can be caused by several factors such as inexperience of the observers (Sacket 1985), differences between observers regarding boundary lines of categories, personality differences and mistakes in scoring (van den Berghe et al. 1979). Furthermore, kappa values are influenced by the proportion of subjects in each category and the number of categories (Cohen 1960).

Inter-observer agreement for the detailed aspects of quality of movement might therefore be further improved by prior training of all observers and if necessary, better definitions of the categories.

In summary we can conclude that the judgement of several aspects of the quality of general movements in full-term infants is a reproducible and therefore reliable clinical tool for evaluating motor behaviour in the neonatal period. 
Chapter 5

Spontaneous motor behaviour in full-term appropriate for gestational age newborn infants

5.1 Neurological examination

5.2 Quantitative aspects of motor behaviour

5.3 Posture

5.4 Influence of head position change on body posture

5.5 Quality of movement

5.6 Follow-up at the age of 9 months 


\subsection{Neurological examination}

All infants in the AGA group had a normal neonatal neurological examination.

\subsection{Quantitative aspects of motor behaviour}

The duration of the complete observation session ranged from 154.82 to 199.42 min. (median $181.50 \mathrm{~min}$.). The total observation time of the 15 infants was 45 hours. An example of an actogram is shown in figure 5.1. During the observation session most infants had to be manipulated several times due to nursing routines such as feeding and changing diapers, and persistent crying. The median duration of manipulation per observation session was $33.97 \mathrm{~min}$., ranging from 0.00 to $79.45 \mathrm{~min}$. As manipulation might influence motility the manipulation time was excluded from the analysis. The remaining observation time ranged from 119.97 to 175.93 min., median 136.83 min. All percentages and rates are calculated using the total observation time with subtraction of manipulation time. This will be referred to as real observation time.

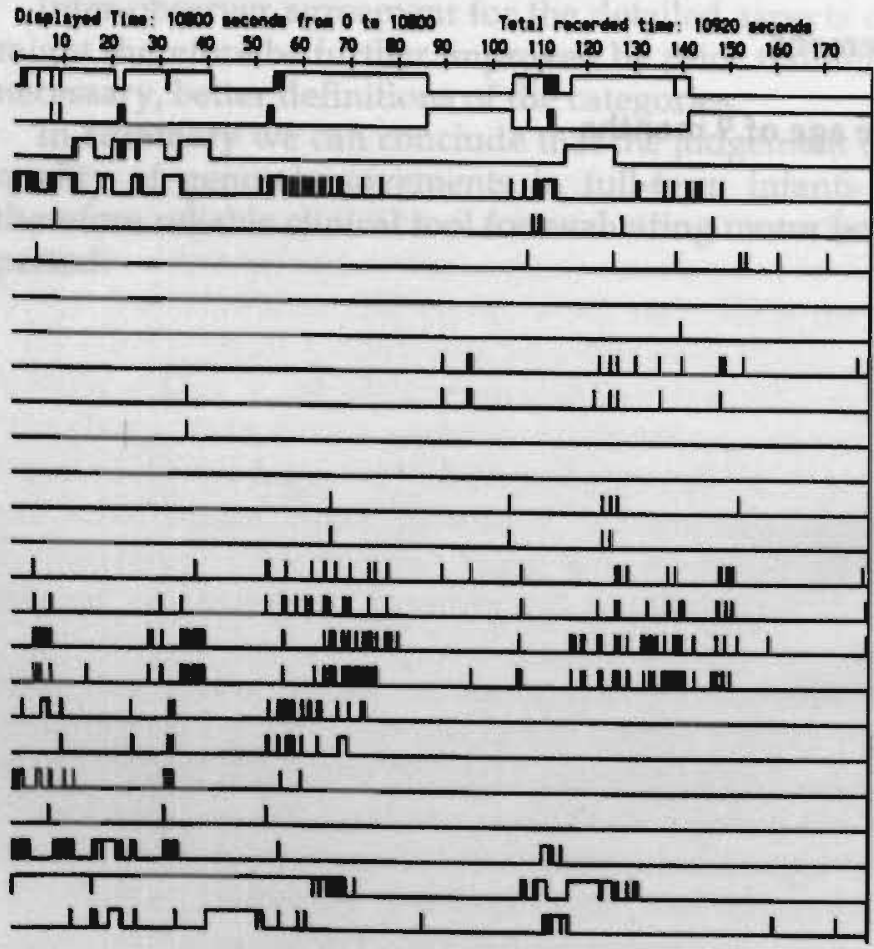

\begin{tabular}{|c|c|c|c|c|c|}
\hline \multirow{2}{*}{\multicolumn{2}{|c|}{ aimuts }} & \multicolumn{2}{|c|}{ Filemien: } & \multirow{2}{*}{\multicolumn{2}{|c|}{$\frac{111.001}{\text { TorN. STIX }}$}} \\
\hline & & $\mathrm{WX}$ & & & \\
\hline 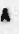 & Head Loft & $x$ & 24 & 618 & 450 \\
\hline & Hend Right & $x$ & 11 & $\sin$ & $m$ \\
\hline 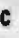 & and in/out & $x$ & 10 & 102 & 200 \\
\hline 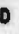 & Em. Hovenent & $x$ & 51 & 1248 & \\
\hline 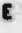 & Stroteh & $x$ & 7 & & \\
\hline & Stertle & $x$ & $\sqrt{-1}$ & & \\
\hline 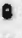 & Twitch L-arn & $x$ & 0 & & \\
\hline 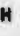 & Twitch R-an & $x$ & 1 & & \\
\hline 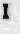 & Twiteh L-tes & $x$ & 17 & & \\
\hline 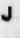 & Twiteh a-les & $x$ & 10 & & \\
\hline 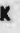 & Clenes L-en & $x$ & 1 & & \\
\hline e & 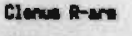 & $x$ & 0 & & \\
\hline & Clome L-Leg & $x$ & 6 & & \\
\hline & Clemes R-Log & $x$ & 4 & & \\
\hline & $t m 1.4=0$ & $x$ & 34 & & \\
\hline & $I=01 . \quad M=0$ & $x$ & 3 & & \\
\hline & $I=1.4=$ & $x$ & 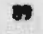 & & \\
\hline & $i=01 . \quad R=$ & $x$ & 103 & & \\
\hline & Wat-thea L & $x$ & $a$ & 291 & 11 \\
\hline & Hent-fece a & $x$ & 16 & 210 & 24 \\
\hline & Hontereuth L & $x$ & 19 & 113 & 13 \\
\hline & Han-anuth R & $x$ & 3 & 17 & \\
\hline & oryins & $x$ & $\mathbf{3}$ & r4 & 3 \\
\hline & Ex & $x$ & $\mathbf{x}$ & the & 50 \\
\hline & Monipula & $x$ & 24 & 1201 & 133 \\
\hline
\end{tabular}

Figure 5.1 Actogram of the complete observation period of a full-term AGA infant. 
A wide interindividual variability existed in the percentage of real observation time spent in the different states. A significantly lower percentage of time was spent in state $C$ than in states $A$ and $B$ (p-values 0.016 and 0.040 respectively). The median percentage of the real observation time spent in state $A$ was $62 \%$ (range $0-100 \%$ ). The median percentage of the real observation time spent in state B was $25 \%$ (range $1-99 \%$ ). The median percentage of the real observation time spent in state $C$ was $9 \%$ (range $0-55 \%$ ). The occurrence of the different movement patterns and some other variables in the total observation session is shown in tables 5.1 and 5.2. In tables 5.3 and 5.4 the occurrence of the movement patterns in the different states is shown.

Table 5.1 Occurrence of different movement patterns of varying duration during the real observation time. Percentage (\%) of real observation time, median (range).

\begin{tabular}{lc} 
Movement pattern & Percentage o \\
\hline Head left & $52 \%(0-100)$ \\
Head right & $44 \%(0-100)$ \\
Head in midline & $1 \%(0-7)$ \\
Dummy in & $3 \%(0-46)$ \\
General movements & $35 \%(5-68)$ \\
Hand-face contact left hand & $2 \%(0-13)$ \\
Hand-face contact right hand & $1 \%(0-6)$ \\
Hand-mouth contact left hand & $1 \%(0-2)$ \\
Hand-mouth contact right hand & $0 \%(0-13)$
\end{tabular}

Table 5.2 Occurrence of different movement patterns of limited duration during the real observation time. Total number during real observation time, median (range).

Movement pattern

Total number during observation

Stretch

Startle

Twitch left arm

Twitch right arm

Twitch left leg

Twitch right leg

Clonus left arm

Clonus right arm

Clonus left leg

Clonus right leg

Isolated left arm movement

$23(2-57)$

$1(0-12)$

$1(0-18)$

$18(0-72)$

$17(0-52)$

$0(0-4)$

$0(0-2)$

$2(0-27)$

$2(0-24)$

Isolated right arm movement

$41(26-95)$

Isolated left leg movement

$53(27-69)$

Isolated right leg movement

$53(17-162)$

$60(34-154)$ 
Table 5.3 Occurrence of movement patterns of varying duration in different states.

Percentage (\%) of total time of the state concerned, median (range).

\begin{tabular}{llll}
\hline Movement pattern & State A & State B & State C \\
\hline General movements & $9 \%(3-40)$ & $55 \%(26-77)$ & $99(86-100)$ \\
Hand-face contact LA & $1 \%(0-8)$ & $2 \%(0-21)$ & $0(0-9)$ \\
Hand-face contact RA & $0 \%(0-6)$ & $3 \%(0-10)$ & $0(0-55)$ \\
Hand-mouth contact LA & $0 \%(0-3)$ & $1 \%(0-25)$ & $0(0-4)$ \\
Hand-mouth contact RA & $0 \%(0-36)$ & $0 \%(0-14)$ & $0(0-46)$ \\
\hline
\end{tabular}

$\mathrm{LA}=$ left arm; $\mathrm{RA}=$ right arm; $\mathrm{LL}=$ left leg; $\mathrm{RL}=$ right leg

Table 5.4 Occurrence of movement patterns of limited duration in different states.

Rate/10 min. of real observation time, median (range).

\begin{tabular}{llll}
\hline Movement pattern & State A & State B & State C \\
\hline Stretch & $0.30(0.00-1.39)$ & $0.00(0.00-1.09)$ & $0.00(0.00)$ \\
Startle & $2.44(0.34-8.30)$ & $0.59(0.00-2.35)$ & $0.00(0.00-1.79)$ \\
Twitches LA & $0.12(0.00-1.16)$ & $0.00(0.00-0.18)$ & $0.00(0.00)$ \\
Twitches RA & $0.20(0.00-1.16)$ & $0.00(0.00-0.48)$ & $0.00(0.00)$ \\
Twitches LL & $1.74(0.00-4.98)$ & $0.00(0.00-0.97)$ & $0.00(0.00)$ \\
Twitches RL & $1.68(0.00-4.70)$ & $0.00(0.00-0.74)$ & $0.00(0.00)$ \\
Cloni LA & $0.00(0.00-0.39)$ & $0.00(0.00-0.18)$ & $0.00(0.00)$ \\
Cloni RA & $0.00(0.00-0.19)$ & $0.00(0.00)$ & $0.00(0.00)$ \\
Cloni LL & $0.27(0.00-0.75)$ & $0.00(0.00-0.69)$ & $0.00(0.00-0.63)$ \\
Cloni RL & $0.17(0.00-1.55)$ & $0.00(0.00-0.55)$ & $0.00(0.00)$ \\
Isolated movements LA & $2.92(1.79-6.78)$ & $3.72(0.00-0.87)$ & $0.00(0.00-2.20)$ \\
Isolated movements RA & $3.14(1.24-8.87)$ & $5.09(0.00-8.84)$ & $0.00(0.00-2.20)$ \\
Isolated movements LL & $5.09(1.87-11.19)$ & $5.17(1.46-8.29)$ & $0.00(0.00-1.90)$ \\
Isolated movements RL & $4.77(3.03-9.66)$ & $5.71(2.02-9.76)$ & $0.00(0.00-1.26)$ \\
\hline
\end{tabular}

$\mathrm{LA}=$ left arm; RA=right arm; LL=left leg; $\mathrm{RL}=$ right leg.

\section{Head position}

A median of $52 \%$ of the real observation time was spent with the head turned to the left (range $0-100 \%$ ), against a median of $44 \%$ to the right (range $0-100 \%$ ). A head position with the head in the midline was rare (median 1\%, range 0-7\%).

In state B a significantly higher percentage of time was spent with the head to the left than in states $A$ and $C$ (p-values < 0.05). However, the significance was low. No significant difference between the 3 states could be demonstrated for a head position to the right or in the midline.

As the duration of a head position to the left or to the right could be influenced by the presence of a dummy, the percentages were also calculated 
with exclusion of time spent sucking a dummy. This lead to a median percentage of $53 \%$ spent with the head turned to the left (range $0-100 \%$ ) and a median of $44 \%$ spent with the head turned to the right side (range 0-99\%). No significant difference between time spent with a head position to the left and to the right could be demonstrated (Wilcoxon matched-pairs signed-ranks test).

\section{General movements}

A median of $29 \%$ of the real observation time was spent in general movements (range 5-68\%). This percentage was highest in state C, with a median of $99 \%$ of the total state $C$ time spent in general movements. The median percentage of time spent in general movements in states A and B was $9 \%$ (range $3-40 \%$ ) and $55 \%$ (range 26-77\%) respectively. The differences in occurrence of general movements between the states were statistically significant ( $p$-values $<0.01$ ).

\section{Stretches}

The occurrence of stretches was rare. In the real observation time a median of 2 stretches was observed (rate $/ 10 \mathrm{~min} .=0.17$ ), with a minimum of 0 and a maximum number of 15 stretches. They occurred significantly more in state $A$, than in states $B$ and $C$ (both p-values 0.035 ). In state $A$ the median rate of occurrence was $0.30 / 10 \mathrm{~min}$. (range $0.00-1.39 / 10 \mathrm{~min}$.). In state $B$ a median of $0.00 / 10 \mathrm{~min}$. was observed (range $0.00-1.09 / 10 \mathrm{~min}$.). In state $C$ no stretches were observed.

\section{Startles}

In the complete observation a median of 23 startles were seen (range 2-57). The median rate of startles in state A was $2.44 / 10 \mathrm{~min}$. (range $0.34-8.30 / 10 \mathrm{~min}$.), in state $B 0.59 / 10 \mathrm{~min}$. (range $0.00-2.35$ ). In state $C$ startles were rare, with a maximum rate of occurrence of $1.79 / 10 \mathrm{~min}$. (median and minimum $0.00 / 10$ $\mathrm{min}$.). The difference in occurrence of startles between the 3 states was statistically significant ( $\mathrm{p}$-values $<0.02$ ).

\section{Twitches}

Twitches of the arms occurred only sporadically with a median of 1 for each arm in the complete observation session (range left arm 0-12; right arm 0-18). They occurred significantly more often during sleep (state A) than during wakefulness and crying. Only for the left arm the difference in occurrence between sleep and wakefulness was not significant. No significant difference existed between states $B$ and $C$.

Twitches were seen more often in the legs than in the arms with a median occurrence in the complete observation session of 18 for the left leg (range $0-72$ ) and 17 (range 0-52) for the right leg. The rate of occurrence was highest in state A (left leg median $1.74 / 10 \mathrm{~min}$., right leg $1.68 / 10 \mathrm{~min}$.). The median rate of occurrence in state B was $0.00 / 10 \mathrm{~min}$. for each leg. The difference 
between state A and B was statistically significant ( $\mathrm{p}$-values $<0.01$ ). No significant difference existed between state B and state $C$.

\section{Cloni}

The occurrence of cloni of the arms was rare. In most infants no cloni were observed during the complete observation session (range left arm 0-4; right arm 0-2). The range of the rate of occurrence in state $A$ was $0.00-1.16 / 10 \mathrm{~min}$. for each arm. In state $B$ the range of the rate of occurrence was $0.00-0.18 / 10$ min. for the left arm and $0.00-0.48 / 10 \mathrm{~min}$. for the right arm. In state $C$ no cloni of the arms occurred. The only significant difference in occurrence of cloni was found between states $A$ and $C$.

Cloni were seen more often in the legs than in the arms with a median number in the complete observation session of 2 for the left leg (range 0-27) and 2 for the right leg (range $0-24$ ). The rate of occurrence was highest in state A (left leg median $0.27 / 10 \mathrm{~min}$., range $0.00-0.75 / 10 \mathrm{~min}$.; right leg median $0.17 / 10 \mathrm{~min}$., range $0.00-1.55 / 10 \mathrm{~min}$.). The median rate of occurrence in states B and C was $0.00 / 10 \mathrm{~min}$. for both legs. Statistical significance could only be demonstrated for the difference between states $A$ and $C(p<0.05)$.

\section{Isolated limb movements}

Isolated arm movements occurred frequently during the complete observation session (left arm median 41, range 26-41; right arm median 53, range 27-96). They occurred significantly more often in states A and B than in state C. The median rate of occurrence in state $A$ was $2.92 / 10 \mathrm{~min}$. for the left arm (range 1.79-6.78/10 $\mathrm{min}$.) and 3.14/10 $\mathrm{min}$. for the right arm (range 1.24$8.87 / 10 \mathrm{~min}$.). In state $B$, isolated movements of the left arm occurred with a median of $3.72 / 10 \mathrm{~min}$. (range $0.00-8.66$ ). The median rate of occurrence for the right arm was $5.09 / 10 \mathrm{~min}$. (range $0.00-8.84$ ). The occurrence in state $C$ was significantly lower (table 5.4). No significant difference in the rate of occurrence of isolated arm movements between states $A$ and state $B$ could be demonstrated.

Isolated leg movements occurred with a median of 53 for the left leg and 60 for the right leg during the complete observation session (left leg range $17-162$ ); right leg range $34-154$ ). They also occurred significantly more often in States $A$ and $B$ than in state $C$. The median rate of occurrence in state $A$ was $5.09 / 10 \mathrm{~min}$. for the left leg (range 1.87-11.19/10 min.) and 4.77/10 $\mathrm{min}$. for the right leg (range $3.03-9.66 / 10 \mathrm{~min}$.). In state $B$, isolated movements of the left leg occurred with a median of $5.17 / 10 \mathrm{~min}$. (range 1,46-8.29). The median rate of occurrence for the right leg was 5.71/10 $\mathrm{min}$. (range 2.02-9.76). No difference in the rate of occurrence between states A and B could be demonstrated for both legs. 


\section{Hand-face contact}

In state $\mathrm{A}$ a median of $1 \%$ and $0 \%$ was spent in hand-face contact of respectively the left hand (range 0-8\%) and the right hand (range 0-6\%). In state B a median of $2 \%$ and $3 \%$ was spent in hand-face contact of respectively the left hand (range $0-21 \%$ ) and the right hand (range $0-10 \%$ ). A median of $0 \%$ was spent in hand-face contact of the left and right hand in state C. A significant difference in the percentage of time spent in hand-face contact could only be demonstrated for the left hand between state $C$ and states $A$ and $B(p<0.05)$.

\section{Hand-mouth contact}

In state $\mathrm{A}$ a median of $0 \%$ was spent in hand-mouth contact of the left hand (range $0-3 \%$ ) and the right hand (range $0-36 \%$ ). In state B a median of $1 \%$ and $0 \%$ was spent in hand-mouth contact of respectively the left hand (range $0-25 \%$ ) and the right hand (range $0-14 \%$ ). A median of $0 \%$ was spent in hand-mouth contact of the left and right hand in state $C$. Only the difference between the occurrence of hand-mouth contact of the left hand in states $B$ and state $C$ was statistically significant $(p<0.05)$.

\section{The influence of head position on limb movements}

Firstly, the frequency of occurrence of limb movements during a left-sided head position was compared to the frequency of occurrence of limb rnovements during a right-sided head position in infants who showed periods of right-sided and periods of left-sided head position (10 infants).

A significantly higher percentage of time was spent with hand-mouth contact of the left arm during a head position to the left than during a head position to the right $(p<0.05)$. Furthermore, during a left-sided head position, isolated movements of the left leg occurred significantly more often than during a right-sided head position $(p<0.05)$. No other significant differences in occurrence of limb movements between a right-sided and a left-sided head position could be demonstrated.

Secondly, the frequency of occurrence of movements of the left arm and leg was compared to the frequency of occurrence of movements of the right arm and leg during a left- or right-sided head position (Wilcoxon-matched-pairs signed-ranks test).

During a left-sided head position twitches occurred with a higher frequency in the right arm than in the left. Furthermore, cloni had a higher frequency of occurrence in the left than in the right leg. However, these differences failed to reach statistical significance. A significantly higher percentage of the time with a left-sided head position was spent in hand-face and hand-moith contact of the left hand, than of the right hand $(\mathrm{p}<0.05)$. The only significant difference between movements of the left and right extremities during a right sided head position was the higher percentage of time spent in hand-mouth contact of the right hand $(p<0.05)$. 
In conclusion:

1. No significant head position preference could be demonstrated in the AGA infants.

2. In state $\mathrm{C}$ a significantly higher percentage of time was spent in general movements than in states A and B. Furthermore, the percentage of time spent in general movements in state B was significantly higher than in state A. Startles, stretches and twitches occurred significantly more in state A than in states B and C.

3. Head position influences the occurrence of hand-face and hand-mouth contact. The hand on the side the head is turned to spent a higher percentage of time in contact with the face and/or the mouth than the contralateral hand.

4. All movement patterns except hand-face and hand-mouth contact have a symmetrical distribution, independent of the head position.

\subsection{Posture}

Fourteen infants were included in the final analysis of posture. One infant was excluded from the postural analysis because, due to manipulation and frequent movements, the postural data were considered to be insufficient $(<10$ minutes) for an analysis of (preference) posture (AGA infant 1). The median number of postural data was 85 (range 14-154).

First the data on the complete posture were analyzed (analysis 1). Eleven AGA infants $(79 \%)$ showed a preference posture. However, these postures were all different (Figure 5.2); there was no dominant group preference posture. The median percentage of the postural observation time during which the preference posture was observed was $11.8 \%$ (range $4.1-33.3 \%$ ).

The median duration of the longest uninterrupted posture was 7 minutes (range 2-17). The preference posture and the longest uninterrupted posture were identical in 7 infants. Each infant had a wide postural repertoire, with a median number of 35 (range 11-86) different postures. The most frequently observed combinations of the position of both arms, both legs, left arm-left leg, right arm-right leg, left arm-right leg and right arm-left leg, were calculated for every infant. No dominant group combination could be demonstrated.

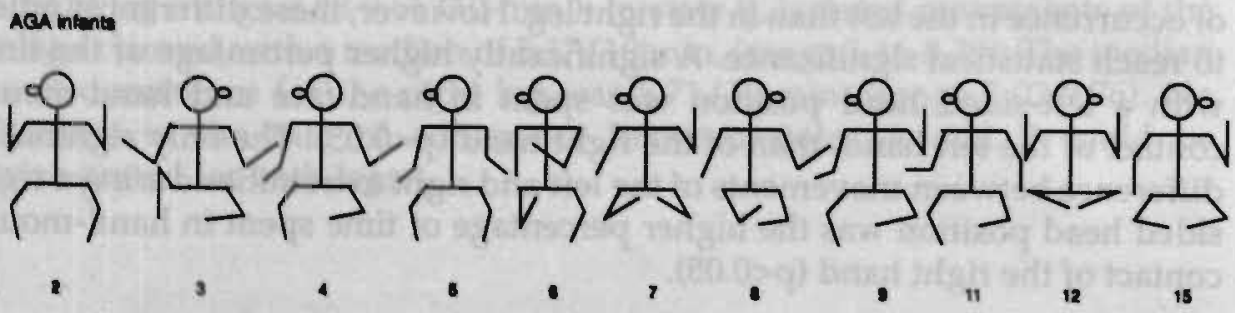

Figure 5.2 Preference posture of full-term AGA infants. 
Using a reduced number of classes in analyses 2 (considering only abduction/adduction and flexion/extension) and 3 (considering only flexion/extension), we were unable to demonstrate a dominant group preference posture in this group. In analysis 4, however, considering only abduction and adduction in shoulder and hip, a preference posture was found in 12 infants. Nine of these infants $(75 \%)$ showed a preference posture with all four limbs in 0-90 degrees abduction.

Finally the four limbs were analyzed separately considering only abduction/adduction (analysis 5) and flexion/extension (analysis 6). With regard to the degree of abduction and adduction of the four limbs there was a clear preference for an abduction of 0-90 degrees of all four limbs (Figure 5.3). A position with an abduction of 0-90 degrees occurred significantly more often than all other categories of abduction/adduction in all limbs (Wilcoxon matched-pairs signed-ranks test with Bonferroni correction, $p$-values $<0.05$ ). Only in the left leg was the difference between the occurrence of a position with $0-90$ degrees abduction and a position with an abduction of 90 degrees not statistically significant.

With regard to the degree of flexion and extension of the elbows and knees, there was considerable interindividual variability (Figure 5.4). However, a fully extended position occurred significantly less often than the other categories of flexion and extension (Wilcoxon matched-pair signed-ranks test with Bonferroni correction, p-values $<0.05$ ). Only in the right arm was the difference between the occurrence of a fully extended and a partly flexed position of the elbow not statistically significant.

In conclusion:

1. There was a wide inter-individual variability in postural repertoire in these full-term AGA infants.

2. Most of these AGA infants showed a real preference posture, but, there was no group preference posture.

3. Considering the positions of the limbs separately, a preference for a position of 0-90 degrees abduction was demonstrated for all limbs.

\subsection{Influence of head position change on body posture}

A total number of 91 "pure" head turnings (without lateral, dorsal or ventral flexion) were analyzed (median 2.5; range $0-18$ ). Forty-eight head turnings $(53 \%)$ were directed to the right, 43 head turnings $(47 \%)$ were directed to the left. Of the total amount of 91 head turnings, $27(30 \%)$ were noted during state A, $56(61 \%)$ during state $B(9 \%)$ and eight during state $C$.

Five infants showed no spontaneous head turnings without lateral, dorsal or ventral flexion. They were excluded from further analysis. Three of the remaining 10 infants, showed only pure spontaneous head turnings to the 
mow

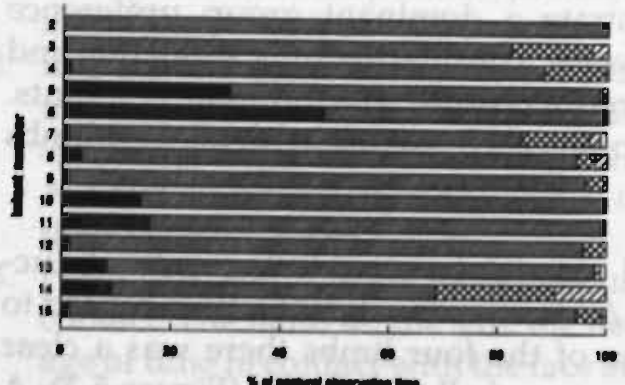

ming

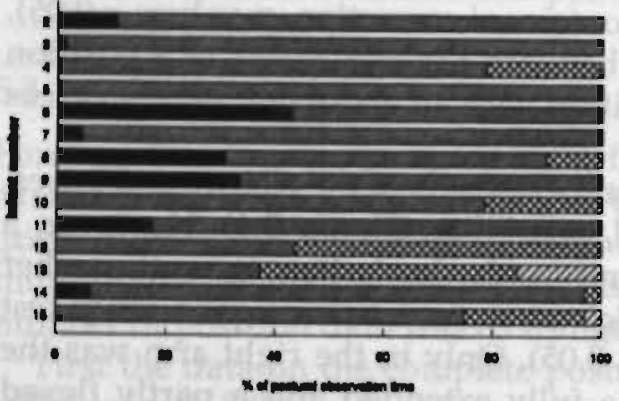

QDena nestra

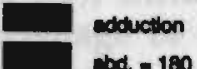

bd. $=180$
Whater

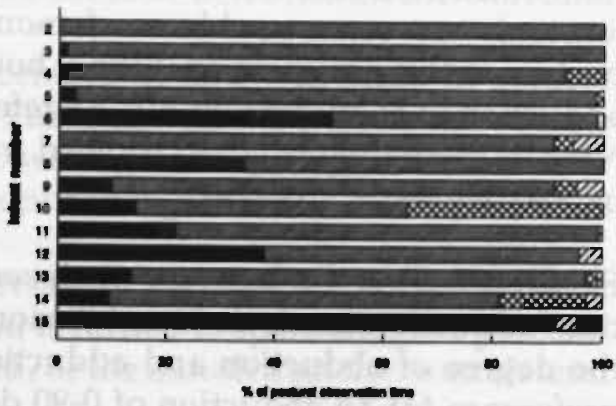

ithis the

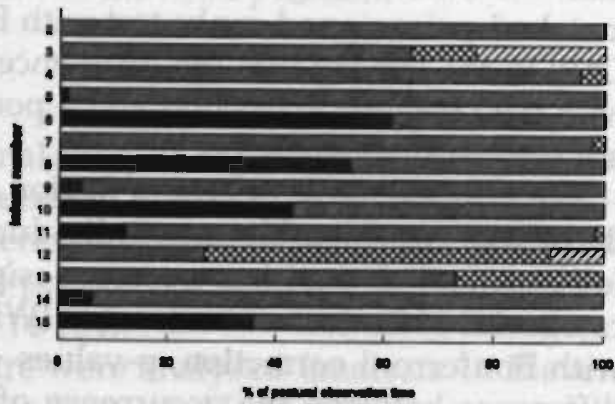

abd. $0-90 \quad$ ad. $=90$

ch. $>180$

Figure 5.3 Degree of abduction and adduction of the four limbs in full-term AGA infants. $A b d=$ abduction .

right. The other seven infants showed head turnings to the right as well as to the left. The median number of head turnings in these ten infants was 10 (range 1-18).

Table 5.5 shows the relationship between the direction of the head turning and the positional changes of the limbs. There was a wide intra- and interindividual variability with respect to the positional changes of the limbs after a spontaneous head turning, as can be concluded from the wide ranges of the percentages of the occurrence of various positional changes.

Neither a head turning to the right nor a head turning to the left was followed by a dominant reaction pattern of one of the four limbs. There were no significant differences between the occurrence of flexion, extension or no positional change (Wilcoxon matched-pairs signed-ranks test with Bonferroni correction). 


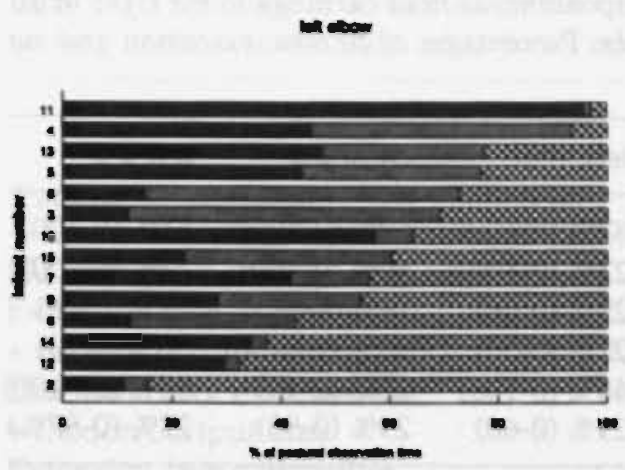

that the

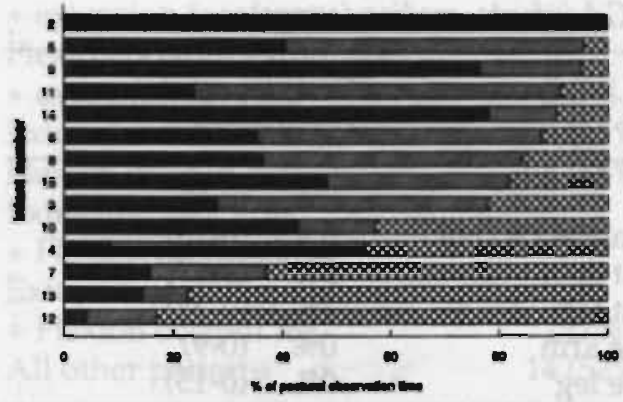

fr. ext.

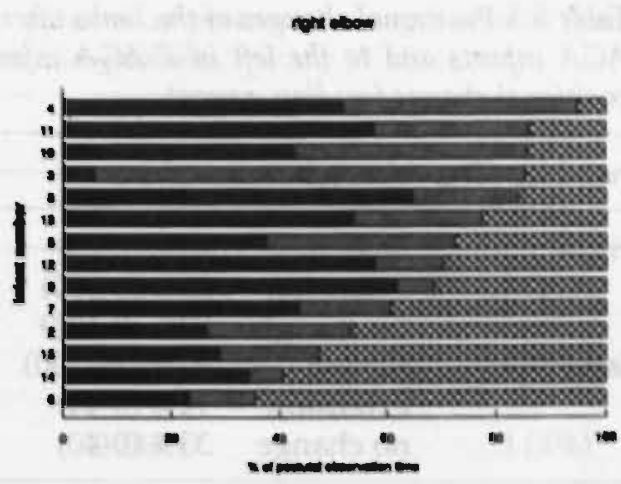

thin ine

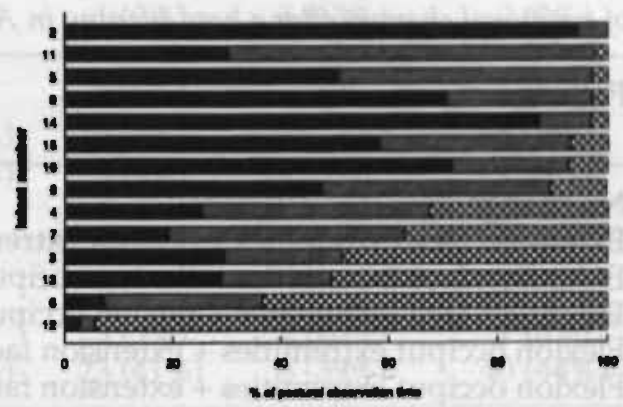

per fex. 8 tull fex.

Figure 5.4 Degree of flexion and extension of the four limbs in full-term AGA infants. Full. ext. $=$ fully extended, part. ext.$=$ partly extended, part. flex. $=$ partly flexed, full. flex. $=$ fully flexed.

In table 5.6 the occurrence of several reaction patterns, such as the asymmetric tonic neck reflex (ATNR) as described in the literature (Magnus and de Kleyn, 1912), and several derived patterns is shown. A wide interindividual variability existed. A "pure" ATNR as described in the literature was rare. It occurred only after 6 of the 91 head turnings $(7 \%)$. No significant difference between the occurrence of the ATNR, ATNR-derived patterns, and "no change" could be demonstrated.

The number of pure head turnings per infant per state was variable. State A: median $2(0-8)$; state B: median $5(0-11)$; state C: median $0(0-6)$. The occurrence of the ATNR and ATNR-derived patterns in the different states is summarized in table 5.7. As most infants had a very small number of head turnings per state, the data for all infants were pooled and no statistical analysis was performed. However, the differences in the occurrence of the 
Table 5.5 Positional changes of the limbs after spontaneous head turnings to the right in 10 AGA infants and to the left in 7 AGA infants. Percentages of flexion, extension and no positional change (median, range).

\begin{tabular}{|c|c|c|c|c|c|}
\hline head turning & change & right arm & left arm & right leg & left leg \\
\hline right & $\begin{array}{l}\text { flexion } \\
\text { extension } \\
\text { no change }\end{array}$ & $\begin{array}{l}29 \%(0-75) \\
33 \%(0-100) \\
33 \%(0-100)\end{array}$ & $\begin{array}{l}37 \%(0- \\
23 \%(0- \\
25 \%(0-\end{array}$ & $\begin{array}{l}-100) \\
-100) \\
-66)\end{array}$ & $\begin{array}{r}54 \% \\
7 \% \\
23 \%\end{array}$ \\
\hline left & $\begin{array}{l}\text { flexion } \\
\text { extension } \\
\text { no change }\end{array}$ & $\begin{array}{l}57 \%(20-100) \\
14 \%(0-44) \\
33 \%(0-40)\end{array}$ & $\begin{array}{l}27 \%(0-50) \\
40 \%(0-100) \\
29 \%(0-60)\end{array}$ & $\begin{array}{l}50 \%(20-100) \\
20 \%(0-40) \\
29 \%(0-50)\end{array}$ & $\begin{array}{l}25 \%(0-66) \\
0 \%(0-20) \\
66 \%(29-100) \\
27 \%(0-57 \%)\end{array}$ \\
\hline
\end{tabular}

Table 5.6 Frequency of occurrence (\% of total number of head turnings) of various patterns of positional changes after a head turning in AGA infants, median (range).

\begin{tabular}{lcl}
\hline Pattern & \multicolumn{2}{c}{$\begin{array}{l}\text { Frequency of } \\
\text { occurrence }\end{array}$} \\
\hline No change & $0 \%$ & $(0-6)$ \\
Extension face extremities + occiput extremities (ATNR) & $0 \%$ & $(0-23)$ \\
Extension face extremities + flexion occiput arm & $0 \%$ & $(0-17)$ \\
Extension face extremities + flexion occiput leg & $7 \%$ & $(0-34)$ \\
Flexion occiput extremities + extension face arm & $0 \%$ & $(0-9)$ \\
Flexion occiput extremities + extension face leg & $0 \%$ & $(0-15)$ \\
Extension face extremities & $9 \%$ & $(0-100)$ \\
Flexion occiput extremities & $4 \%$ & $(0-100)$ \\
Extension face arm + flexion occiput arm & $0 \%$ & $(0-9)$ \\
Extension face leg + flexion occiput leg & $0 \%$ & $(0-28)$ \\
All other patterns & $39.5 \%(0-67)$ \\
\hline
\end{tabular}

ATNR and ATNR-derived patterns between the different states, as can be seen in the table, were small.

The tonic character of the influence of a head turning on body posture was investigated by studying the duration of the assumed position of the extremities after a head turning. In 72 headl turnings (79\%), the position assumed after the head turning lasted less than one second. Four positions lasted 1 to 5 seconds, 3 positions lasted 6 to 10 seconds, 2 positions lasted 11 to 20 seconds and 10 positions lasted more than 20 seconds. The duration of the 6 asymmetric tonic neck positions was less than 1 second in 4 positions, whereas the other two positions lasted more than 20 seconds. From these results it may be concluded that a possible influence of a head position change on body posture was not tonic in character. 
Table 5.7 Frequency of occurrence of various patterns of positional changes after a head turning in the different states (data for all infants are pooled).

\begin{tabular}{|c|c|c|c|c|}
\hline \multirow[b]{2}{*}{ Pattern } & \multicolumn{4}{|l|}{ State } \\
\hline & A & B & C & Total \\
\hline $\begin{array}{l}\text { No change } \\
\text { Extension face extremities }\end{array}$ & - & $1(2 \%)$ & - & $1(1 \%)$ \\
\hline + occiput extremities (ATNR) & $1(4 \%)$ & $5(9 \%)$ & - & $6(7 \%)$ \\
\hline $\begin{array}{l}\text { Extension face extremities } \\
+ \text { flexion occiput arm } \\
\text { Extension face extremities }\end{array}$ & - & $2(4 \%)$ & - & $3(3 \%)$ \\
\hline $\begin{array}{l}\text { + flexion occiput leg } \\
\text { Flexion occiput extremities }\end{array}$ & $1(4 \%)$ & $8(14 \%)$ & $1(13 \%)$ & $10(11 \%)$ \\
\hline $\begin{array}{l}\text { + extension face arm } \\
\text { Flexion occiput extremities }\end{array}$ & - & $1(2 \%)$ & $1(13 \%)$ & $2(2 \%)$ \\
\hline + extension face leg & $2(7 \%)$ & $3(5 \%)$ & - & $5(5 \%)$ \\
\hline Extension face extremities & $3(11 \%)$ & $5(9 \%)$ & - & $8(9 \%)$ \\
\hline $\begin{array}{l}\text { Flexion occiput extremities } \\
\text { Extension face arm }\end{array}$ & $4(15 \%)$ & $3(5 \%)$ & - & $7(8 \%)$ \\
\hline $\begin{array}{l}\text { + Flexion occiput arm } \\
\text { Extension face leg }\end{array}$ & - & $2(4 \%)$ & - & $2(2 \%)$ \\
\hline $\begin{array}{l}\text { + Flexion occiput leg } \\
\text { All other patterns }\end{array}$ & $\begin{array}{c}2(7 \%) \\
14(52 \%)\end{array}$ & $\begin{array}{c}3(5 \%) \\
23(41 \%)\end{array}$ & $\begin{array}{l}2(26 \%) \\
3(39 \%)\end{array}$ & $\begin{array}{c}7(8 \%) \\
40(44 \%)\end{array}$ \\
\hline Total number of head turnings & 27 & 56 & 8 & 91 \\
\hline
\end{tabular}

The occurrence of an asymmetric neck posture in the resting postures was studied. An asymmetric tonic neck posture (ATNP) was defined as a posture in which the face-side extremities were relatively more extencled than the occiput-side extremities. All postures were classified as asymmetric tonic neck posture (ATNP), asymmetric tonic neck position of arms, asymmetric tonic neck position of legs or no ATNP. The median percentage of asymmetric tonic neck postures was $6 \%$ (range $0-25 \%$ ). The median percentage of an ATNP of the arms was $24 \%$ (range 7-45\%). The occurrence of an ATNP of the legs ranged from $0 \%$ to $37 \%$ (median $19 \%$ ). In a median percentage of $54 \%$ (range 18-75\%) no ATNP existed. The results for every infant are shown in figure 5.5. Significant differences existed between the occurrence of the 4 classifications (Wilcoxon signed ranks test with Bonferroni correction, all p-values < 0.05). Postures without any ATNP-derived pattern occurred in a significantly higher percentage than postures with an ATNP or an ATNP of arms or legs only. Furthermore, an ATNP occurred in a significantly lower percentage than postures with an ATNP of arms or legs only. No significant 


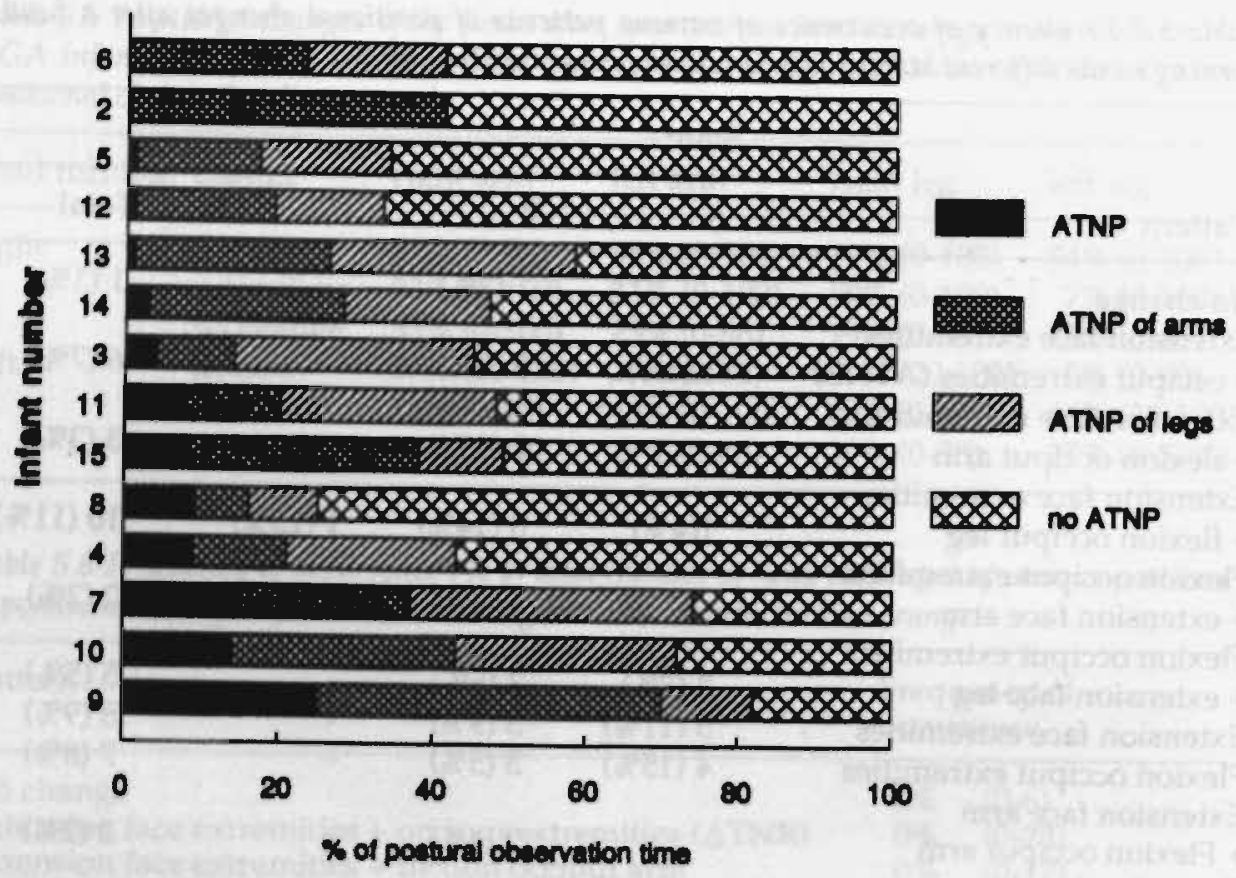

Figure 5.5 Occurrence of an Asymmetric Tonic Neck Posture (ATNP) in full-term AGA infants.

difference existed between the occurrence of postures with an ATNP of the arms and the occurrence of postures with an ATNP of the legs only.

In conclusion:

1. The occurrence of an ATNR following a spontaneous head turning in full-term AGA infant is rare.

2. Considerable interindividual variability exists in the occurrence of several ATNR-derived patterns. No significant flexion/extension pattern could be demonstrated.

3. A possible influence of head turning on body position in AGA infants has no tonic character. The majority of positions assumed after a spontaneous head turning lasted less than one second.

\subsection{Quality of movement}

General analysis

A total number of 106 general movements could be judged regarding the qualitative aspects of the movement. Thirty-two $(30 \%)$ general movements were observed in state A and $74(70 \%)$ in state B. One infant did not show 
general movements with a minimal duration of 20 seconds and was therefore excluded from the analysis (AGA infant 11). The analysis thus included general movements of 14 AGA infants.

There was a median number of 8 general movements per infant (range 2-15). The mean duration of the general movements per AGA infant ranged from 31 to 75 seconds, median 40 seconds (table 5.8 ). The general movements during state A and state B were analyzed separately. Five infants showed general movements with a minimal duration of 20 seconds in both state $A$ and state $B$. Two infants showed general movements with a duration of more than 20 seconds in state A only, seven infants showed general movements in state B only.

No significant differences existed in the mean duration of the general movements, nor in the frequency of occurrence of the different categories per item between state A and state B. Therefore, the general analysis was carried out without taking into consideration the state of the infant.

In table 5.9 the relative frequency (median and range) of the different categories per item are shown. All items, except item 3 and item 7 , showed a significant difference between the frequency of occurrence of their categories (all p-values < 0.05).

\section{Pattern analysis}

The existence of significant correlations between the different items was tested (Spearman rank-order correlation coefficient) to investigate whether different patterns (types) of movement quality could be isolated from the total group of general movements. The results are shown in table 5.10.

As any significant pattern would most likely be determined by the detailed items of movement quality which showed significant mutual correlation, we decided to use the items $3,9,10,11$ and 12 in our search for different types of movement quality. The global judgment is a complex integration of the more detailed aspects of movement quality and is therefore already a certain classification of the movement quality. Therefore, this judgment was not considered in the search for different types of movement quality.

From the 106 general movements, 3 dominant patterns could be classified (Table 5.11).

Type I general movements are characterized by a fluent performance of the movement, with variable speed and amplitude. The movement pattern is variable, which also holds true for the movement patterns of arms and legs separately. The movements mostly have a smooth onset and end. The speed may be predominantly fast or predominantly slow.

Type II general movements are fast movements with an abrupt and jerky appearance. They are variable in speed and amplitude and they are complex and variable, not stereotyped. Most of them have a predominantly large amplitude. 
Table 5.8 Data concerning the general analysis of the general movements.

Number of infants included

14

Total number of general movements 106

Number of general movements in state A

Number of general movements in state B

General movements per infants (median, range)

$32(30 \%)$

$74(70 \%)$

$8(2-15)$

Average duration (median, range)

$40(31-75)$

Table 5.9 Relative frequencies (\%) of the different categories per item. Median and range.

Item

1. Onset of movement

2. Variability in speed

3. Overall speed

4. Speed of arms compared to legs

5. Force against gravity

6. Variability in amplitude

7. Overall amplitude

8. amplitude of arms compared to legs

9. Fluency

10. Variability in movement pattern

11. Variability in arm patterns

12. Variability in leg patterns

13. Fine distal movements

14. End of movement

15. Global judgement
Category

abrupt

smooth

absent

present

predominantly fast

predominantly slow

higher

lower

equal

absent

present

absent

present

predominantly large

predominantly small

larger

smaller

equal

not fluent: tremulous

flapping

abrupt, jerky

fluent

absent

present

absent

present

absent

present

absent

present

absent

present

abnormal

normal
Relative frequency

$27 \%(0-50)$

$74 \%(50-100)$

$0 \%(0)$

$100 \%(0)$

$77 \%(0-100)$

$24 \%(0-100)$

$0 \%(0-17)$

$12 \%(0-64)$

$89 \%(36-100)$

$0 \%(0)$

$100 \%(0)$

$0 \%(0)$

$100 \%(0)$

$81 \%(0-100)$

20\% (0-100)

$0 \%(0-33)$

$6 \%(0-67)$

$83 \%(33-100)$

$0 \%(0-10)$

$0 \%(0-11)$

$25 \%(0-87)$

$71 \%(13-100)$

$0 \%(0-50)$

$100 \%(11-100)$

$19 \%(0-62)$

$82 \%(31-100)$

$0 \%(0-40)$

$100 \%(60-100)$

$0 \%(0)$

$100 \%(0)$

$0 \%(0-25)$

$100 \%(75-100)$

$14 \%(0-75)$

$87 \%(25-100)$ 
Table 5.10 Significant correlations $(+=p<0.05)$ between the items of movement quality.

\begin{tabular}{llllllllllllllll} 
ITEM & 1 & 2 & 3 & 4 & 5 & 6 & 7 & 8 & 9 & 10 & 11 & 12 & 13 & 14 & 15 \\
\hline
\end{tabular}

1

2

3

4

5

6

7

8

9

10

11

12

13

14

15

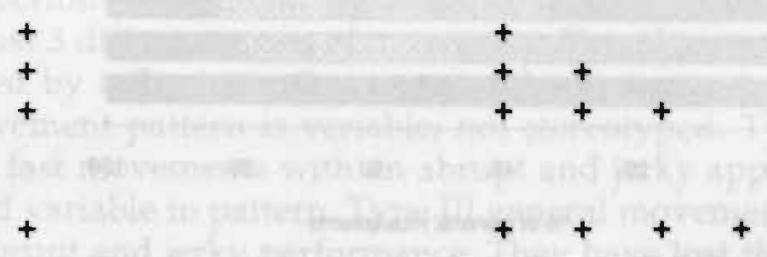

Table 5.11 Characteristics of the types (I-III) of movement quality.

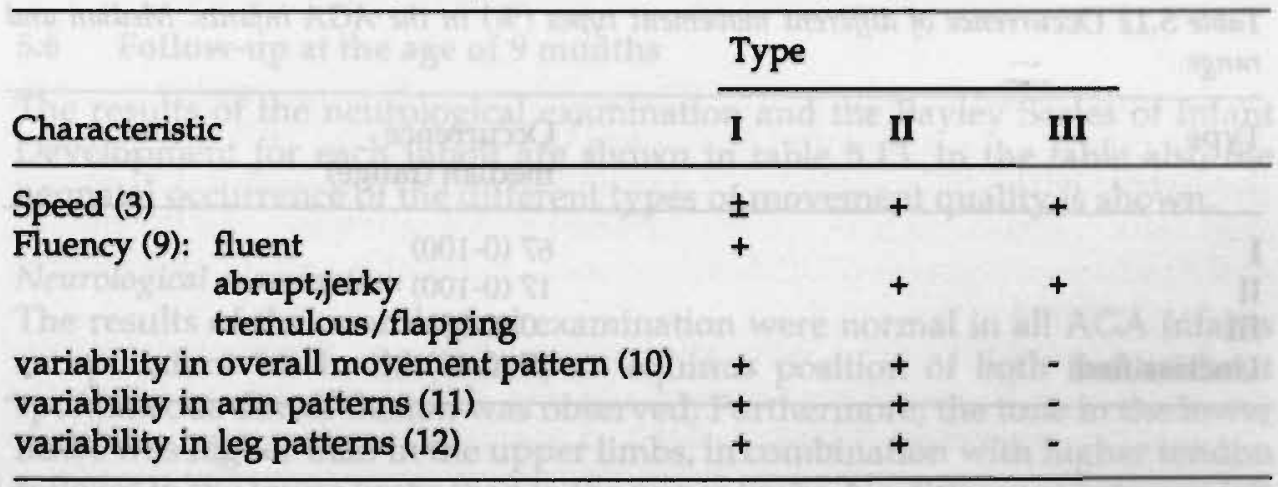

Speed: fast $(+)$, slow $(-)$, fast or slow $(t)$; all other characteristics: present $(+)$, absent $(-)$.

Type III general movements are characterized by an abrupt and jerky performance. Furthermore, they have lost their variability and complexity in the overall movement pattern, as well as in the patterns of arms and legs. It makes a stereotyped impression. These movements mostly have a predominantly high speed and large amplitude.

All general movements which were characterized by another pattern of quality of movement were judged "unclassified". 


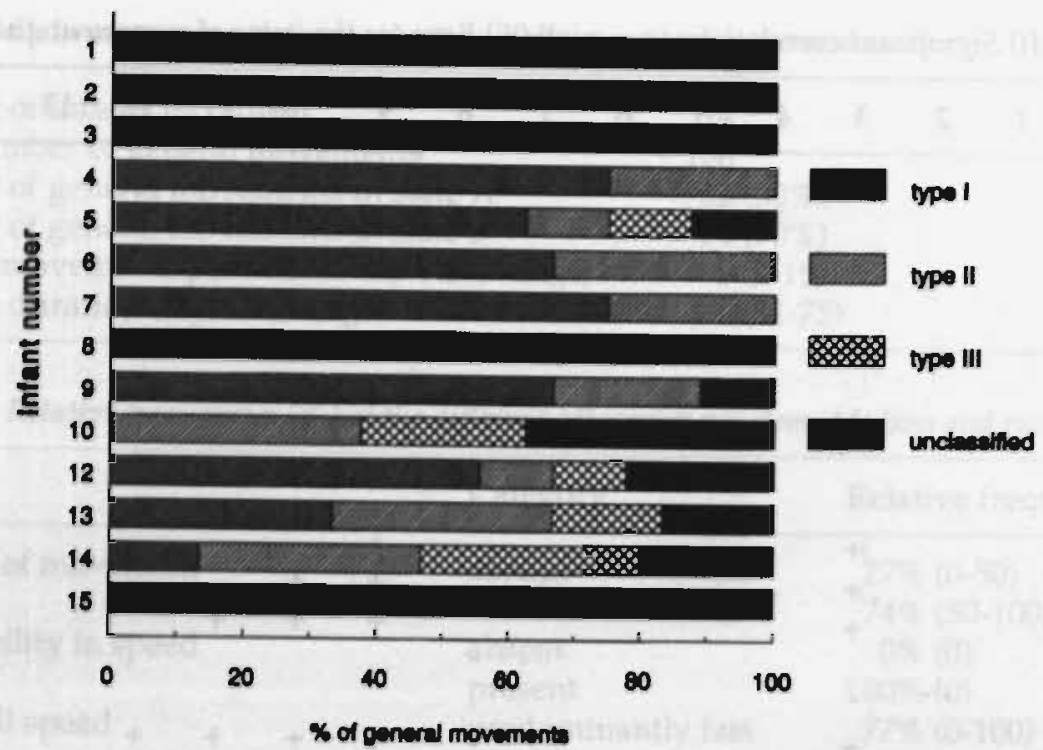

Figure 5.6 Occurrence of the different types of quality of general movements in the AGA infants.

Table 5.12 Occurrence of different movement types (\%) in the AGA infants. Median and range.

\begin{tabular}{lc} 
Type & $\begin{array}{l}\text { Occurrence } \\
\text { median (range) }\end{array}$ \\
\hline I & $67(0-100)$ \\
II & $17(0-100)$ \\
III & $0(0-33)$ \\
Unclassified & $17(0-46)$ \\
\hline
\end{tabular}

The frequency of occurrence of the general movement types was calculated for the individual infants (figure 5.6). Median and range of the frequency of occurrence of each type in the infants are shown in table 5.12.

Significant differences existed between the occurrence of the different movement types (Friedman two-way analysis of variance, $p<0.0001$ ). Type I movements occurred significantly more often than type II and III movements (Wilcoxon matched-pairs signed-ranks test, $\mathrm{p}<0.01$ ). Type II occurred more often than type III movements (Wilcoxon matched-pairs signed-ranks test, $p<0.05$ ). 
The frequency of occurrence of the different types of general movements in states $A$ and $B$ were calculated. No significant differences between states $A$ and $B$ existed ( $p>0.05)$.

The proportion of the total number of general movements of each type of movement quality that was previously judged as normal or abnormal was calculated. From type I $100 \%$ was judged as normal; $80 \%$ of the type II movements were judged as normal. All type III movements were judged to be abnormal.

In conclusion:

The normal repertoire of general movements in healthy full-term infants consists of at least 3 different types of movement. Type I general movements are characterized by a fluent performance of the movement, with variable speed. The movement pattern is variable, not stereotyped. Type II general movements are fast movements with an abrupt and jerky appearance. They are complex and variable in pattern. Type III general movements are characterized by an abrupt and jerky performance. They have lost their variability and complexity in movement pattern. Most of the movements have a predominantly high speed.

\subsection{Follow-up at the age of 9 months}

The results of the neurological examination and the Bayley Scales of Infant Development for each infant are shown in table 5.13. In the table also the neonatal occurrence of the different types of movement quality is shown.

\section{Neurological examination}

The results of the neurological examination were normal in all AGA infants except infant 14. In this infant, an equinus position of both feet without spontaneous dorsal flexion was observed. Furthermore, the tone in the lower limbs was higher than in the upper limbs, in combination with higher tendon reflexes in the lower limbs than in the upper limbs. No difference between left and right limbs was observed.

\section{Bayley Scales of Infant Development}

The median Mental Developmental Index (MDI) was 106, ranging from 62 to 127. One of the infants had an MDI of 62 , which is below the normal range (infant 12). Another AGA infant had an MDI which was 127, which is well above the normal range (infant 1 ).

The median Psychomotor Developmental Index (PDI) was 96 with a minimum of 78 and a maximum of 120 . Two infants had a PDI below the normal range (infant 5 and 6 ). 
Table 5.13 Follow-up results at the age of 9 months in combination with the neonatal neurological examination and the occurrence of different types of movement quality in $A G A$
infants.

\begin{tabular}{|c|c|c|c|c|c|c|c|c|}
\hline Infant & N.N.E. & Type I & Type & II Type III & Unclassified & MDI & PDI & N.E. 9 months \\
\hline 1 & normal & 80 & 0 & 0 & 20 & 127 & 105 & normal \\
\hline 2 & normal & 83 & 0 & 0 & 17 & 103 & 120 & normal \\
\hline 3 & normal & 55 & 0 & 0 & 45 & 104 & 96 & normal \\
\hline 4 & normal & 75 & 25 & 0 & 0 & 110 & 120 & normal \\
\hline 5 & normal & 63 & 13 & 13 & 11 & 104 & 78 & normal \\
\hline 6 & normal & 67 & 33 & 0 & 0 & 92 & 79 & normal \\
\hline 7 & normal & 75 & 25 & 0 & 0 & 110 & 110 & normal \\
\hline 8 & normal & 100 & 0 & 0 & 0 & 106 & 102 & normal \\
\hline 9 & normal & 67 & 22 & 0 & 11 & 108 & 91 & normal \\
\hline 10 & normal & 0 & 38 & 25 & 37 & 106 & 91 & normal \\
\hline 12 & normal & 56 & 11 & 11 & 22 & 62 & 87 & normal \\
\hline 13 & normal & 33 & 33 & 17 & 17 & 92 & 89 & normal \\
\hline 14 & normal & 13 & 33 & 33 & 21 & 107 & 85 & suspect \\
\hline 15 & normal & 80 & 0 & 0 & 20 & 115 & 116 & normal \\
\hline
\end{tabular}

N.N.E.: Neonatal Neurological Examination; N.E.: Neurological examination; MDI: Mental Developmental Index; PDI: Psychomotor Developmental index.

To investigate whether there was significant correlation between the results of the follow-up examination at the age of nine months and the neonatal occurrence of the different types of movement quality (see section 5.5), Spearman rank correlations between the different movement types and the mental (MDI) and psychomotor (PDI) developmental index at the age of nine months were calculated.

A significantly positive correlation existed between the neonatal occurrence of type I general movements and the PDI at the age of 9 months (correlation coefficient $0.6586, \mathrm{p}<0.05$ ). A significantly negative correlation existed between the occurrence of type III general movements and the PDI at 9 months. No significant correlation existed between the different movement types and the MDI at 9 months of age.

\section{In conclusion:}

1. Most AGA infants had normal neurological findings and normal results at the Bayley Scales of Infant Development at the age of 9 months.

2. A significantly positive correlation existed between the neonatal occurrence of type I general movements and the PDI at the age of 9 months. Furthermore, a significantly negative correlation existed between the neonatal occurrence of type III general movements and the PDI at the age of nine months. 


\section{Chapter 6}

\section{Spontaneous motor behaviour in full-term small for gestational age newborn infants}

6.1 Neurological examination

6.2 Quantitative aspects of motor behaviour

$6.3 \quad$ Posture

6.4 Influence of head position change on body posture

6.5 Quality of movement

6.6 Follow-up at the age of 9 months 


\subsection{Neurological examination}

In the SGA group the neurological examination was normal in eight infants. Seven infants had deviant neurological findings: three infants showed slight hyperexcitability (infant 2,8 and 13); in one of them this was combined with a preference position of head and eyes to the right (infant 13). Hypertonia was found in one infant (infant 14), whereas one infant had hypertonia of the legs only (infant 10). Two infants showed hypotonia (infant 6 and 12); one of them also had jerky eye movements (infant 6).

\subsection{Quantitative aspects of motor behaviour}

The median duration of the complete observation session was $179.85 \mathrm{~min}$. (range 120.57 to $191.53 \mathrm{~min}$.). The total observation time of the 15 infants together was 43 hours and 51 minutes. An example of an actogram is shown in figure 6.1. During the observation session most infants had to be manipulated several times due to nursing routines such as feeding and changing diapers and persistent crying. The duration of manipulation per observation

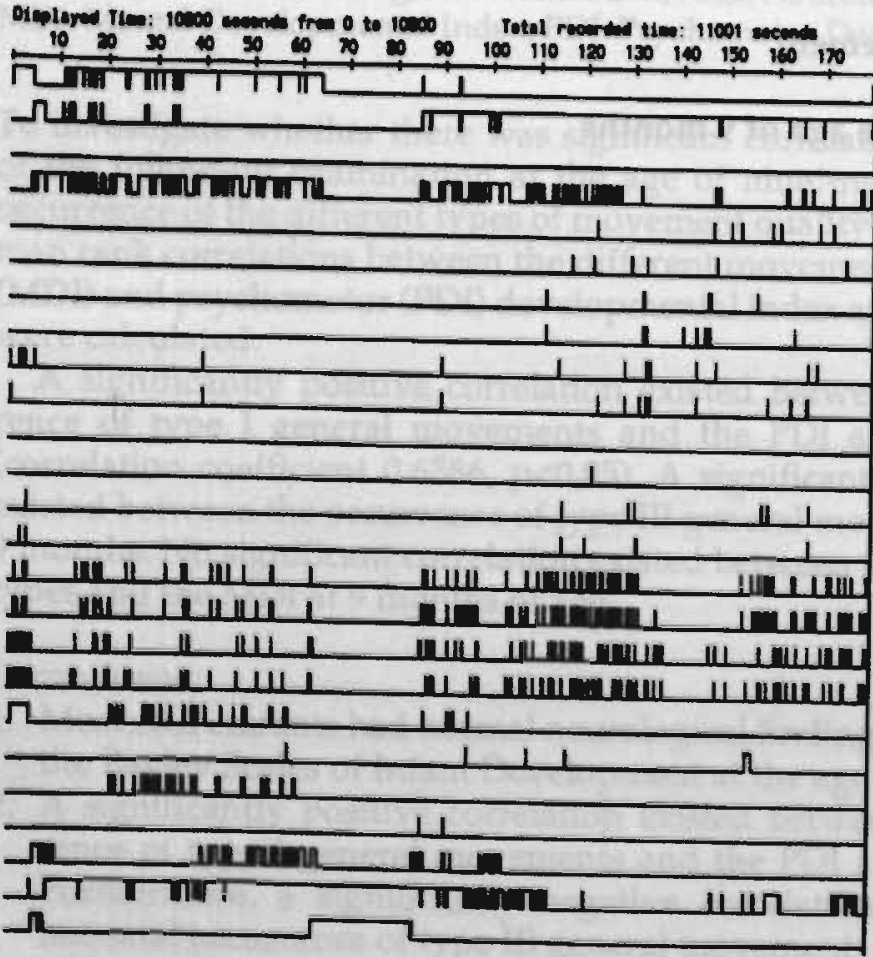

\begin{tabular}{|c|c|c|c|c|c|}
\hline & mits & $\frac{\text { illem }}{5 x}$ & & $\frac{20}{1010}$ & $\frac{03, P O 1}{\text { sive }}$ \\
\hline A & Head Loft & $x$ & $3 \mathbf{1}$ & 300 & 131 \\
\hline 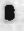 & Head Ripht & $x$ & $\approx$ & 503 & 50 \\
\hline C & $D \rightarrow$ in/out & $x$ & 0 & 0 & 0 \\
\hline 0 & en. Novment & $x$ & n & 3 & 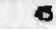 \\
\hline E & Strateh & $x$ & 8 & & \\
\hline 5 & Sturtio & $x$ & 8 & & \\
\hline e & Iritch L-em & $x$ & 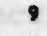 & & \\
\hline H & Triteh R-ern & $x$ & 12 & & \\
\hline 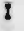 & Tritch Ltes & $x$ & 19 & & \\
\hline J & Triteh A-Le & $x$ & 14 & & \\
\hline $\mathbf{x}$ & Clenes L-ar & $x$ & 0 & & \\
\hline $\mathbf{L}$ & Clenes Arem & $x$ & 1 & & \\
\hline n & clane Ltes & $x$ & 7 & & \\
\hline M & Clow R-Let & $x$ & ? & & \\
\hline 0 & Ind. LA Em & $x$ & $\boldsymbol{w}$ & & \\
\hline P & Inel. $\mathrm{A}=$ & $x$ & 143 & & \\
\hline 9 & Iml. $4 \mathrm{~mm}$ & $x$ & 116 & & \\
\hline 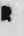 & Inol R. ON & $x$ & 118 & & \\
\hline$\$$ & Hontiea L & $x$ & 3 & 320 & 3 \\
\hline $\boldsymbol{T}$ & Hentficon $R$ & $x$ & 5 & $\mathbf{n}$ & 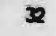 \\
\hline u & Wunteowth L & $x$ & 3 & 134 & \\
\hline$v$ & Hortenth & $x$ & 3 & 1 & 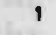 \\
\hline$n$ & aris & $x$ & 4 & m) & 21 \\
\hline$x$ & 5 & $x$ & 57 & 4116 & 30 \\
\hline $\boldsymbol{Y}$ & mimelotion & $x$ & 4 & $\operatorname{lax}$ & $\omega$ \\
\hline
\end{tabular}

Figure 6.1 Actogram of the complete observation period of a full-term SGA infant. 
Table 6.1 Occurrence of different movement patterns of varying duration during the real observation time. Percentage (\%) of real observation time, median (range).

Movement pattern

Head left

Head right

Head in midline

Dummy in

General movement

Hand-face contact left hand

Hand-face contact right hand

Hand-mouth contact left hand

Hand-mouth contact right hand
Percentage of real observation time

session ranged from 13.63 to $99.35 \mathrm{~min}$. (median $23.20 \mathrm{~min}$.). As manipulation might influence motility the manipulation time was excluded from the analysis. The median duration of the remaining observation time was 150.73 $\mathrm{min}$. (range 76.78 to $169.85 \mathrm{~min}$.). All percentages and rates in this section are calculated using the total observation time with subtraction of manipulation time. This will be referred to as real observation time.

A significantly lower percentage of time was spent in state $C$ than in states $A$ and $B$ ( $p$-values 0.0066 and 0.0045 respectively).

The median percentage of the real observation time spent in state $A$ was 43\% (range 6-100\%). The median percentage of the real observation time spent in state B was $44 \%$ (range $0-75 \%$ ). The median percentage of the real observation time spent in state $C$ was $9 \%$ (range $0-55 \%$ ).

The occurrence of the different movement patterns and some other variables in the total observation session is shown in tables 6.1 and 6.2 .

In tables 6.3 and 6.4 the occurrence of the movement patterns in the different states is shown.

\section{Head position}

A median of $34 \%$ of the real observation time was spent with the head turned to the left (range $0-98 \%$ ), as opposed to a median of $62 \%$ to the right (range $1-100 \%$ ). A head position with the head in the midline was rare (median $0 \%$, range $0-5 \%$ ).

As the duration of a head position could be influenced by the presence of a dummy, the percentages were also calculated with exclusion of time spent sucking a dummy. This led to a median percentage of $53 \%$ spent with the head turned to the left (range $0-100 \%$ ) and a median of $44 \%$ spent with the head turned to the right side (range 0-99\%). No significant difference between time spent with a head position to the left and to the right could be demonstrated 
Table 6.2 Occurrence of different movement patterns of limited duration during the real observation time. Total number during real observation time, median (range).

\begin{tabular}{lc} 
Movement pattern & Total number \\
\hline Stretch & $2(0-14)$ \\
Startle & $12(6-30)$ \\
Twitch left arm & $1(0-9)$ \\
Twitch right arm & $0(0-12)$ \\
Twitch left leg & $9(0-40)$ \\
Twitch right leg & $8(0-42)$ \\
Clonus left arm & $0(0)$ \\
Clonus right arm & $0(0-1)$ \\
Clonus left leg & $1(0-24)$ \\
Clonus right leg & $2(0-9)$ \\
Isolated left arm movement & $43(13-101)$ \\
Isolated right arm movement & $39(11-148)$ \\
Isolated left leg movement & $52(19-152)$ \\
Isolated right leg movement & $61(23-146)$ \\
\hline
\end{tabular}

Table 6.3 Occurrence of movement patterns of varying duration in different states. Percentage \% of total time of the state concerned, median (range).

\begin{tabular}{llll}
\hline Movement pattern & State A & State B & State C \\
\hline General movements & $15 \%(2-32)$ & $62 \%(28-71)$ & $99(89-100)$ \\
Hand-face contact LA & $5 \%(0-38)$ & $4 \%(0-36)$ & $1(0-9)$ \\
Hand-face contact RA & $5 \%(0-33)$ & $9 \%(0-45)$ & $1(0-7)$ \\
Hand-mouth contact LA & $0 \%(0-12)$ & $0 \%(0-16)$ & $0(0-12)$ \\
Hand-mouth contact RA & $0 \%(0-5)$ & $0 \%(0-27)$ & $0(0-1)$ \\
\hline
\end{tabular}

$\mathrm{LA}=$ left arm; $R A=$ right arm; $L L=$ left leg; $R L=$ right leg.

(Wilcoxon matched pairs signed ranks test). There was no significant difference in the percentages of time spent with the head on the left or right side between states $\mathrm{A}, \mathrm{B}$ or $\mathrm{C}$.

\section{General movements}

A median of $43 \%$ of the real observation time was spent in general movements (range 15-66\%). This percentage was highest in state $C$, with a median percentage of $99 \%$ (range $86-100 \%$ ). The median percentage of time spent in general movements in states A and B was $15 \%$ and $62 \%$ respectively. The difference between the three states was statistically significant (all p-values $<0.01$ ). 
Table 6.4 Occurrence of movement patterns of limited duration in different states. Rate/10 min. of real observation time, median (nange).

\begin{tabular}{llll}
\hline Movement pattern & State A & State B & State C \\
\hline Stretch & $0.27(0.00-1.08)$ & $0.00(0.00-0.29)$ & $0.00(0.00)$ \\
Startle & $1.84(0.58-3.54)$ & $0.43(0.00-1.45)$ & $0.00(0.00-1.09)$ \\
Twitches LA & $0.17(0.00-1.17)$ & $0.00(0.00-0.12)$ & $0.00(0.00)$ \\
Twitches RA & $0.00(0.00-1.56)$ & $0.00(0.00-0.27)$ & $0.00(0.00)$ \\
Twitches LL & $1.16(0.00-5.36)$ & $0.00(0.00-1.60)$ & $0.00(0.00)$ \\
Twitches RL & $1.04(0.00-5.21)$ & $0.11(0.00-2.90)$ & $0.00(0.00)$ \\
Cloni LA & $0.00(0.00)$ & $0.00(0.00)$ & $0.00(0.00)$ \\
Cloni RA & $0.00(0.00-0.13)$ & $0.00(0.00)$ & $0.00(0.00)$ \\
Cloni LL & $0.00(0.00-2.14)$ & $0.00(0.00-0.14)$ & $0.00(0.00)$ \\
Cloni RL & $0.15(0.00-1.17)$ & $0.00(0.00-0.27)$ & $0.00(0.00)$ \\
Isolated movements LA & $3.35(0.00-7.36)$ & $3.47(0.00-6.02)$ & $0.00(0.00-2.93)$ \\
Isolated movements RA & $2.56(0.34-11.60)$ & $3.14(0.00-10.87)$ & $0.00(0.00-2.93)$ \\
Isolated movements LL & $5.31(0.85-10.77)$ & $3.10(0.00-6.97)$ & $0.00(0.00-2.20)$ \\
Isolated movements RL & $5.23(0.85-11.34)$ & $3.51(0.00-10.15)$ & $0.00(0.00-1.47)$ \\
\hline
\end{tabular}

$\mathrm{LA}=$ left arm; $\mathrm{RA}=$ right arm; $\mathrm{LL}=$ left leg; $R L=$ right leg.

\section{Stretches}

The occurrence of stretches was rare. In the real observation time a median of 2 stretches was observed (media rate $/ 10 \mathrm{~min} .=0.13$ ), with a minimum of 0 and a maximum number of 14 stretches. Stretches occurred significantly more often in state A (median $0.27 / 10 \mathrm{~min}$., range $0.00-1.08 / 10 \mathrm{~min}$.) than in states $B$ (median of $0.00 / 10 \mathrm{~min}$., range $0.00-1.09 / 10 \mathrm{~min}$.) and C. None of the infants showed stretches in state $C$.

\section{Startles}

In the complete observation a median of 12 startles was seen (range 6-30). The median rate of startles in state A was $1.84 / 10 \mathrm{~min}$. (range $0.58-3.54 / 10 \mathrm{~min}$.), in state $B 0.43 / 10 \mathrm{~min}$. (range $0.00-1.45$ ). In state $C$ startles were rare, with a maximum rate of occurrence of $1.09 / 10 \mathrm{~min}$. (median and minimum $0.00 / 10$ $\mathrm{min}$.). The difference in occurrence of startles between state $A$ and states $B$ and $C$ was statistically significant ( $p$-values $<0.01$ ), just like the difference between state $B$ and state $C$.

\section{Twitches}

Twitches of the arms occurred sporadically with a median of 1 in the complete observation session (range left arm 0-9; right arm 0-12).

They occurred more often during sleep (state $A$ ), with a median rate of occurrence of 0.17 and $0.00 / 10 \mathrm{~min}$. for the left and right arm respectively, 
than during wakefulness (state $B$ ) and crying (state $C$ ). The difference between state $A$ and states $B$ and $C$ was significant only for the left arm.

Twitches were seen more often in the legs than in the arms with a median occurrence in the complete observation session of 9 for the left leg (range 0-40) and 8 (range $0-42$ ) for the right leg. The rate of occurrence was highest in state A (left leg median 1.16/10 min., right leg median 1.04/10 min.). The difference between state $A$ and states $B$ and $C$ was statistically significant for both legs $(p<0.01)$. The difference between states $B$ and $C$ was significant only for the right leg.

\section{Cloni}

The occurrence of cloni of the arms was rare. In most infants no cloni were observed during the complete observation session (left arm: cloni in none of the infants, right arm: range $0-1$ ). Cloni were seen more often in the legs than in the arms with a median occurrence in the complete observation session of 1 for the left leg (range 0-24) and 2 for the right leg (range 0-9). The rate of occurrence was slightly higher in state $\mathrm{A}$. For the left leg no significant difference between the three states could be demonstrated. For the right leg only the difference between the rate of occurrence in state $A$ (median 0.15/10 min.) and state $C$ (median $0.00 / 10$ min.) was significant $(p<0.05)$.

\section{Isolated limb movements}

Isolated arm movements occurred frequently during the complete observation session (left arm median 43, range 13-101; right arm median 39, range 11-148). In both arms they occurred significantly less in state $C$ than in states $A$ and $B$. No significant difference could be demonstrated between states $A$ and $B$. The median rate of occurrence in state $A$ was $3.35 / 10 \mathrm{~min}$. for the left arm and $2.56 / 10 \mathrm{~min}$. for the right arm. In state $B$, isolated movements of the left arm occurred with a median of $3.47 / 10 \mathrm{~min}$. (range $0.00-6.02$ ). The median rate of occurrence for the right arm was $3.14 / 10 \mathrm{~min}$. (range $0.00-10.87$ ). The rate of isolated left and right arm movements in state $C$ was generally low, with a median of $0.00 / 10 \mathrm{~min}$. (range $0.00-2.93 / 10 \mathrm{~min}$. for both arms).

Isolated leg movements occurred with a median of 52 for the left leg and 61 for the right leg during the complete observation session (left leg range 19-152; right leg range 23-146). In both legs they occurred significantly less often in state $C$ than in states $A$ and $B$. The median rate of occurrence in state $A$ was $5.31 / 10 \mathrm{~min}$. for the left leg (range $0.85-10.77 / 10 \mathrm{~min}$.) and 5.23/10 $\mathrm{min}$. for the right leg (range $0.85-11.34 / 10 \mathrm{~min}$.). In state $B$, isolated movements of the left leg occurred with a median of $3.10 \mathrm{~min}$. (range $0.00-6.97$ ). The median rate of occurrence for the right leg was $3.51 / 10 \mathrm{~min}$. (range $0.00-10.15$ ). The difference between states $A$ and $B$ was not statistically significant. The occurrence of isolated leg movements in state $C$ was rare in rnost of the infants, with a median of $0.00 / 10 \mathrm{~min}$. for both legs (left leg range $0.00-2.20 / 10 \mathrm{~min}$; right leg 0.00-1.47/10 min.). 


\section{Hand-face contact}

A significant difference existed in the percentage of time spent in hand-face contact of the left hand between states B and C only, of the right hand between all three states. In state $\mathrm{A}$ a median of $5 \%$ was spent in hand-face contact of the left hand (range 0-38\%) and the right hand (range 0-33\%). In state B a median of $4 \%$ and $9 \%$ was spent in hand-face contact of respectively the left hand (range $0-36 \%$ ) and the right hand (range $0-45 \%$ ). A median of $1 \%$ was spent in hand-face contact of the left and right hand in state C.

\section{Hand-mouth contact}

In state $\mathrm{A}$ median of $0 \%$ was spent in hand-mouth contact of the left hand (range $0-12 \%$ ) and the right hand (range $0-5 \%$ ). In state $B$ median of $0 \%$ was spent in hand-mouth contact of the left hand (range 0-16\%) and the right hand (range $0-27 \%$ ). A median of $0 \%$ was spent in hand-mouth contact of the left and right hand in state $C$. The difference between the three states was not statistically significant.

\section{The influence of head position on limb movements}

Firstly, the frequency of occurrence of limb movements during a left-sided head position was compared to the frequency of occurrence of limb movements during a right-sided head position in infants who showed both periods with the head turned to the left, and periods with the head turned to the right (8 infants).

Significant differences could be demonstrated between the percentage of time spent in hand-mouth contact of the left and right arm during a right or left-sided head position. A significantly higher percentage of time was spent with hand-mouth contact of the left arm during a head position to the left than during a head position to the right (Wilcoxon signed ranks test, $\mathrm{p}<0.05$ ). Furthermore, a significantly higher percentage of time was spent with handmouth contact of the right arm during a head position to the right than during a head position to the left (Wilcoxon signed ranks test, $\mathrm{p}<0.05$ ). No other significant differences between a right-sided and left-sided head position could be demonstrated.

Secondly, the frequency of occurrence of movements of left arm and leg was compared to the frequency of occurrence of movements of right arm and leg during a left-or right-sided head position (Wilcoxon matched pairs signed ranks test).

A significantly higher percentage of the time with a left-sided head position was spent in hand-face and hand-mouth contact of the left hand than of the right hand ( $p$-values 0.01 ).

During a right-sided head position isolated movements of the left arm had a significantly higher rate of occurrence (median $2.88 / 10 \mathrm{~min}$.) than isolated movements of the right arm (median 1.98/10 min.). Furthermore, a hig;her 
percentage of time was spent in hand-mouth contact of the right hand than of the left hand $(p<0.01)$.

In conclusion:

1. No significant head position preference could be demonstrated in the SGA infants.

2. In state $C$ a significantly higher percentage of time was spent in general movements than in states A and B. Furthermore, the percentage of time spent in general movements was significantly higher in state $B$ than in state A. Startles, stretches and twitches of the legs occurred significantly more in state $A$ than in states $B$ and $C$. Isolated movements occurred more often in states A and B than in state C.

3. Head position influences hand-mouth contact. The hand on the side that the head is turned to spends a higher percentage of time in contact with the mouth than the contralateral hand.

4. All movement patterns except hand-face and hand-mouth contact show a symmetrical distribution, independent of head position.

\subsection{Posture}

Fourteen infants were included in the final analysis of posture. One SGA infant was excluded from the postural analysis because, due to manipulation and frequent movements, the postural data were considered to be insufficient (< 10 minutes) for analysis of (preference) posture (SGA infant 13). The median number of postural data was 57 (range 11-123).

Considering the complete posture, 11 infants $(79 \%)$ showed a preference posture. The postures were all different (Figure 6.2); there was no dominant group preference posture.

The median percentage of the postural observation time during which the preference posture was observed was $16(6-43)$.

The median duration of the longest uninterrupted posture was 7 minutes (2-13). The preference posture and the longest uninterrupted posture were identical in 7 infants. Each infant had a wide postural repertoire, with a median number of 26 different postures (range 7-61).

The most frequently observed combinations of the positions of 2 limbs were calculated for every infant. In 10 infants $(71 \%)$, the most frequently occurring combination of left and right arm was a combination in which both arms were abducted 0-90 degrees, externally rotated in the shoulder and fully flexed (< 60 degrees) in the elbow. No other dominant group combinations could be demonstrated.

Using a reduced number of classes in analyses 2 and 3, no dominant group preference posture could be demonstrated. In analysis 4 , considering only abduction and adduction in shoulder and hip, a preference posture was found 


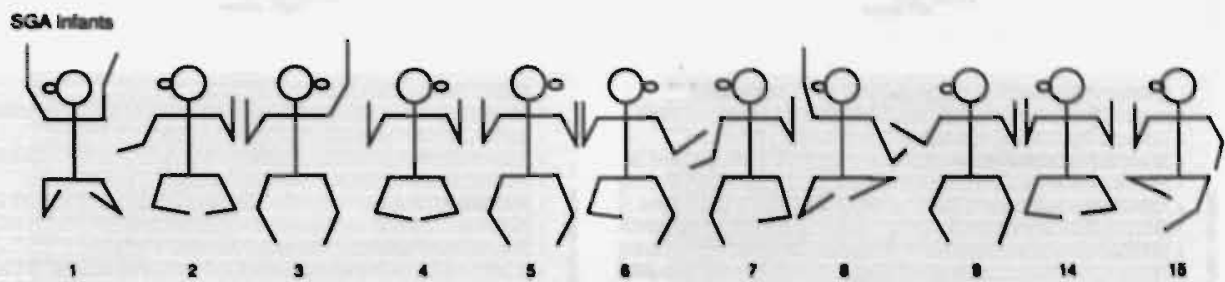

Figure 6.2 Preference posture of full-term SGA infants.

in 10 SGA infants. Nine of these SGA infants (90\%) showed a preference posture with all four limbs in 0-90 degrees abduction.

The four limbs were analyzed separately considering abduction/adduction (analysis 5) and flexion/extension (analysis 6). With regard to the degree of abduction and adduction of the four limbs there was a clear preference for an abduction of 0-90 degrees of all four limbs (Figure 6.3). A position with an abduction of 0-90 degrees occurred significantly more often than all other categories of abduction/adduction in all limbs $(p<0.05)$.

With regard to the degree of flexion and extension of elbows and knees, there was considerable interindividual variability (Figure 6.4). However, a fully extended position occurred significantly less often than the other categories of flexion and extension $(p<0.05)$. Only in the left arm no significant difference existed between the occurrence of a fully extended and a partly extended position of the elbow. Furthermore, in the left elbow a fully flexed position occurred significantly more often than all other categories of flexion/extension (Wilcoxon matched pairs signed ranks test with Bonferroni correction, $\mathrm{p}<0.05$ ).

In conclusion:

1. There was a wide inter-individual variability in postural repertoire in full-term SGA infants.

2. Most SGA infants showed a real preference posture, but, there was no group preference posture.

3. Considering the positions of the limbs separately, a preference for a position of 0-90 degrees abduction was demonstrated for all limbs.

\subsection{Influence of head position change on body posture}

A total of 96 "pure" head turnings (without lateral, dorsal or ventral flexion) were analyzed (median 0.5; range 0-36). Fifty-two head turnings (54.\%) were directed to the right, 44 head turnings ( $46 \%$ ) were directed to the left. Of the total amount of 96 head turnings, 34 were noted during state A, 53 during state $B$ and nine during state $C$. 

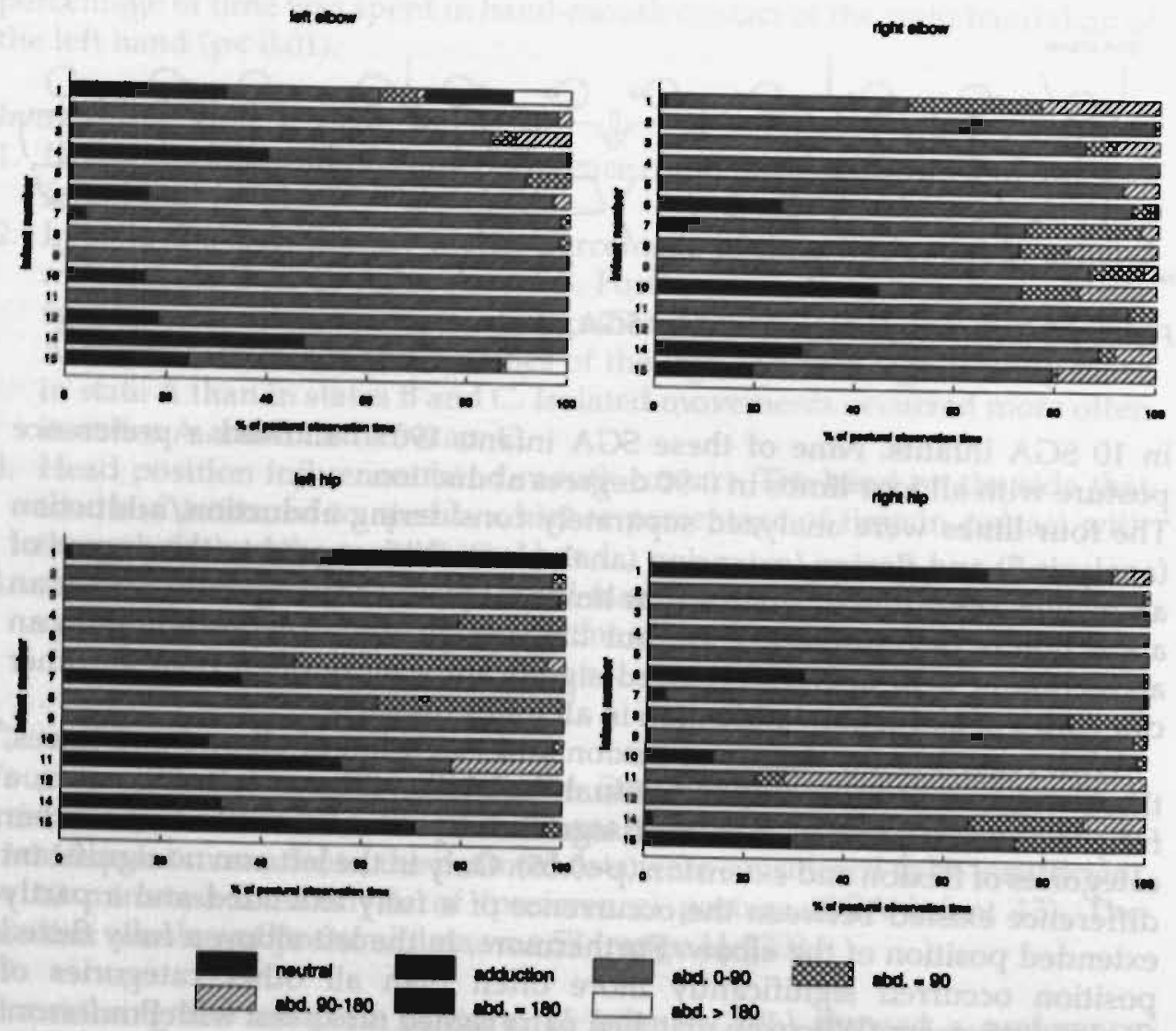

abd. $0-90$ ad. -80 cbd. $>180$

Figure 6.3 Degree of abduction and adduction of the four limbs in full-term SGA infants.
Abd.= abduction.

Seven infants showed no spontaneous head turnings without lateral, dorsal or ventral flexion. They were excluded from further analysis. The median number of head turnings of the remaining 8 infants was 6 , with a minimum of 1 and a maximum of 36 head turnings. One infant showed only pure spontaneous head turnings to the right, whereas one infant showed only pure spontaneous head turnings to the left. The other 6 infants showed head turnings both to the right and to the left.

Table 6.5 shows the relationship between the direction of the head turning and the positional changes of the limbs. There was a wide intra- and interindividual variability.

Neither a head turning to the right nor a head turning to the left was followed by a dominant reaction pattern of one of the four limbs. There were 
in then

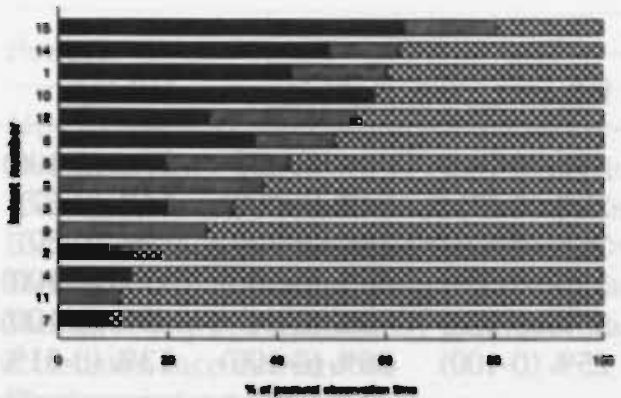

intores

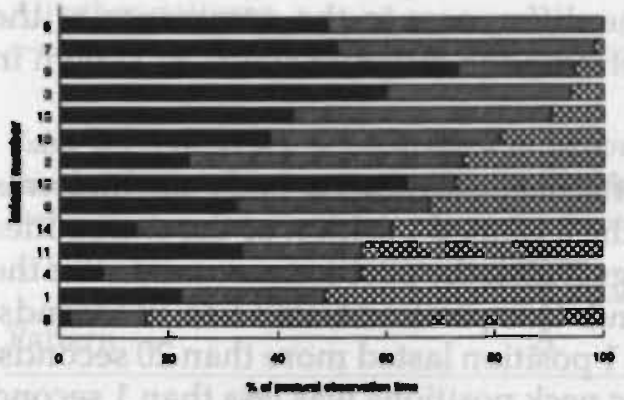

1. that ex.

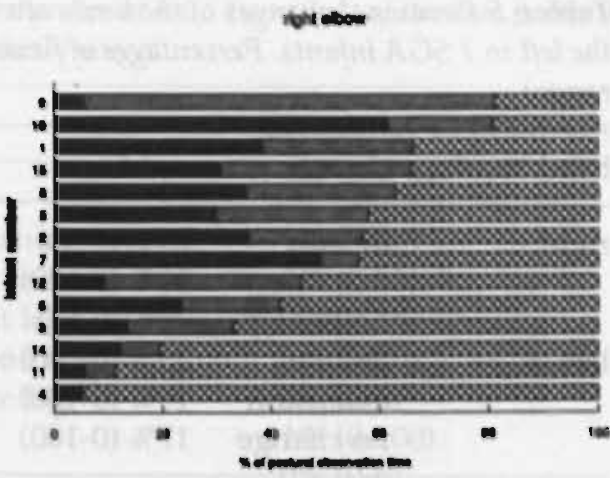

Ninke

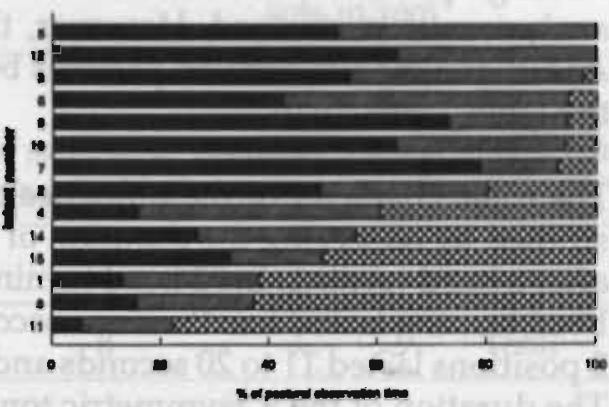

pert finx. 8888 will fox.

Figure 6.4 Degree of flexion and extension of the four limbs in full-term SGA infants.

Full. ext. $=$ fully extended, part. ext. $=$ partly extended, part. flex. $=$ partly flexed, full. flex. = fully flexed.

no significant differences between the occurrence of flexion, extension or no positional change (Wilcoxon matched-pairs signed-ranks test with Bonferroni correction $\mathrm{p}>0.05$ ).

A wide interindividual variability was found in the occurrence of several reaction patterns, such as asymmetric tonic neck reaction (ATNR) as described in the literature (Magnus and de Kleyn 1912), and several ATNRderived patterns (table 6.6). No significant differences between the occurrence of the ATNR, ATNR-derived patterns, and "no change" could be demonstrated. An ATNR occurred after 9 of the 96 head turnings $(9 \%)$. The number of head turnings per infant per state was very variable. State $A$ : median 1 (0-24); state B: median $6(0-20)$; state C: median 0 (0-6). The occurrence of the ATNR and ATNR-derived patterns in the different states is summarized in table 6.7. As most infants had a very small number of head 
Table 6.5 Positional changes of the limbs after spontaneous head turnings to the right and to the left in 7 SGA infants. Percentages of flexion, extension and no positional change (median, range).

\begin{tabular}{llllll}
\hline head turning & change & right arm & left arm & right leg & left leg \\
\hline right & flexion & $23 \%(0-33)$ & $33 \%(0-100)$ & $0 \%(0-43)$ & $57 \%(0-100)$ \\
& extension & $50 \%(0-100)$ & $25 \%(0-67)$ & $54 \%(0-100)$ & $14 \%(0-67)$ \\
& no change & $29 \%(0-67)$ & $36 \%(0-50)$ & $14 \%(0-100)$ & $29 \%(0-50)$ \\
left & flexion & $33 \%(0-100)$ & $22 \%(0-50)$ & $48 \%(0-100)$ & $17 \%(0-100)$ \\
& extension & $19 \%(0-100)$ & $50 \%(0-100)$ & $0 \%(0-24)$ & $63 \%(0-100)$ \\
& no change & $17 \%(0-100)$ & $25 \%(0-100)$ & $38 \%(0-100)$ & $13 \%(0-31 \%)$ \\
\hline
\end{tabular}

turnings per state, the data for all infants were pooled and no statistical analysis was performed. However, the differences in the occurrence of the ATNR and ATNR-derived patterns between the different states, as shown in the table, were small.

The tonic character of the influence of a head turning on body posture was studied by observing the duration of the assumed position of the extremities after a head turning. In 92 head turnings ( $96 \%$ ), the position assumed after the head turning lasted less than one second. One position lasted 6 to 10 seconds, 2 positions lasted 11 to 20 seconds and 1 position lasted more than 20 seconds. The duration of the 9 asymmetric tonic neck positions was less than 1 second in 8 positions, whereas one position lasted more than 10 seconds. It could be concluded that a possible influence of a head position change on body posture in this group of infants was not tonic in character.

The occurrence of an asymmetric neck posture in the resting postures (section 6.1) was studied. An asymmetric tonic neck posture (ATNP) was defined as a posture in which the face-side extremities were relatively more extended than the occiput-side extremities. All postures were classified as asymmetric tonic neck posture (ATNP), asymmetric tonic neck position of arms, asymmetric tonic neck position of legs or no ATNP.

The median percentage of asymmetric tonic neck postures was $13 \%$ (range $0-28 \%$ ). The median percentage of an ATNP of the arms was $18 \%$ (range $0-54 \%)$. The occurrence of an ATNP of the legs ranged from $0 \%$ to $50 \%$ (median $14 \%$ ). In a median percentage of $51 \%$ (range $18-86 \%$ ) no ATNP existed.

The results for each infant are shown in figure 6.5.

Postures without any ATNP-derived pattern occurred in a significantly higher percentage than postures with an ATNP or an ATNP of arms or legs (Wilcoxon matched-pairs signed-ranks test with Bonferroni correction, $\mathrm{p}<$ 
Table 6.6 Frequency of occurrence (\% of total number of head turnings) of various patterns of positional changes after a head turning, median (range).

Frequency of occurrence

No change

Extension face extremities + occiput extremities (ATNR) $11 \%(0-50)$

Extension face extremities + flexion occiput arm

Extension face extremities + flexion occiput leg

Flexion occiput extremities+ extension face arm

Flexion occiput extremities+ extension face leg

Extension face extremities

Flexion occiput extremities

Extension face arm + Flexion occiput arm

Extension face leg+ Flexion occiput leg

All other patterns

$$
\begin{gathered}
0 \%(0) \\
11 \%(0-50) \\
0 \%(0-13) \\
0 \%(0-15) \\
0 \%(0-20) \\
0 \%(0-6) \\
11 \%(0-100) \\
0 \%(0-8) \\
0 \%(0-3) \\
0 \%(0-8) \\
50 \%(0-100)
\end{gathered}
$$

\begin{tabular}{|c|c|c|c|c|}
\hline \multirow[b]{2}{*}{ Pattern } & \multicolumn{4}{|l|}{ State } \\
\hline & A & B & C & Total \\
\hline No change & - & - & - & - \\
\hline Extension face extremities & & & & \\
\hline $\begin{array}{l}\text { + occiput extremities (ATNR) } \\
\text { Extension face extremities }\end{array}$ & $4(12 \%)$ & $5(9 \%)$ & $-\quad 149$ & $9(9 \%)$ \\
\hline + flexion occiput arm & $1(3 \%)$ & - & - & $1(1 \%)$ \\
\hline Extension face extremities & & & & \\
\hline $\begin{array}{l}\text { + flexion occiput leg } \\
\text { Flexion occiput extremities }\end{array}$ & $2(6 \%)$ & $5(9 \%)$ & $1(11 \%)$ & $8(8 \%)$ \\
\hline + extension face arm & $1(3 \%)$ & $1(2 \%)$ & $1(11 \%)$ & $3(3 \%)$ \\
\hline $\begin{array}{l}\text { Flexion occiput extremities } \\
+ \text { extension face leg }\end{array}$ & $2(6 \%)$ & $2(4 \%)$ & 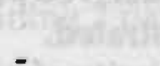 & (4\%) \\
\hline Extension face extremities & $2(6 \%)$ & $8(15 \%)$ & $2(22 \%)$ & $12(13 \%)$ \\
\hline Flexion occiput extremities & $3(9 \%)$ & $1(2 \%)$ & $1(11 \%)$ & $5(5 \%)$ \\
\hline $\begin{array}{l}\text { Extension face arm } \\
+ \text { flexion occiput arm } \\
\text { Extension face leg }\end{array}$ & - & $1(2 \%)$ & - & $1(1 \%)$ \\
\hline + flexion occiput leg & $1(3 \%)$ & $4(8 \%)$ & $1(11 \%)$ & $6(6 \%)$ \\
\hline All other patterns & $18(53 \%)$ & $26(49 \%)$ & $3(33 \%)$ & $43(49 \%)$ \\
\hline Total number of head turnings & 53 & 36 & 9 & 96 \\
\hline
\end{tabular}

Table 6.7 Frequency of occurrence of various patterns of positional changes after a head turming in the different states (data of all infants are pooled). 


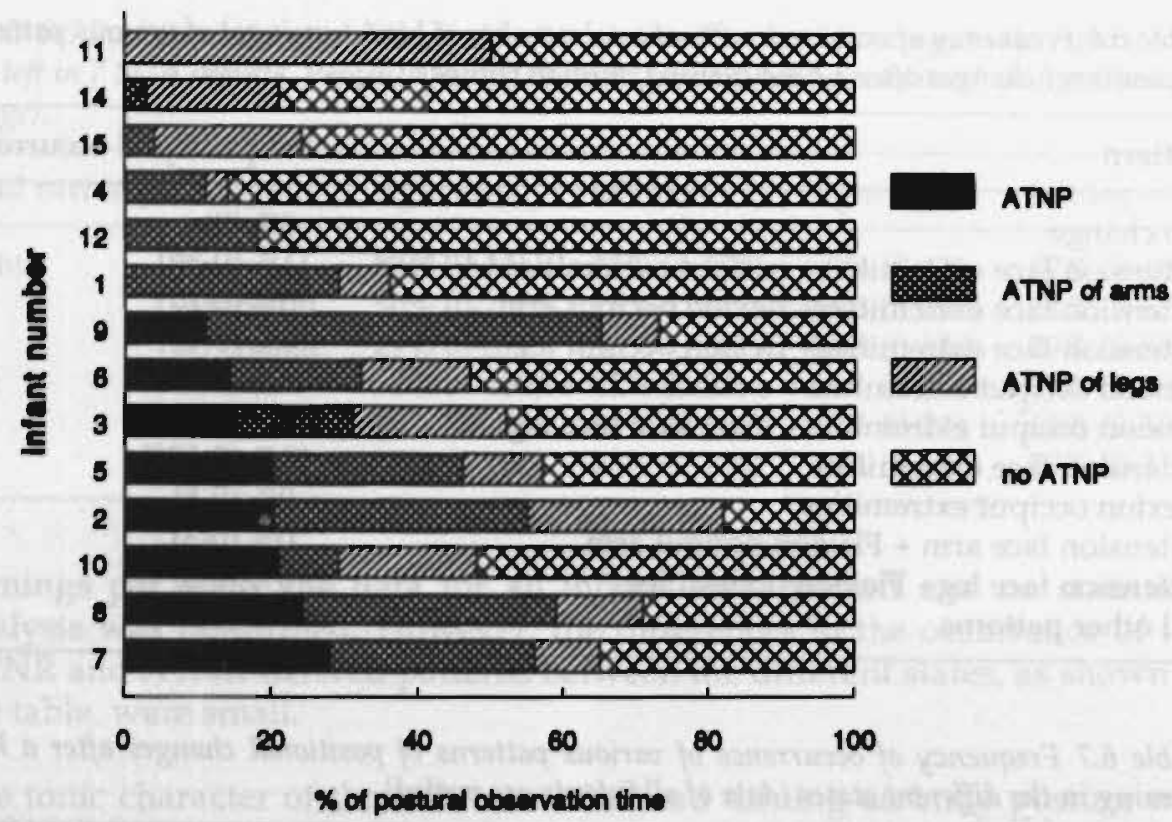

Figure 6.5 Occurrence of an Asymmetric Tonic Neck Posture (ATNP) in full-term SGA infants.

0.05). No significant differences existed between the occurrence of an ATNP, of an ATNP of the arms and of an ATNP of the legs only.

In conclusion:

1. The occurrence of an ATNR following a spontaneous head turning in full-term SGA infants is rare.

2. Considerable interindividual variability exists in the occurrence of several ATNR-derived patterns. No significant flexion/extension pattern could be demonstrated.

3. The majority of positions assumed after a spontaneous head turning lasted less than one second.

\subsection{Quality of movement}

General analysis

One hundred and eighty-seven general movements could be judged with regard to the qualitative aspects of the movement. Twenty-four general movements (13\%) were observed in state $A$ and $163(87 \%)$ in state B. There was a median number of 13 general movements (range 2-16) in this group. The mean 
Table 6.8 Data concerning the genera! analysis of the general movements.

Number of infants included

Total number of general movements

number of general movements in state $\mathbf{A}$

number of general movements in state B

general movements per infants (median, range)

average duration (median, range)
15

187

$24(13 \%)$

$163(87 \%)$

$13(2-16)$

$52(36-67)$

duration of the general movements per infant ranged from 36 to 67 seconds (median 52 seconds) (table 6.8).

The general movements during state $A$ and state $B$ were analyzed separately. Six infants showed general movements with a minimal duration of 20 seconds in both state $\mathrm{A}$ and state $\mathrm{B}$. One infant showed general movements with a duration of more than 20 seconds in state A only, 8 infants showed general movements in state B only.

There were no significant differences in the mean duration of the general movements, nor in the frequencies of occurrence of the different categories per item between state $A$ and state $B$ (Wilcoxon matched pairs signed ranks test, $p>0.05$ ). Therefore, the general analysis was carried out without taking into consideration the state of the infant.

In table 6.9 the relative frequencies (median and range) of the different categories per item are shown. All items except the items 3, 10, 11, 12 and 15 showed significant differences between the frequency of occurrence of their categories $(p<0.05)$.

\section{Pattern analysis}

In this group of infants the same items as in the AGA infants (items 3, 9, 10, 11 and 12) were used in the search for different types of movement quality.

From the 187 general movements in the SGA group, 5 dominant patterns could be isolated. Three of them were identical to the 3 patterns classified in the AGA group (table 6.10, type I, II and III). The remaining 2 patterns (table 6.10 , type IV and V) were not seen in the AGA infants.

Type I general movements are characterized by a fluent performance of the movement, with variable speed and amplitude. The movement pattern is variable, which also holds true for the movement patterns of arms and legs separately. The movements mostly have a smooth onset and end. The speed may be predominantly fast or predominantly slow.

Type II general movements are fast movements with an abrupt and jerky appearance. They are variable in speed and amplitude and they are complex and variable, not stereotyped. Most of them have a predominantly large amplitude. 
Table 6.9 Relative frequencies (\%) of the different categories per item. Median and range.

\begin{tabular}{|c|c|c|}
\hline Item & Category & Relative frequency \\
\hline 1. Onset of movement & $\begin{array}{l}\text { abrupt } \\
\text { smooth }\end{array}$ & $\begin{array}{l}9 \%(0-44) \\
91 \%(13-100)\end{array}$ \\
\hline 2. Variability in speed & absent & $0 \%(0-8)$ \\
\hline 3. Overall speed & $\begin{array}{l}\text { present } \\
\text { predominantly fast } \\
\text { predominantly slow }\end{array}$ & $\begin{array}{c}100 \%(92-100) \\
50 \%(0-94) \\
50 \%(6-100)\end{array}$ \\
\hline 4. Speed of arms compared to legs & $\begin{array}{l}\text { higher } \\
\text { lower } \\
\text { equal }\end{array}$ & $\begin{array}{c}0 \%(0-50) \\
0 \%(0-62) \\
93 \%(38-100)\end{array}$ \\
\hline 5. Force against gravity & $\begin{array}{l}\text { absent } \\
\text { present }\end{array}$ & $\begin{array}{l}0 \%(0) \\
100 \%(0)\end{array}$ \\
\hline 6. Variability in amplitude & & $\begin{array}{r}0 \%(0) \\
100 \%(0)\end{array}$ \\
\hline 7. Overall amplitude & $\begin{array}{l}\text { predominantly large } \\
\text { predominantly small }\end{array}$ & $\begin{array}{l}67 \%(31-100) \\
33 \%(0-69)\end{array}$ \\
\hline 8. amplitude of arms compared to legs & $\begin{array}{l}\text { larger } \\
\text { smaller } \\
\text { equal }\end{array}$ & $\begin{array}{l}8 \%(0-100) \\
8 \%(0-69) \\
67 \%(0-100)\end{array}$ \\
\hline 9. Fluency & $\begin{array}{l}\text { not fluent: tremulous } \\
\text { flapping } \\
\text { fluent }\end{array}$ & $\begin{array}{l}17 \%(0-92) \\
0 \%(0-67) \\
8 \%(0-62) \\
56 \%(0-100)\end{array}$ \\
\hline 10. Variability in movement pattern & $\begin{array}{l}\text { absent } \\
\text { present }\end{array}$ & $50 \%(0-100)$ \\
\hline riability in arm patterns & $\begin{array}{l}\text { absent } \\
\text { present }\end{array}$ & $\begin{array}{l}69 \%(0-100) \\
31 \%(0-100)\end{array}$ \\
\hline 12. Variability in leg patterns & $\begin{array}{l}\text { absent } \\
\text { present }\end{array}$ & $50 \%(0-100)$ \\
\hline 13. Fine distal movements & $\begin{array}{l}\text { absent } \\
\text { present }\end{array}$ & $\begin{array}{r}0 \%(0) \\
100 \%(0)\end{array}$ \\
\hline ovement & absent & $\begin{array}{c}0 \%(0-9) \\
100 \%(91-100)\end{array}$ \\
\hline 15. GI & $\begin{array}{l}\text { abnormal } \\
\text { normal }\end{array}$ & $\begin{array}{l}50 \%(0-100) \\
50 \%(0-100)\end{array}$ \\
\hline
\end{tabular}


Table 6.10 Characteristics of the types (I-V) of movement quality.

\begin{tabular}{|c|c|c|c|c|c|}
\hline \multirow[b]{2}{*}{ Characteristic } & \multicolumn{4}{|c|}{ Type } & \multirow[b]{2}{*}{ V } \\
\hline & I & II & III & IV & \\
\hline Speed (3) & \pm & + & + & - & \pm \\
\hline Fluency (9): fluent & + & & & + & F \\
\hline $\begin{array}{l}\text { abrupt,jerky } \\
\text { tremulous/flapping }\end{array}$ & & + & + & & + \\
\hline variability in overall movement pattern (10) & + & + & - & - & - \\
\hline variability in arm patterns (11) & + & + & - & - & - \\
\hline variability in leg patterns (12) & + & + & - & - & - \\
\hline
\end{tabular}

Speed: fast (+), slow (-), fast or slow ( () ; all other characteristics: present $(+)$, absent $(-)$.

Type III general movements are characterized by an abrupt and jerky performance. Furthermore, they have lost their variability and complexity in the overall movement pattern, as well as in the patterns of arms and legs. They make a stereotyped impression. Mostly the movements have a predominantly high speed and large amplitude.

Type IV general movements are performed fluently with a predominantly slow speed. They are stereotyped, without variability in the overall movement pattern and in the patterns of arms and legs.

Type $\mathbf{V}$ general movements are performed tremulous, sometimes flapping, with a stereotyped character. There is no variability in the overall movement pattern, nor in the patterns of arms and legs. They may have a fast or slow speed.

All general movements with another pattern of movement quality were judged "unclassified". The frequency of occurrence of the general movement types was calculated for the individual infants (figure 6.6). Median and range of the frequency of occurrence of each type in the SGA group are shown in table 6.11.

Significant differences between the occurrence of the types of general movements existed in the SGA infants (Friedman two-way analysis of variance $\mathrm{p}<0.05)$. Type I general movements occurred significantly more often than type II, III and IV (Wilcoxon matched-pairs signed-ranks test $p<0.005$ ). Type $V$ general movements occurred significantly more often than type IV general movements in this group (Wilcoxon matched-pairs signed-ranks test $p<0.05$ ).

The frequency of occurrence of the different types of general movements in states A and B were calculated. No significant differences between states A and $B$ existed. 


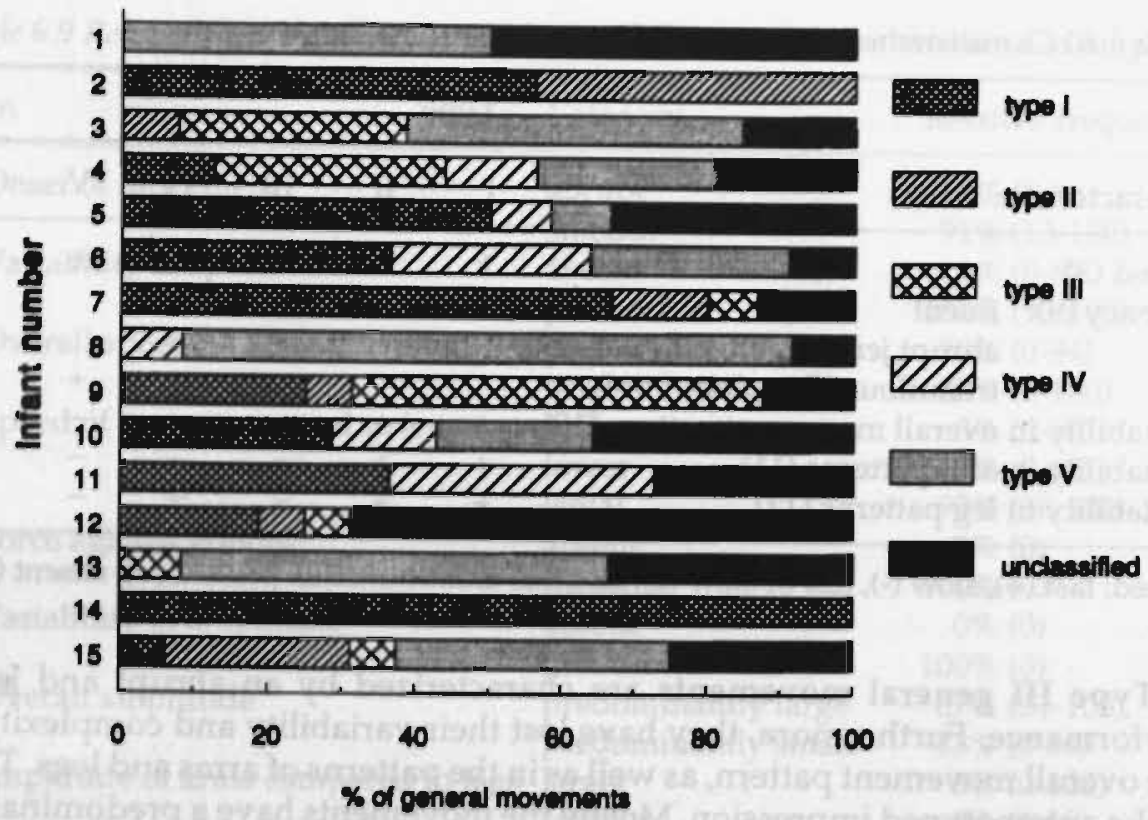

Figure 6.6 Occurrence of the different types of quality of general movements in the SGA infants.

Table 6.11 Occurrence of different movement types (\%) in the SGA infants. Median and range.

\begin{tabular}{ll}
\hline Type & $\begin{array}{l}\text { Occurrence } \\
\text { median (range) }\end{array}$ \\
\hline I & $25(0-100)$ \\
II & $0(0-44)$ \\
III & $0(0-56)$ \\
IV & $0(0-27)$ \\
V & $25(0-38)$ \\
Unclassified & $19(0-69)$ \\
\hline
\end{tabular}

The proportion of the total number of general movements of each type of movement quality that was previously judged as nornnal or abnormal was calculated. From type I, $100 \%$ was judged as normal. $75 \%$ of the type II movements were judged as normal. All type III movements were judged to be abnormal. Thirty-one percent of the type IV movements were judged to be normal. All type V movements were judged to be abnormal. 
In conclusion:

The repertoire of general movements in full-term SGA infants consists of at least 5 different types of movement. Three of them were identical to the movement types identified in the AGA infants (type I, II and III). The remaining two patterns (IV and V) were unique for the SGA infants. Type IV general movements are performed fluently with a predominantly slow speed. They are stereotyped, without variability in the overall movement pattern and in the patterns of arms and legs. Type $\mathrm{V}$ general movements are performed tremulously, sometimes flapping, with a stereotyped character. They may have a fast or slow speed.

\subsection{Follow-up at the age of 9 months}

The results of the neurological examination and the Bayley Scales of Infant Development for each infant are shown in table 6.12.

Due to social circumstances follow-up results of infant number 10 could not be obtained. Furthermore, due to organisational problems the results of the neurological examination of infant number 5 are missing.

\section{Neurological examination}

The neurological examination was normal in 10 SGA infants. Three infants had deviant neurological findings. Infant 6 showed a dominant extension pattern of the legs. In infant 7 a distinct plagiocephalia existed, probably due to a head position preference to the right. Infant 11 had developed a slight right hemiplegia with a higher tone of the right limbs compared to the left limbs.

\section{Bayley Scales of Infant Development}

The median Mental Developmental Index (MDI) was 105, ranging from 64 to 130. One of the infants had an MDI of 64, which is below the normal range (infant 6). SGA infant 3 had an MDI which was 130 , which is well above the normal range.

The median Psychomotor Developmental Index (PDI) was 96 with a minimum of 73 and a maximum of 132 . Two infants had a PDI below the normal range (infants 3 and 11), whereas two others had a PDI above the normal range (infants 4 and 7 ).

In order to investigate whether there was a significant correlation between the results of the follow-up examination at the age of nine months and the neonatal occurrence of the different movement types (see section 6.5), Spearman rank correlations between the occurrence of different movement types and the mental (MDI) and psychomotor (PDI) developmental index at the age of 9 months were calculated. 
Table 6.12 Follow-up results at the age of 9 months in combination with the neonatal neurological examination and the occurrence of different types of movement quality in SGA infants.

\begin{tabular}{|c|c|c|c|c|c|c|c|c|c|c|}
\hline Infant & N.N.E & $\begin{array}{c}\text { type } \\
\text { I }\end{array}$ & $\begin{array}{l}\text { type } \\
\text { II }\end{array}$ & $\begin{array}{l}\text { type } \\
\text { III }\end{array}$ & $\begin{array}{l}\text { type } \\
\text { IV }\end{array}$ & $\begin{array}{c}\text { type } \\
V\end{array}$ & $\begin{array}{l}\text { unclas- } \\
\text { sified }\end{array}$ & MDI & PDI & $\begin{array}{l}\text { N.E. } \\
9 \text { months }\end{array}$ \\
\hline 1 & normal & 0 & 0 & 0 & 0 & 50 & 50 & 93 & 114 & normal \\
\hline 2 & suspect & 56 & 44 & 0 & 0 & 0 & 0 & 112 & 96 & normal \\
\hline 3 & normal & 0 & 8 & 31 & 0 & 46 & 23 & 130 & 73 & normal \\
\hline 4 & normal & 13 & 0 & 31 & 13 & 25 & 18 & 108 & 132 & normal \\
\hline 5 & normal & 50 & 0 & 0 & 8 & 8 & 34 & 99 & 81 & $?$ \\
\hline 6 & suspect & 36 & 0 & 0 & 27 & 27 & 10 & 64 & 81 & suspect \\
\hline 7 & normal & 67 & 13 & 7 & 0 & 0 & 13 & 119 & 127 & suspect \\
\hline 8 & suspect & 0 & 0 & 0 & 8 & 83 & 9 & 93 & 96 & normal \\
\hline 9 & normal & 25 & 6 & 56 & 0 & 0 & 13 & 119 & 100 & normal \\
\hline 11 & normal & 36 & 0 & 0 & 0 & 36 & 28 & 106 & 77 & suspect \\
\hline 12 & suspect & 19 & 6 & 6 & 0 & 0 & 69 & 100 & 96 & normal \\
\hline 13 & suspect & 0 & 0 & 8 & 0 & 58 & 34 & 103 & 85 & normal \\
\hline 14 & suspect & 100 & 0 & 0 & 0 & 0 & 0 & 108 & 109 & normal \\
\hline 15 & normal & 6 & 25 & 6 & 0 & 38 & 25 & 104 & 96 & normal \\
\hline
\end{tabular}

N.N.E: Neonatal neurological examination; N.E.:Neurological examination; MDI: Mental Developmental Index; PDI: Psychomotor Developmental Index.

No significant correlation between the occurrence of one of the 5 movement types and the PDI at the age of nine months could be demonstrated. However, for the MDI a significant positive correlation with type II (correlation coefficient $0.6105, p=0.03$ ) and type III (correlation coefficient $0.5941, p=0.03$ ) was found.

In conclusion:

1. Most SGA infants had normal neurological findings and normal results at the Bayley Scales of Infant Development at the age of nine months.

2. No significant correlations existed between the neonatal occurrence of the 5 different types of movement quality and the PDI at the age of nine months. However, for the MDI a significant positive correlation with type II and type III was found. 


\section{Chapter 7}

Comparison between spontaneous motor behaviour of full-term small for gestational age and appropriate for gestational age newborn infants

7.1 Neurological examination

7.2 Quantitative aspects of motor behaviour

7.3 Posture

7.4 The influence of head position change on body posture

7.5 Quality of movement

7.6 Follow-up at the age of 9 months 


\subsection{Neurological examination}

Since deviant neonatal neurological findings were an exclusion criterion for the AGA infants, all infants in the AGA group had a normal neonatal neurological examination. In the SGA group 7 infants (47\%) had deviant neonatal neurological findings.

\subsection{Quantitative aspects of motor behaviour}

There was no significant difference between the two groups of infants considering the duration of the complete observation session, nor considering the real observation time (=observation time with exclusion of manipulation time).

No significant difference existed between the two groups considering the percentage of time spent in states A, B and C.

\section{Head position}

No significant difference existed between the AGA and SGA infants when considering the percentage of the real observation time and of the real observation time with exclusion of the time when sucking a dummy, spent with a head position to the right, left or in the middle.

There was no significant difference between AGA and SGA infants considering the percentages of time spent with the head turned to the left, to the right or in the midline in the three states.

General analysis without considering the state of the infants

Considering the duration or frequency of occurrence of the different movement patterns in the real observation time, two significant differences were found.

Firstly, the percentage of time spent with hand-face contact of the right arm was significantly higher in SGA infants $(p<0.01)$. This could not be explained by a higher percentage of time spent with the head to the right in SGA infants, as no significant difference in the percentage of time spent with the head to the right between the two groups existed, as was mentioned earlier.

Secondly, in the AGA infants, a significantly higher rate of occurrence of startles existed (median $1.67 / 10$ minutes against $0.98 / 10$ minutes in SGA infants; $\mathrm{p}<0.05$ ).

No other significant differences could be demonstrated.

\section{State A}

The only significant difference between the two groups, found in this state, was the percentage of time spent with hand-face contact of the right hand, which was significantly higher in SGA infants ( $p<0.001$ ). No other significant differences between the two groups could be demonstrated when considering state A separately. Twitches of the right arm occurred more in the AGA 
infants, however, this difference failed to reach statistical significance. The significant difference in the occurrence of startles between the AGA and SGA infants, as was found in the general analysis, could not be demonstrated in this state.

\section{State B}

During wakefulness, the SGA infants spent a significantly higher percentage of time in hand-face contact of the right hand $(p<0.05)$, as was also demonstrated for the general analysis and for state A. No other differences between the AGA and SGA infants were found, although the percentage of time spent in general movements and the rate of occurrence of twitches of the right leg was higher in SGA infants ( $p=0.089$ and 0.088 resp.), and the rate of occurrence of isolated left leg movements was higher in AGA infants $(p=0.089)$. However, these differences failed to reach statistical significance.

\section{State C}

No significant differences in the occurrence of different movement patterns between AGA and SGA infants during crying could be demonstrated.

\section{The influence of head position on limb movements}

An influence of head position on symmetry of limb movement was demonstrated for the percentage of observation time spent in hand-face or hand-mouth contact, which was generally higher for the hand ipsilateral to the face in both groups. In the SGA group, during a right-sided head position, significantly more isolated movements occurred in the left arm than in the right arm. In the AGA group this difference could not be demonstrated. In both groups of infants all other movement patterns showed a symmetrical distribution independent of head position.

In conclusion:

1. The percentage of time spent in hand-face contact of the right hand was significantly higher in the SGA group, independent of the state of the infant. The difference was not explained by a difference in percentage of time spent with the head to the right.

2. A significantly higher rate of occurrence of startles was found in the AGA infants. However, the difference could not be demonstrated in the analysis of each state separately.

\subsection{Posture}

Fourteen infants of each group were included in the final analysis of posture. There was no significant difference between the two groups in the number of postural data (AGA group: median 85, range 14-154; SGA group median 57, range 11-123; $p=0.09$ ). 
In both groups, 11 infants (79\%) showed a preference posture (analysis 1). There was no dominant group preference posture in either of the groups.

When considering the median percentage of the postural observation time during which the preference posture was observed, no significant difference between the two groups existed $(p=0.12)$. Each infant had a wide postural repertoire, with a median number of 35 different postures in the AGA group and 26 in the SGA group ( $\mathrm{p}=0.12$ ).

In 10 infants in the SGA group (71\%), the most frequently occurring combination of left and right arm position was a posture in which both arms were abducted 0-90 degrees, externally rotated in the shoulder and fully flexed (< 60 degrees) in the elbow. There was no such dominant group combination in the AGA group. Neither in the SGA nor in the AGA group could other dominant group combinations be demonstrated.

Using a reduced number of classes (analyses 2 and 3), we were unable to demonstrate a dominant group preference posture in either of the groups. In analysis 4, considering only abduction and adduction in shoulder and hip, a preference posture was found in $12 \mathrm{AGA}$ and 10 SGA infants. Of these infants 9 AGA (75\%) and 9 SGA (90\%) showed a preference posture with all four limbs in 0-90 degrees abduction.

In the separate analysis of the four limbs considering only abduction/adduction (analysis 5) a preference for an abduction of 0-90 degrees of all four limbs in both groups was found. There were no significant differences in the degree of abduction and adduction of the limbs between the AGA and SGA infants (table 7.1).

With regard to the degree of flexion and extension of elbows and knees (analysis 6), there was considerable interindividual variability. However, there were significant differences between the two groups in the degree of flexion and extension of the arms (table 7.2). A fully flexed position of the right and left arm occurred significantly more often in the SGA group (p-values respectively 0.02 and 0.03 ). A full extension of the right arm occurred significantly more often in the AGA group $(p=0.03)$. There were no significant differences with regard to flexion and extension of the legs.

In conclusion:

1. There was a wide inter-individual variability in postural repertoire in healthy full-term AGA and SGA infants. Most infants showed a real preference posture, but, there was no group preference posture in either of the groups.

2. The SGA group showed significantly more often a fully flexed position of the arms in comparison to the AGA group. 
Table 7.1 Degree of abduction and adduction for sepanate limbs in the AGA and the SGA infants. Median and range of percentage $(\%)$ of postural observation time.

\begin{tabular}{llcl}
\hline Limb & Posture & AGA infants & SGA infants \\
\hline Right arm & neutral & $9(0-64)$ & $0(0-44)$ \\
& adduction & $0(0-34)$ & $0(0-13)$ \\
& $0^{\circ}<$ abduction $<90^{\circ}$ & $80(24-100)$ & $80(29-100)$ \\
& abduction $=90^{\circ}$ & $1(0-36)$ & $5(0-27)$ \\
& $90^{\circ}<$ abduction $<180^{\circ}$ & $0(0-6)$ & $5(0-24)$ \\
& abduction $=180^{\circ}$ & $0(0-5)$ & $0(0-1)$ \\
& abduction $>180^{\circ}$ & $0(0-1)$ & $0(0)$ \\
Left arm & neutral & $3(0-30)$ & $3(0-40)$ \\
& adduction & $0(0-44)$ & $1(0-37)$ \\
& $0^{\circ}<$ abduction $<90^{\circ}$ & $86(52-100)$ & $83(1-100)$ \\
& abduction $=90^{\circ}$ & $4(0-22)$ & $0(0-9)$ \\
& $90^{\circ}<$ abduction $<180^{\circ}$ & $1(0-9)$ & $0(0-11)$ \\
& abduction $=180^{\circ}$ & $0(0)$ & $0(0-18)$ \\
& abduction $>180^{\circ}$ & $0(0-1)$ & $0(0-12)$ \\
Right leg & neutral & $1(0-54)$ & $0(0-56)$ \\
& adduction & $0(0-40)$ & $0(0-24)$ \\
& $0^{\circ}<$ abduction $<90^{\circ}$ & $80(27-10)$ & $91(22-100)$ \\
& abduction $=90^{\circ}$ & $0(0-63)$ & $1(0-26)$ \\
& $90^{\circ}<$ abduction $<180^{\circ}$ & $0(0-24)$ & $0(0-72)$ \\
& abduction $=180^{\circ}$ & $0(0)$ & $0(0)$ \\
& abduction $>180^{\circ}$ & $0(0)$ & $0(0)$ \\
& & $2(0-39)$ & $0(0-50)$ \\
Left leg & neutral & $0(0-4)$ & $0(0-26)$ \\
& adduction & $77(9-100)$ & $74(22-100)$ \\
& $0^{\circ}<$ abduction $<90^{\circ}$ & $7(0-56)$ & $1(0-50)$ \\
& abduction $=90^{\circ}$ & $0(0-16)$ & $0(0-22)$ \\
& $90^{\circ}<$ abduction $<180^{\circ}$ & $0(0)$ & $0(0)$ \\
& abduction $=180^{\circ}$ & $0(0)$ & $0(0)$ \\
& abduction $>180^{\circ}$ & & \\
\hline & & &
\end{tabular}

\subsection{Influence of head position change on body posture}

Five AGA infants and seven SGA infants showed no pure head turnings. Therefore, 10 AGA infants and 8 SGA infants were included in the final analysis. A total of 91 head turnings in the AGA group and 96 head turnings in the SGA group were analyzed.

Analysis of the head turnings to the right and to the left separately demonstrated no significant differences in the occurrence of a flexion or 
Table 7.2 Degree of flexion and extension of elbows and knees in the AGA and the SGA grc 'ip. Median and range for percentage of postural observation time.

\begin{tabular}{llcc}
\hline Limb & Posture & AGA & \multicolumn{1}{c}{ SGA infants } \\
\hline Right arm & fully extended & $6(0-29)$ & $0(0-12)^{*}$ \\
& partly extended & $36(4-58)$ & $18(5-56)$ \\
& partly flexed & $22(6-79)$ & $20(0-76)$ \\
& fully flexed & $29(5-65)$ & $44(19-95)^{*}$ \\
Left arm & fully extended & $2(0-25)$ & $0(0-27)$ \\
& partly extended & $25(7-92)$ & $18(0-59)$ \\
& partly flexed & $28(1-58)$ & $14(0-37)$ \\
& fully flexed & $38(3-84)$ & $60(20-91)^{*}$ \\
Right leg & fully extended & $0(0)$ & $0(0-2)$ \\
& partly extended & $39(3-93)$ & $45(6-79)$ \\
& partly flexed & $28(3-67)$ & $30(14-52)$ \\
& fully flexed & $9(0-94)$ & $13(0-78)$ \\
Left leg & fully extended & $0(0)$ & $0(0)$ \\
& partly extended & $36(4-100)$ & $36(2-73)$ \\
& partly flexed & $28(0-67)$ & $39(9-51)$ \\
& fully flexed & $17(0-83)$ & $27(0-84)$ \\
\hline
\end{tabular}

* p-value $<0.05$

extension pattern or no positional change between SGA and AGA infants (Mann-Whitney U-test).

The occurrence of the different patterns of reaction after a head turning is shown in figure 7.1. No significant differences in the occurrence of the ATNR, ATNR-derived-patterns, "no change" and "all other patterns" could be demonstrated between the AGA and SGA infants (Mann-Whitney U test).

Analyzing the occurrence of an asymmetric neck posture in the resting postures, no significant differences between AGA and SGA infants could be demonstrated when considering the percentage of resting postures spent in ATNP, ATNP of arms or legs and postures without ATNP.

\section{In conclusion:}

No significant differences between AGA and SGA infants existed, concerning the influence of head position change on limb position. In both groups the occurrence of an ATNR following a spontaneous head turning was rare. Considerable interindividual variability existed in the occurrence of several ATNR-derived patterns in both AGA and SGA infants. 


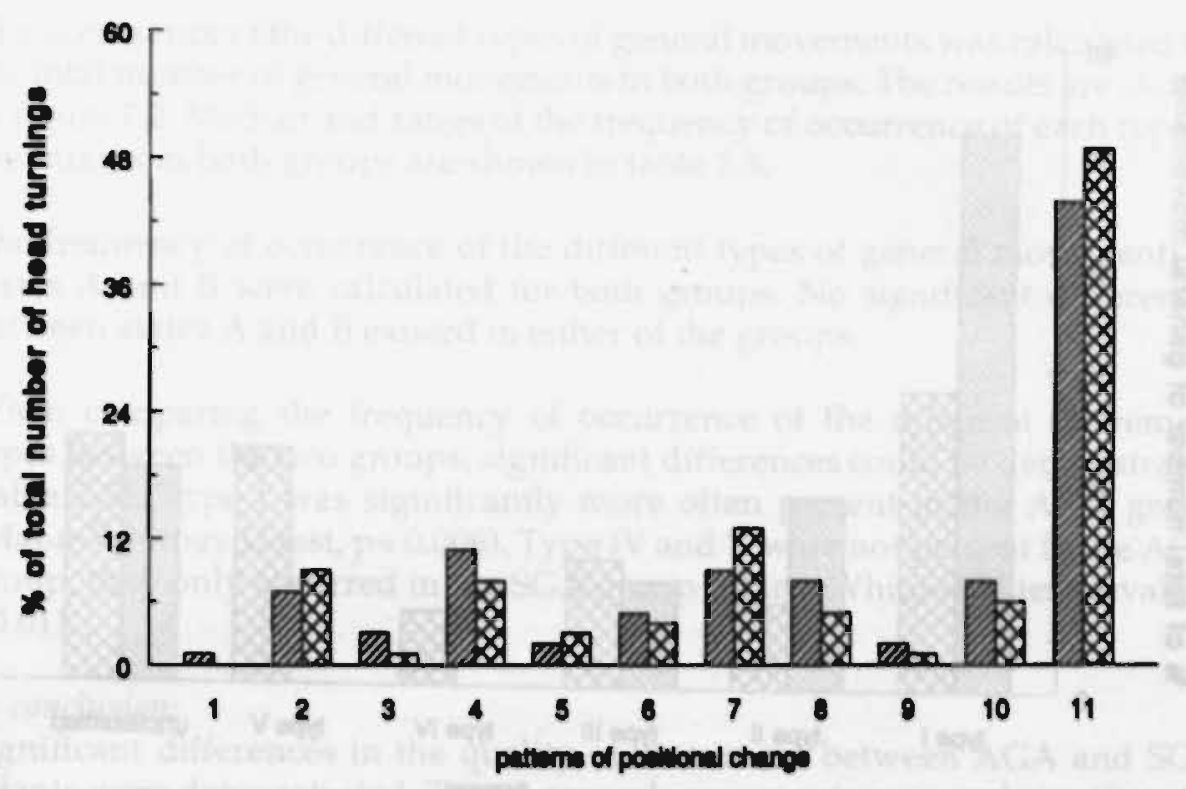

UIIIIA ACA intents

88808 sanhents

Figure 7.1 Occurrence of different patterns of positional change following a head turning in AGA and SGA infants. 1 = No change; $2=$ Extension face extremities + flexion of occiput extremities (ATNR); $3=$ Extension face extremities + flexion occiput arm; $4=$ Extension face extremities + flexion occiput leg; $5=$ Flexion occiput extremities + extension face arm; $6=$ Flexion occiput extremities + extension face leg; $7=$ Extension face extremities; $8=$ Flexion occiput extremities; $9=$ Extension face arm + flexion occiput arm; $10=$ Extension face leg + flexion occiput leg; $11=$ All other patterns.

\subsection{Quality of movement}

\section{General analysis}

Significant differences existed between the SGA and AGA infants in the frequency of occurrence of the categories of the items $9,10,11,12$ and 15 . The general movements of the SGA infants more often showed a tremulous component (Mann-Whitney $U$ test, $p<0.05$ ). The variability in the total pattern of the movement (item 10) and in the movement patterns of arms (item 11) and legs (item 12) separately was more often absent in the SGA infant (MannWhitney $U$ test, $p<0.01$ ). They showed movements with a monotonous, stereotyped character more frequently.

\section{Pattern analysis}

From the 106 general movements in the AGA group, 3 dominant patterns could be classified (table 5.11, type I, II and III). From the 187 general move- 


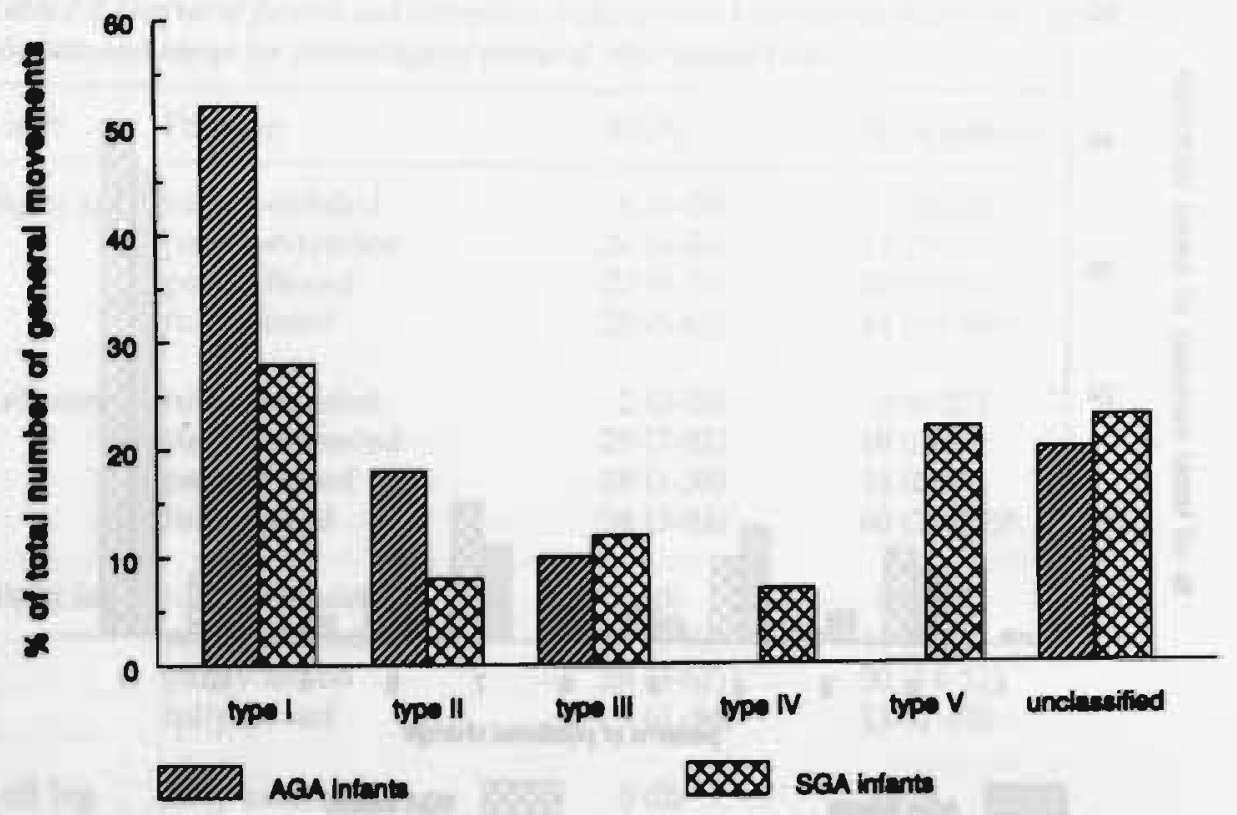

Figure 7.2 Occurrence of the different types of general movements in the AGA and SGA group.

Table 7.3 Occurrence of different movement types (\%) in the 2 groups of infants. Median (range).

\begin{tabular}{lll}
\hline & \multicolumn{2}{l}{ Group } \\
\cline { 2 - 3 } Type & AGA & SGA \\
\hline I & $67(0-100)$ & $25(0-100)^{*}$ \\
II & $17(0-100)$ & $0(0-44)$ \\
III & $0(0-33)$ & $0(0-56)$ \\
IV & $0(0)$ & $0(0-27)^{*}$ \\
V & $0(0)$ & $25(0-38)^{*}$ \\
Unclassified & $17(0-46)$ & $19(0-69)$ \\
\hline
\end{tabular}

* p-value $<0.05$

ments in the SGA group, 5 dominant patterns could be isolated. Three of them were identical to the 3 patterns classified in the AGA group (type I, II and III). The remaining 2 patterns (table 6.10, type IV and V) were not seen in the AGA infants. 
The occurrence of the different types of general movements was calculated for the total number of general movements in both groups. The results are shown in figure 7.2. Median and range of the frequency of occurrence of each type in the infants in both groups are shown in table 7.3.

The frequency of occurrence of the different types of general movements in states A and B were calculated for both groups. No significant differences between states $A$ and $B$ existed in either of the groups.

When comparing the frequency of occurrence of the different movement types between the two groups, significant differences could be demonstrated (table 7.3). Type I was significantly more often present in the AGA group (Mann-Whitney U test, $p=0.008$ ). Type IV and V were not present in the AGA group, they only occurred in the SGA group (Mann-Whitney U test p-values $<0.01$ ).

In conclusion:

Significant differences in the quality of movement between AGA and SGA infants were demonstrated. Type I general movements occurred significantly more often in AGA infants, whereas type IV and V general movements were only observed in the SGA infants.

\subsection{Follow-up at the age of 9 months}

Neurological examination

In the AGA group 1 infant and in the SGA group 3 infants had deviant neurological findings at the age of nine months.

\section{Bayley Scales of infant development}

There was no significant difference between the two groups considering the $\mathrm{PDI}$ and MDI at nine months. In the AGA group the MDI ranged from 62 to 127 (median 106) and the PDI ranged from 78 to 120 (median 96). In the SGA group the MDI ranged from 64 to 130 (median 105) and the PDI ranged from 73 to 132 (median 96).

In the AGA group, a significant positive correlation existed between the neonatal occurrence of type I general movements and the PDI at the age of 9 months. A significant negative correlation existed between the occurrence of type III general movements and the PDI at 9 months. No significant correlation existed between the different movement types and the MDI at 9 months of age. In the SGA infants, no significant correlation between the occurrence of the 5 movement types and the PDI at the age of nine months could be demonstrated. However, for the MDI a significant positive correlation with type II and type III was found. 
In conclusion:

1. No significant difference in MDI and PDI at the age of nine months could be demonstrated between the two groups of infants.

2. In the AGA infants a significant correlation existed between the occurrence of type I and III general movements and the PDI at the age of nine months. In the SGA infants a significant correlation between the occurrence of types II and III and the MDI was found. 


\section{Chapter 8}

\section{General discussion}

The objective of this investigation was threefold: Firstly, to provide an accurate description of spontaneous motor behaviour in healthy full-term AGA infants, secondly, to study the influence of IUGR on spontaneous motor behaviour in full-term SGA infants, and thirdly to investigate whether alteration of spontaneous motor behaviour in the neonatal period is related to future neurological and neuropsychological development.

It is of substantial importance to have information on CNS function in infants at risk for neurological and neurodevelopmental disturbances, since early detection of neurological and neurodevelopmental problems may help to predict prognosis, and allows possible interventions to stimulate future neurological development. As the conventional neonatal neurological examination has several disadvantages, a new instrument was sought which firstly could provide information on CNS function in the neonatal period and, secondly, could provide a prognostic indication concerning future neurological and behavioural development.

From studies on spontaneous motility in the fetus (de Vries et al. 1982, 1985; Bekedam et al. 1985; Prechtl 1985, 1988; Visser et al. 1985) and the preterm infant (Gesell and Amatruda 1945; Prechtl et al. 1979; Vles 1988; Vles et al. 1988a, 1988b, 1988c, 1989) it was known that observation of spontaneous motor behaviour is a non-invasive procedure which, in addition to the neurological examination, may give extra information on the condition of the nervous system in the newborn.

To study spontaneous motor behaviour, the following features can be observed: quantitative aspects of motility, posture, the influence of head position and head position change on body posture and limb movements, and quality of movement. However, information on different aspects of spontaneous motor behaviour in healthy full-term infants was limited (Hopkins and Prechtl 1984; Prechtl and Hopkins 1986; Erkunjintti 1988; Cioni et al. 1989; Hadders-Algra et al. 1992). Furthermore, with regard to the assessment of quality of movement, which is a new method of observation, inter- and intra-observer agreement rates corrected for chance were not available in the literature. 
Therefore, before the observation of spontaneous motor behaviour could be used as a clinical tool to study infants at risk, inter- and intra-observer agreement for the assessment of quality of movement in the full-term newborn had to be determined (Chapter 4), and the different aspects of spontaneous motor behaviour in a group of healthy full-term AGA infants had to be described (Chapter 5).

\section{Reliability of the assessment of quality of movement in the newborn}

The results of the reliability study confirm that several qualitative aspects of motility in the newborn can be reliably assessed by observers of different disciplines with a certain experience in observing infant motor behaviour. However, the items "amplitude", "variability in movement pattern" and "variability in leg patterns" appeared to be quite difficult to judge. The interand intra-observer agreement corrected for chance for the global judgement of the movement was high. It seemed to be easier to give a general judgement on normality or abnormality of a movement than to judge the different qualitative aspects separately. This may be ascribed to the fact that the global judgement is not merely a linear summation, but a complex partly unconscious integration of the judgement of the separate items. Furthermore, the categories of the more detailed aspects of quality of movement are difficult to define and the inter- and intra-observer agreement would therefore be sensitive to the observational experience of the observer.

In summary we can conclude that the judgement of the quality of general movements in full-term infants is a reproducible and therefore reliable clinical tool for evaluating motor behaviour in the neonatal period.

\section{Full-term AGA infants}

In this thesis a detailed description of quantitative aspects of motility, posture, influence of head position on limb position and quality of spontaneous motor behaviour in healthy full-term AGA infants is given (Chapter 5).

Regarding the quantitative aspects of motor behaviour, an important finding in the AGA infants was the absence of a significant head position preference. This finding is in agreement with the results of Cioni et a!. (1989) who studied head position preference in the resting posture of 10 healthy full-terrn infants on the first and fourth postnatal days. Furthermore, they confirm the results of Vles et al. (1991) who studied supine and prone head orientation preference in 62 full-term infants at three different times within 24 hours after birth.

In contrast, several authors (Gesell and Halverson 1942; Turkewitz and Creighton 1974; Casaer 1979; Hopkins et al. 1987) observed a head position preference to the right in full-term infants. However, the results of Gesell and Halverson were obtained from the observation of only one infant. In the study 
of Hopkins et al. only one of the 12 infants was able to turn his head across the midline spontaneously. Their conclusion is therefore based on the head position assumed after only one release from the midline position in each infant.

In the AGA infants, the majority of movement patterns were state related. In state $\mathrm{C}$ a significantly higher percentage of time was spent in general movements than in states A and B. Most small movements (twitches, cloni and isolated limb movements) occurred significantly less often in state $C$ than in states A and B. The percentage of time spent in general movements was significantly higher in state B than in state A. Startles, stretches and twitches most frequently occurred during sleep (state $\mathrm{A}$ ). The differences are probably explained by the state of arousal which is highest during crying and lowest during sleep. Apparently a higher state of arousal finds expression in an increase of gross motor activity or a suppression of isolated limb movements.

An influence of head position on symmetry of limb movements could only be demonstrated for the percentage of observation time spent in hand-face or hand-mouth contact, which was generally higher for the hand ipsilateral to the face. This might be explained by the shorter distance of the ipsilateral hand to the mouth and face. The ispilateral hand therefore has an easier starting-position. For hand-mouth contact this concurs with the results of Hopkins et al. (1987). However, in contrast to our results they did not find a relationship between hand-face contact and head position. A clinically important finding, is that all other movement patterns show a symmetrical distribution, independent of head position. As a consequence, head position is not important in the observation of quantitative aspects of spontaneous motor behaviour.

Studying postural behaviour in the AGA infants, the main finding was that a wide inter-individual variability in postural repertoire existed in this group of infants. Although most AGA infants showed a real preference posture, no group preference posture could be demonstrated.

This is in contrast to the results of several authors (Andre-Thomas and Saint-Anne Dargassies 1952; Amiel-Tison 1968; Saint-Anne Dargassies 1977; Prechtl 1979; Dubowitz and Dubowitz 1981; Touwen 1984) who described a preference posture in full-term infants which consisted of a fully flexed position of all limbs. However, our results are in agreement with the results of Cioni et al. (1989) who could not confirm this preference posture in a study on spontaneous posture and motility in healthy full-term infants. They also observed a large inter- and intra-individual variability in postural repertoire.

The Asymmetric Tonic Neck Reflex (ATNR) was first described by Magnus and de Kleyn (1912). They investigated the influence of head position on the extremities in decerebrated animals, and demonstrated an increase in tone of the extension muscles on the side that the head was turned to and a decrease in tone of the extension muscles on the opposite side. The animals were 
decerebrated to prevent voluntary movements. Furthermore, both labyrinths were removed to prevent the occurrence of labyrinth reflexes.

Extrapolation of the results obtained from animal experiments to the human, especially the human neonate, needs very careful consideration with regard to interspecies differences. When the results are obtained from animals in which the normal anatomy is completely altered by the experimental methodology (decerebrated animals with removed labyrinths), it is impossible to translate the results to the healthy human baby (with an intact CNS anatomy and labyrinths). Therefore, the description of the ATNR by Magnus and de Kleyn (1912) should not have been applied to human newborns. This was also reported by Magnus and de Kleyn (1912) who could not demonstrate the ATNR, as described in their animals experiments, in full-term human newborns. Our results confirm that the occurrence of an ATNR following a spontaneous head turning in full-term AGA infants is rare. Considerable interindividual variability exists in the occurrence of several ATNR-derived patterns. This is in agreement with the results of several authors (Magnus 1924; Vasella and Karlsson 1962; Paine et al. 1964; Prechtl and Beintema 1976). The majority of positions assumed after a spontaneous head turning had no tonic character as they lasted less than one second. The occurrence of an asymmetric tonic neck posture (ATNP) in the resting postures was rare (median 6\%). This concurs with the results of Cioni et al. (1989), who found only a small percentage of (inconsistent) ATNP in the preference postures of normal full-term infants.

The discrepancy between the percentages of occurrence of the ATNR reported in the literature might be explained by variable definition and scoring of the ATNR, and by the different methods of studying the ATNR: passively elicited versus spontaneous patterns.

From our results we may conclude that the influence of head position and change of head position on body posture is not reflected by an asymmetric tonic neck reflex as described by Magnus and de Kleyn (1912). Probably the ATNR should not be considered as a true reflex, but as an inconsistently occurring response to a change of head position, which does not dominate other reaction patterns which may occur after a (spontaneous) head position change. We therefore propose that the term ATNR should be abolished, and replaced by a more general term such as "head turning-limb reaction", which in this study seemed to follow no specific pattern, but could be almost any possible combination of positional change of the four limbs.

Studying the quality of spontaneous general movements in the AGA infants, 3 different types of general movements could be distinguished. Since the infants in the present study were healthy full-term infants, these three different types of general movements could be taken as the normal repertory of quality of movement in full-term infants. This could be used as a reference for the evaluation of quality of movement in high-risk full-term newborns. How- 
ever, in the judgment of the quality of each movement, an overall judgment of the movement was also included. As no definition of normal and abnormal general movements of full-term newborns was found in the literature, the classification normal/abnormal was given according to the general impression and interpretation of the observer. All type I general movements and $80 \%$ of the type II movements in the AGA group were judged to be normal. However, all type III movements and $20 \%$ of the type II movements were judged to be abnormal. From these results it may be concluded that although some type II and III general movements may give an impression of abnormality, they would have to be judged as general movements belonging to the behavioural repertory of healthy full-term newborn infants. Since different types of general movements may be present in one infant, it seems advisable to evaluate the quality of several general movements before giving an overall judgment of the quality of movement of the infant concerned.

In the AGA infants no difference could be demonstrated between the frequency of occurrence of the different types of general movement during sleep and wakefulness.

Hopkins and Prechtl gave a description of the quality of spontaneous movements in full-term infants (Hopkins and Prechtl 1984; Prechtl and Hopkins 1986). They analyzed the qualitative aspects of general movements in 11 healthy awake newborn infants during the first hour after birth, thus at a time when the infant was still recovering from birth (Escardo and de Coriat 1960). All newborn infants showed general movements with a writhing quality which were defined as "squirming, cramped movements which spread, with waxing and waning, throughout the whole body. They are awkward and often ungraceful in appearance. They are of small to moderate amplitude and slow speed". In a recent publication Hadders-Algra et al. (1992) reported on developmental changes of general movements in healthy full-term infants from 2-18 weeks of age. They described the existence of 'tight' and 'loose' writhing movements in healthy full-term infants from 2 to 10 weeks of age. They found no relationship between general movement development and birth weight. However, all infants studied had a birth weight within the normal range (2560-4930, median $3600 \mathrm{gm}$ ).

The above-mentioned studies reported that newborn infants at one hour after birth and at 2 weeks of age show general movements with a writhing quality which may be loose or tight. However, neither of the studies mentioned above accurately described the method by which the classification of the movements was developed. In the publication of Hopkins and Prechtl (1984) a pilot-study was described in which two observers commented on the general movements of six infants. Similar comments in the transcripts of both observers were used as a basis for the classification system. However, from the description it is not clear whether the observers received instructions concerning the items which had to be observed, how many general movements were studied, and in what percentage of the general movements the 
comments were similar, resulting in a certain classification. Furthermore, no data on inter-observer agreement corrected for chance for the different classifications were provided.

In none of the above mentioned studies was the number of general movements judged per infant, or the percentage of general movements per infant showing a writhing quality of movement, mentioned. As the definitions of the observed movement qualities, using terms as 'tight' and loose writhing', squirming, are very difficult to interpret for people who are unfamiliar with this method of observation, the results of these studies are difficult to compare with the results of the present study. None of the three types (type I- III) described above is completely covered by the definitions of the writhing quality as given in the aforementioned studies. Probably the judgments of the quality of movement were based on different features.

A significant positive correlation existed between the neonatal occurrence of type I general movements and the PDI at the age of 9 months. Furthermore, a significant negative correlation existed between the neonatal occurrence of type III general movements and the PDI at the age of nine months.

\section{Full-term SGA infants}

Several conditions in the pre- and perinatal period may disturb the structural and functional integrity of the central nervous system (CNS) of the fetus/infant. One of these conditions is intrauterine growth retardation, a frequent complication of pregnancy (Chiswick 1985). Intrauterine malnutrition has been demonstrated to modify several processes in brain development, such as neuronal and glial cell multiplication, myelination, synaptogenesis and dendritic branching (Dobbing and Sands 1971, 1973; Dobbing 1974; Sarma and Rao 1974; Chase 1972, 1976), leading to diffuse quantitative deficits and distortion of quantitative relationships between CNS structures (Dobbing 1979).

Despite the numerous follow-up studies of SGA infants, there is no definite answer to the question regarding the neurological and developmental consequences of these changes in brain development for the small for gestational age infant. Reviewing these follow-up studies it can be concluded that although there may be a slightly increased risk of major neurological problems, the vast majority of the full-term SGA infants will have no major handicap. However, there is good evidence of an increased risk of minor neurological dysfunction and neurodevelopmental and behavioural problems at around school age in term SGA infants (Chapter 2).

Significant differences in neonatal neurological and neurobehavioural performance between full-term SGA and appropriate for gestational age (AGA) infants were described by several authors (Michaelis et al. 1970; Als et al. 1976; Low et al. 1978; Jurgens-van der Zee et al. 1979; Frederickson and Brown 1980; Ounsted et al. 1988). According to Als et al. (1970) the SGA infant appears in 
general to be more stressed on handling than his AGA counter part. This might influence the results of a neurological examination which involves frequent manipulations, a disadvantage not encountered in observational studies of spontaneous motor behaviour.

In this thesis posture, influence of head position on limb position, quantity and quality spontaneous motor behaviour in full-term SGA infants are described (Chapter 6) and a comparison with healthy full-term infants was made (Chapter 7).

Studying quantitative aspects of motor behaviour in the SGA infants and comparing them with the results of the AGA infants, the only difference found was the percentage of time spent in hand-face contact of the right hand which was significantly higher in the SGA group, independent of the state of the infant. This difference cannot be explained by a difference in percentage of time spent with the head to the right, as no such difference could be demonstrated. We do not have an explanation for this solitary difference, nor do we know the clinical significance of this finding. Head position in the SGA infants only influenced the occurrence of hand-face and hand-mouth contact, which was higher in the hand ipsilateral to the face. This concurs with the results found in the AGA infants.

Just like in the AGA group, the analysis of the complete posture failed to demonstrate a group preference posture in the SGA group. A wide inter-individual variability in posture was found. However, in the separate analysis of the positions of the 4 limbs, the SGA infants as a group showed significantly more often full flexion of the arms than the infants in the AGA group. Furthermore, there was a dominant group combination of left and right arm in the SGA group, in which both arms were in a fully flexed position. In the AGA group there was no dominant group combination. These differences might be due to an increased flexor tone in SGA infants. This is in agreement with the results of Dubowitz et al. (1982) who described a relative hypertonia of SGA infants. In contrast, our results do not concur with the results of Als et al. (1976), who observed poor muscle tone in SGA infants. However, Als et al. (1976) and Dubowitz et al. (1982), described tone judged by manipulation, and not by observing resting posture. As muscle tone might be influenced by the handling procedure, the results are difficult to compare.

Amiel-Tison $(1968,1986)$ described an increase of muscle tone in flexor muscles in caudocephalic progression from 28 to 40 weeks postmenstrual age, as a reflection of CNS maturation, resulting in a full flexion posture of all limbs at term age. Within the first year of life, she describes a decrease in flexor tone in a cephalocaudal direction, starting with the upper extremities and proceeding to the lower extremities. Some studies have described the fact that that prenatal stress can accelerate neurological and neurophysiological maturation (Gould et al. 1977; Amiel-Tison 1980; Pettigrew et al. 1985). In this 
case we would expect the full-term SGA infant to show less flexion in the arms compared to AGA infants, due to an accelerated CNS maturation. Other studies showed that intrauterine growth retardation has an impact on neural and glial multiplication and myelination (Chase et al. 1972; Sarma and Rao 1974; Dobbing 1979), therefore, we would rather expect the SGA infant to show a delayed neurological maturation, and thus less flexion in the arms than the full-term AGA infant as described for the preterm infant (AmielTison 1968, 1986). According to Amiel-Tison's description of resting posture as a reflection of CNS maturation, the increased occurrence of arm flexion in resting posture of SGA infants can neither be explained by a delayed, nor by an accelerated maturation. There are two possible explanations for this discrepancy. Firstly, intrauterine malnutrition might not cause a delay or acceleration in CNS development but an alteration of biochemical and neurobiological composition of the brain, resulting in postural differences between AGA and SGA infants instead of a delay or acceleration in postural development. Secondly, posture might not be correlated to CNS maturation. The results of Prechtl et al. (1979) and Vles et al. (1989) are in favour of the last theory. They could not demonstrate a correlation between preference posture and gestational age.

Oligohydramnios, a condition which occurs more often when the fetus is growth retarded (Gross and Sokol 1989, Lin et al. 1990), might influence postnatal posture due to intrauterine spatial restriction. However, in our SGA group, oligohydramnios was diagnosed in only one infant (SGA infant 3). Therefore, we do not believe that decreased intrauterine space had a major influence on postnatal posture in the SGA group.

With regard to the influence of head position change on body posture, our results suggest that, comparable to the AGA infants, the occurrence of an ATNR following a spontaneous head turning in full-term SGA infants is rare. No significant differences between AGA and SGA infants existed. The occurrence of an asymmetric tonic neck posture (ATNP) in the resting postures was rare in both groups of infants (AGA median $6 \%$, SGA median 13\%)

In studying the quality of spontaneous general movements in the SGA infants, 5 different types of general movements were identified. Three of them were identical to the 3 types of general movements in the AGA infants, but the other 2 movement types were completely different. These 2 types of general movements were not seen in AGA infants and they are probably not included in the normal repertory of healthy full-term infants. Both types are monotonous, stereotyped movements with a lack of variability and complexity. Type IV movements are performed fluently, whereas type V movements have a tremulous or even flapping component. In the literature no description of quality of movement in full-term SGA infants is available. Differences in movement quality between normal and intrauterine growth 
retarded fetuses, were first described by Bekedam et al. (1985). In a more recent study Sival et al. (1992) gave a description of quality of general movements in intrauterine growth retarded fetuses. They found no clear effect of uncomplicated intrauterine growth retardation on the quality of general movements. However, when reduction of amniotic fluid occurred, a decrease in speed and amplitude was found. Furthermore, if abnormal fetal heart rate patterns were present, the general movements had a poor repertoire. The quality of general movements observed just before and after birth was identical in all infants with the exception of three infants with cerebral haemorrhages. As we did not study prenatal general movements, nor fetal heart rate patterns, the results are difficult to compare. However, the type III, IV and V general movements were all characterized by stereotyped, monotonous performance ("poor repertoire").

From the differences between the AGA and SGA infants, it may be concluded that the quality of movement, in addition to postural behaviour, is another aspect of spontaneous motor behaviour which expresses alteration of central nervous system development in full-term small for gestational age infants.

Neither in AGA nor in SGA infants could a difference be demonstrated between the frequency of occurrence of the different types of general movement during sleep and wakefulness. This implies that in the clinical situation it is not important whether general movements are judged while the infant is asleep or while it is awake. This is an important advantage to the conventional neurological examination, as most of the responses tested in this examination are suggested to be state-related (Prechtl 1974).

At follow-up at the age of nine months no differences between the AGA and SGA infants could be demonstrated in the results of the neurological examination, nor in the mental and psychomotor development. Thus, although fullterm SGA infants in the neonatal period show motor behaviour which is significantly different from full-term AGA infants, the results of their examination at the age of nine months are within the normal range. Two explanations may be given for this observation.

Firstly, it could indicate that the SGA infants in this study were not severely affected, or that the brain might exhibit catch-up growth involving the developmental processes altered in utero, leading to a certain degree of normalisation of quantitative relationships between $\mathrm{CNS}$ structures.

Secondly, at the age of nine months only a limited number of motor functions have developed to a level at which they may be accurately tested. Furthermore, the infant is still in the pre-linguistic period. Although, an indication of normality of speech and language development may be given at this age, the major part of linguistic development takes place in the second year of life and developmental testing should therefore be postponed to at least the end of the second postnatal year. Since follow-up studies 
demonstrated mainly minor neurological dysfunction, behavioural- speechand language disorders in SGA infants at around school age (Fitzhardinge and Steven 1972; Harvey et al. 1982; Hill et al. 1984; Hadders-Algra et al. 1988), long-term follow-up of these infants is necessary. Probably, long-term developmental follow-up of SGA infants has more clinical value than followup at an early age.

An important clinical question was whether the observation of spontaneous motor behaviour, especially quality of movement could discriminate between infants who are at risk for neurodevelopmental problems and infants who are not. From the correlation of the neonatal quality of movement with the PDI at 9 months of age it can be concluded that type I and III general movements in full-term AGA infants are related to outcome at the age of 9 months. In the SGA group the neonatal occurrence of types II and III were positively correlated to the mental development (MDI) at 9 months of age. No other relations could be demonstrated. Thus, although type IV and V general movements only occurred in SGA infants, they are not related to a better or worse motor development (PDI) at the age of 9 months. However, as was mentioned above, follow-up at later age is necessary in order to investigate whether the different aspects of spontaneous motor behaviour are related to long-term development.

\section{Suggestions for future investigations}

The difference in neonatal posture and quality of movement between AGA and SGA infants may be explained by the influence of intrauterine malnutrition on CNS development. Follow-up at school age is necessary in order to investigate the prognostic value of these findings.

Furthermore, the different aspects of spontaneous motor behaviour have to be studied in other groups of infants who are at risk for neurological and neurobehavioural developmental disorders to investigate their prognostic value. A study considering this topic has been started in our department. 


\section{Chapter 9}

\section{Summary and conclusions}

This thesis describes the spontaneous motor behaviour in full-term appropriate for gestational age (AGA) and small for gestational age (SGA) newborn infants. Several aspects of spontaneous motor behaviour in the first postnatal week were studied. The influence of intrauterine growth retardation (IUGR) on spontaneous motor behaviour in full-term SGA infants and the relationship between spontaneous motor behaviour in the neonatal period and future neurological and neuropsychological development were studied.

In Chapter 2 the literature concerning spontaneous motor behaviour in fullterm AGA infants and the literature concerning aetiology of intrauterine growth retardation, identification of the intrauterine growth retarded infant, influence of prenatal malnutrition on brain development, neonatal neurological and behavioural development and outcome of small for gestational age newborn infants is reviewed.

From the literature it is concluded that there are many factors that can cause or are associated with intrauterine growth retardation, but that in an important percentage of SGA infants no cause for their growth retardation can be identified. Furthermore, it can be concluded from the literature that prenatal malnutrition can influence many processes in brain growth and development. This might explain the differences in neonatal neurological and behavioural development between SGA and AGA infants reported in the literature. Furthermore, an increased risk of minor neurological dysfunction, behavioural and school problems at later age was demonstrated in follow-up studies of full-term SGA infants.

From this review it is also concluded that knowledge of spontaneous motor behaviour in full-term SGA and AGA infants is very limited.

In Chapter 3 infants and methods used in this study are described. Several aspects of spontaneous motor behaviour were studied in full-term AGA and SGA infants. Three-hour video recordings were made of each infant between the third and eighth postnatal day. Subsequently, the various itenns of spontaneous motor behaviour were scored and analyzed. 
Chapter 4 describes a study on inter- and intra-observer agreement in the assessment of the quality of spontaneous movements in the newborn. The inter- and intra-observer agreement for the assessment of several aspects of the quality of spontaneous movements in newborn infants was analyzed by 4 observers. The agreement rates were corrected for chance by the use of kappa statistics, which revealed kappa values ranging from 0.36 to 0.84 . The level of agreement on various items differed. A moderate-to-good agreement was found for the items "onset of movement", "speed", "speed of arms compared to legs", "amplitude of arms compared to legs", "fluency", "variability in arm patterns" and "global judgement of the movement" (kappa values ranging from 0.51 to 0.84 ). Less agreement occurred in the items "amplitude", "variability in movement pattern" and "variability in leg patterns" (kappa values ranging from 0.36 to 0.40 ). Even though it is generally believed that qualitative assessment of spontaneous motor behaviour is very subjective, our results suggest that several qualitative aspects of infant motor behaviour can be reliably judged.

We concluded that the judgement of the quality of general movements in full-term infants is a reproducible and therefore reliable clinical tool for evaluating motor behaviour in the neonatal period.

In Chapter 5 the results of the AGA infants are described. No head position preference could be demonstrated. Most movement patterns were shown to be state-related. No influence of head position on limb movements, other than hand-face and hand-mouth contact, was found. No dominant group preference posture could be demonstrated in the study of postural behaviour. The occurrence of an asymmetric tonic neck reflex (ATNR), as described in the literature, was very scarce. The observation of quality of spontaneous general movements yielded 3 different types of movement quality (type I, II and III) in this group of infants. The occurrence of type I and type III was related to psychomotor development at the age of 9 months in this group of infants.

Chapter 6 describes the results of the SGA infants. No head position preference could be demonstrated in this group of infants. Most movement patterns were shown to be state-related. No influence of head position on limb movements except hand-face and hand-mouth contact could be demonstrated. Although most infants showed a preference position, no dominant group preference posture could be demonstrated. The occurrence of an ATNR as described in the literature was very rare. From the observation of quality of spontaneous general movements 5 different types of movement quality (type I, II, III, IV and V) were distinguished. The occurrence of the types II and III was related to mental development at the age of 9 months.

In Chapter 7 the results of the SGA infants are compared with the results of the AGA infants. Some significant differences were found. 
Firstly, the percentage of time spent in hand-face contact of the right hand was significantly higher in the SGA group, independent of the state of the infant. The difference could not be explained by a difference in percentage of time spent with the head to the right.

Secondly, the SGA infants showed significantly more often a fully flexed position of the arms than the AGA infants.

Thirdly, in the observation of quality of spontaneous general movements in the SGA infants 2 types of quality of movement were distinguished which were not present in the AGA infants (types IV and V). Furthermore type I general movements occurred significantly more often in AGA than in SGA infants.

In Chapter 8 the findings presented in chapters 5,6 and 7 are discussed in relation to studies reported in the literature. Suggestions for future research are presented.

\section{Conclusions}

The main conclusions of this study are the following:

1. There is a wide inter-individual variability in postural repertoire in healthy appropriate for gestational age and small for gestational age full-term infants. Most infants show a real preference posture, but no group preference posture was found in the two groups.

2. SGA infants significantly more often show a fully flexed position of the arms than AGA infants.

3. The occurrence of a spontaneous ATNR as described by Magnus and de Kleyn (1912) in full-term AGA and SGA infants is rare.

4. No significant head position preference exists in full-term AGA and SGA infants.

5. Head position only significantly influences the occurrence of hand-face and hand-mouth contact in healthy AGA and SGA infants. Therefore, head position is not important when studying quantitative aspects of spontaneous motor behaviour.

6. The only significant difference in quantitative aspects of motor behaviour between full-term AGA and SGA infants is the percentage of observation time spent in hand-face contact of the right hand which is higher in SGA infants.

7. The judgement of several aspects of quality of movement in full-term newborn infants is a reproducible and therefore reliable clinical tool for the evaluation of spontaneous motor behaviour in the neonatal period.

8. The normal repertoire of general movements in healthy full-term infants consists of at least 3 different movement types which might be used as a reference for normal spontaneous motor behaviour. 
9. In SGA infants five movement types were present. Two of them (types IV and V) were not seen in AGA infants. It is not known whether they are abnormal movement patterns, or just normal movement patterns for SGA infants. Since these types of movement were present in infants at risk for neurodevelopmental disorders, we might speculate that these patterns of movement represent a neurological abnormality. In order to prove this speculation, we have to study the quality of movement in infants with proven structural CNS abnormalities such as periventricular leucomalacia (PVL) or intracranial haemorrhage (ICH).

10. The differences in postural behaviour, and in qualitative and quantitative aspects of spontaneous motor behaviour between full-term AGA and SGA infants might be due to the influence of intrauterine malnutrition on several processes in the development of the central nervous system.

11. At the age of 9 months no significant difference in psychomotor and mental development between full-term AGA and SGA infants was found. This could indicate that the SGA infants in this study were not severely affected or that there was catch-up growth of the brain concerning the developmental processes altered in utero, compensating for any major neurological sequels. Long term follow-up must be planned to detect small effects on neurodevelopment which could be correlated with the different patterns of movement quality and posture described in the SGA group. 


\section{Samenvatting en conclusies}

In dit proefschrift wordt het spontane motorische gedrag beschreven van à-terme pasgeborenen met een normaal geboortegewicht voor de zwangerschapsduur ("appropriate for gestational age infants") en à-terme pasgeborenen met een te laag geboortegewicht voor de zwangerschapsduur ("dysmaturen" of "small for gestational age infants"). De invloed van intrauteriene groeiretardatie op spontaan motorisch gedrag van à-terme dysmaturen werd onderzocht. Daarnaast werd de relatie tussen spontaan motorisch gedrag in de neonatale periode en de neurologische en neuropsychologische ontwikkeling op latere leeftijd bestudeerd.

Hoofdstuk 2 geeft een overzicht van de relevante literatuur over spontane houding en motoriek van pasgeborenen met een normaal geboortegewicht, oorzaken van intra-uteriene groeiretardatie, identificatie van kinderen met een intra-uteriene groeiretardatie, de invloed van prenatale ondervoeding op de hersenontwikkeling en de neurologische ontwikkeling van dysmaturen in de neonatale periode en op latere leeftijd.

Uit de literatuur wordt geconcludeerd dat er vele factoren zijn die intrauteriene groeiretardatie kunnen veroorzaken of daaraan gerelateerd zijn, doch dat in een belangrijk percentage van de dysmaturen geen oorzaak voor de groeiretardatie gevonden wordt. Daarnaast kan geconcludeerd worden dat prenatale ondervoeding van invloed kan zijn op meerdere processen die belangrijk zijn voor de groei en ontwikkeling van de hersenen. Dit zou een verklaring kunnen zijn voor de in de literatuur beschreven verschillen in neonatale neurologische ontwikkeling tussen dysmaturen en pasgeborenen met een normaal geboortegewicht voor de zwangerschapsduur. In follow-up studies wordt bovendien aangetoond dat dysmaturen een verhoogd risico hebben voor lichte neurologische afwijkingen en gedrags- en leerproblemen op latere leeftijd.

Uit de literatuurstudie wordt tevens geconcludeerd dat de bestaande gegevens over spontaan motorisch gedrag van à-terme dysmaturen en pasgeborenen met een normaal geboortegewicht voor de zwangerschapsduur beperkt zijn.

In hoofdstuk 3 worden de twee studiegroepen en de gebruikte methoden beschreven. Verschillende aspecten van het spontane motorische gedrag werden bestudeerd bij à-terme dysmaturen en à-terme pasgeborenen met een normaal geboortegewicht voor de zwangerschapsduur. Van iedere pasgebo- 
rene werd een drie uur durende video-opname gemaakt tussen de derde en achtste dag post-partum. Daarna werden de verschillende items van spontaan motorisch gedrag (houding en motoriek) gescoord en geanalyseerd.

Hoofdstuk 4 beschrijft een studie betreffende de inter- en intrawaarnemer overeenstemming bij de beoordeling van de kwaliteit van grote lichaamsbewegingen van à-terme pasgeborenen. Deze overeenstemming werd geanalyseerd in een groep van 4 observatoren. De mate van overeenstemming werd gecorrigeerd voor toeval door het gebruik van de statistische waarde 'kappa'. De gevonden kappa-waarden varieerden van 0,36 tot 0,84 . De mate van overeenstemming verschilde per item. Een matig tot goede overeenstemming werd gevonden voor de items "start van de beweging", "snelheid", "snelheid van de armen ten opzichte van de benen", "amplitudo van de armen ten opzichte van de benen", "al dan niet vloeiende uitvoering van de beweging", "variabiliteit van de armen" en "globale beoordeling" (kappa-waarden 0,51 tot 0,84$)$. Er bestond minder overeenstemming bij de items "amplitudo", "variabiliteit in het bewegingspatroon" en "variabiliteit van de benen" (kappa-waarden 0.36 tot 0.40 ).

Er werd geconcludeerd dat de beoordeling van verschillende aspecten van de kwaliteit van grote lichaamsbewegingen van à-terme pasgeborenen een reproduceerbaar en dus betrouwbaar klinische instrument is voor de evaluatie van motorisch gedrag in de neonatale periode.

In hoofdstuk 5 worden de resultaten van het onderzoek voor de pasgeborenen met een normaal geboortegewicht beschreven. Er bestond geen duidelijke voorkeurspositie van het hoofd. De hoofdpositie was niet van invloed op het voorkomen van de bewegingpatronen van de extremiteiten, met uitzondering van hand-gezicht en hand-mondcontact. Het voorkomen van de meeste bewegingpatronen was toestand-afhankelijk. Bij de bestudering van de voorkomende houdingen kon geen gemeenschappelijke voorkeurshouding worden aangetoond.

Het voorkomen van een "asymmetrische tonische nek reflex (ATNR)", zoals beschreven in de literatuur, was zeldzaam.

De beoordeling van de kwaliteit van grote lichaamsbewegingen leverde drie verschillende bewegingstypen op: type I, II en III. Het voorkomen van type I en type III bij deze kinderen was gecorreleerd aan de motorische ontwikkeling op de leeftijd van 9 maanden.

Hoofdstuk 6 beschrijft de resultaten van het onderzoek bij de dysmaturen. Er kon geen voorkeurpositie van het hoofd worden aangetioond. Er bestond geen invloed van de hoofdpositie op het voorkomen van de verschillende bewegingen van de extremiteiten, uitgezonderd hand-gezicht en harid-mond contact. De meeste bewegingen kwamen toestand-afhankelijk voor. Hoewel de meeste kinderen een voorkeurshouding vertoonden, kon er geen gemeenschappe- 
lijke voorkeurshouding binnen de groep worden aangetoond. Het voorkomen van een ATNR was zeldzaam.

Uit de analyse van de kwaliteit van grote lichaamsbewegingen kwamen 5 dominante bewegingstypen naar voren: type I-V. Het voorkomen van type II en III was gecorreleerd aan de mentale ontwikkeling op de leeftijd van 9 maanden.

In hoofdstuk 7 worden de resultaten van de 2 groepen met elkaar vergeleken. Er werden enige significante verschillen gevonden:

- Het percentage van de observatie tijd waarin hand-gezicht contact van de rechterhand voorkwam was significant hoger bij de dysmaturen, onafhankelijk van de toestand (state) van het kind. Dit verschil werd niet verklaard door een verschil in de tijd die doorgebracht werd met het hoofd naar rechts.

- De dysmaturen vertoonden significant vaker een sterk gebogen positie van de armen.

- Bij de analyse van de kwaliteit van grote lichaamsbewegingen werden bij de dysmaturen 2 bewegingstypen aangetoond die niet bij de pasgeborenen met een normaal geboortegewicht voorkwamen (type IV en V). Bovendien kwam type I significant vaker voor bij de kinderen met een normaal geboortegewicht dan bij de dysmaturen.

In hoofdstuk 8 worden de resultaten, gepresenteerd in de hoofdstukken 5, 6 en 7 besproken en vergeleken met de resultaten van studies beschreven in de literatuur. Tevens worden suggesties gegeven voor toekomstige onderzoeken.

\section{Conclusies}

De belangrijkste conclusies van deze studie zijn de volgende:

1. Er is een grote individuele variatie in het houdings-repertoire van zowel à-terme dysmaturen als van à-terme pasgeborenen met een normaal geboortegewicht voor de zwangerschapsduur. Het merendeel van de kinderen vertoond een voorkeurshouding, echter in geen van de twee groepen kon een gemeenschappelijke voorkeurshouding worden aangetoond.

2. Dysmaturen vertonen significant vaker een volledige flexie van de armen dan pasgeborenen met een normaal geboortegewicht voor de zwangerschapsduur.

3. Het voorkomen van een ATNR, zoals beschreven door Magnus en de Kleyn (1912), bij à-terme dysmaturen en à-terme pasgeborenen met een normaal geboortegewicht voor de zwangerschapsduur is zeldzaam.

4. Er bestaat geen significante voorkeurspositie van het hoofd bij dysmaturen en pasgeborenen met een normaal geboortegewicht. 
5. De hoofdpositie beïnvloedt alleen het voorkomen van hand-gezicht- en hand-mond contact. De positie van het hoofd is dus niet van belang bij de bestudering van kwantitatieve aspecten van spontane motoriek bij pasgeborenen.

6. Het enige significante verschil in kwantitatieve aspecten van motorisch gedrag tussen dysmaturen en pasgeborenen met een normaal geboortegewicht voor de zwangerschapsduur is het percentage van de observatie-tijd doorgebracht met hand-gezicht contact van de rechterhand. Dit percentage is hoger bij de dysmaturen.

7. De beoordeling van verschillende aspecten van kwaliteit van bewegen bij de pasgeborene is een reproduceerbare en dus betrouwbare methode voor de evaluatie van spontane motoriek in de neonatale periode.

8. Het normale repertoire van grote lichaamsbewegingen in gezonde à-terme pasgeborenen bestaat uit tenminste 3 verschillende bewegingstypen. Dezen zouden gebruikt kunnen worden als referentie voor normaal spontaan (motorisch) gedrag.

9. Bij de dysmaturen komen 5 verschillende typen grote lichaamsbewegingen voor. Twee van hen (type IV en V) komen niet voor bij pasgeborenen met een normaal geboortegewicht. Het is niet bekend of dit abnormale bewegingspatronen zijn, of normale bewegingspatronen voor dysmaturen. Aangezien deze bewegingspatronen voorkwamen bij kinderen met een verhoogd risico voor ontwikkelingsneurologische stoornissen, kunnen we speculeren dat zij een uiting zijn van een neurologische afwijking. Om deze hypothese te bewijzen moeten we de kwaliteit van bewegen bestuderen van kinderen met bewezen structurele afwijkingen van het zenuwstelsel, zoals intracraniële bloedingen of periventriculaire leucomalacie.

10. De verschillen in houding en motoriek tussen à-terme dysmaturen en a-terme pasgeborenen met een normaal geboortegewicht voor de zwangerschapsduur worden mogelijk veroorzaakt door de invloed van intra-uteriene malnutritie op de verschillende processen die betrokken zijn bij de ontwikkeling van het centraal zenuwstelsel.

11. Op de leeftijd van 9 maanden werd er geen significant verschil in mentale en motorische ontwikkeling tussen à-terme dysmaturen en à-terme pasgeborenen met een normaal geboortegewicht aangetoond. Dit zoul kunnen betekenen dat de dysmaturen in deze studie niet ernstig waren aangedaan of dat er inhaal-groei optrad met betrekking tot de verschillende processen van de hersenontwikkeling, zodat ernstige neurologische afwijkingen op latere leeftijd voorkomen werden. Follow-up op langere termijn is noodzakelijk om lichte afwijkingen in de neurologische ontwikkeling op te sporen die mogelijk gecorreleerd zijn aan de verschillencle neonatale bewegingstypen en houdingen die in de groep dysmaturen gevonden werden. 


\section{References}

Adair LS. Low birth weight and intrauterine growth retardation in Filipino infants. Pediatrics 1989;84(4):613-622.

Allen MC. Developmental outcome and follow up of the small for gestational age infant. Semin Perinatol 1984;8(2):123-156.

Als H, Tronick E, Adamson L, Brazelton TB. The behavior of the full-term but underweight newborn infant. Dev Med Child Neurol 1976;18:590-602.

Altman DG. Practical statistics for medical research. London: Chapman and Hall, 1990: 403-409.

Amiel-Tison C. Neurological evaluation of the maturity of newborn infants. Arch Dis Childh 1968;43:89-93.

Amiel-Tison C. Possible acceleration of neurological maturation following high risk pregnancy. Am J Obstet Gynecol 1980;138:303-306.

Amiel-Tison C, Grenier A. Neurological assessment during the first year of life. New York, Oxford: Oxford University Press Inc. 1986:21-22.

Andre-Thomas, Saint-Anne Dargassies S. Etudes neurologiques sur le nouveau-ne et le jeune nourrisson. Paris: Masson Editeur 1952.

Babson SG. Growth of low-birth-weight infants. J Pediat 1970;77:11-18.

Bayley N. Bayley Scales of Infant Development. New York: The Psychological Corporation 1969.

Bedi KS. Nutrition, environment and brain development. Sci Prog Oxf 1986;70:555-570.

Beintema DJ. A neurological study of newborn infants. Clinics in Developmental Medicine. London: S.I.M.P. 1968;28.

Bekedam DJ, Visser GHA, de Vries JJ, Prechtl HFR. Motor behaviour in the growth retarded fetus. Early Hum Dev 1985;12:155-165.

Berg AT. Indices of fetal growth-retardation, perinatal hypoxia-related factors and childhood neurological morbidity. Early Hum Dev 1989;19:271-283.

Berghe van den JH, Schouten HJA, Boomstra S, van Drunen Littel S, Braakman R. Interobserver agreement in assessment of ocular signs in coma. J Neurol Neurosurg Psychiatry 1979;42:1163-1168.

Beyers RK. Tonic neck reflexes in children considered from a prognostic standpoint. Amer J Dis Child 1938:55:696-742.

Brandt J. Brain growth, fetal malnutrition, and clinical consequences. J Perinat Med 1981,9(3):3-26.

Brazelton TB. Neonatal behavioral assessment scale. Clinics in Developmental Medicine. London: S.I.M.P. 1973;50.

Capute AJ, Palmer FB, Shapiro BK, Wachtel RC, Ross A, Accardo PJ. Primitive reflex profile: a quantitation of primitive reflexes in infancy. Dev Med Child Neurol 1984;26:375-383.

Casaer P. Postural behaviour in newborn infants. Clinics in Developmental Medicine. London: S.I.M.P. $1979 ; 72$.

Cassady G. The small-for-date infant. In: Avery G.B. (Ed) Neonatology: Pathophysiology and management of the newborn. Philiadelphia, Toronto: J.B. Lippincott Company 1981:262-286. 
Chase HP. Undernutrition and growth and development of the human brain. In: Lloyd-Still JDA (Ed) Malnutrition and intellectual development. Lancaster: MTP Press ltd 1976.

Chase HP, Welch NN, Dabiere CS, Vasan NS, Butterfield LJ. Alterations in human brain biochemistry following intrauterine growth retardation. Pediatrics 1972;50(3):403-411.

Chiswick ML Intrauterine growth retardation. Brit Med J 1985;291:854-847.

Cioni G, Ferrari F, Prechtl HFR. Posture and spontaneous motility in full-term infants. Early Hum Dev 1989;7:247-262.

Cioni F, Prechtl HFR. Preterm and early postterm motor behaviour in low-risk premature infants. Early Hum Dev 1990;23:159-191.

Cohen J. A coefficient of agreement for nominal scales. Educational and Psychological Measurement 1960;20:37-46.

Dobbing J. The later development of the brain and its vulnerability. In: JA Davis and J Dobbing (Eds). Scientific Foundations of pediatrics. Sec ed. London: Heinemann 1974.

Dobbing J. Nutrition and brain development. In: Thalhammer O., Baumgarten $\mathrm{K}$. and Pollak A (Eds): Perinatal medicine. 6th European Congress, Vienna. Stuttgart: Thieme 1979.

Dobbing J, Sands J. Timing of neuroblast multiplication in developing human brain. Nature 1970;226:639-640.

Dobbing J, Sands J. Vulnerability of developing brain. Biol Neonate 1971;19:363-378.

Dobbing J, Sands J. Quantitative growth and development of human brain. Arch Dis Child 1973;48:757-767.

Dubowitz L, Dubowitz V. The neurological assessment of the preterm and full-term newborn infant. Clinics in Developmental Medicine. London: S.I.M.P. 1981;79.

Dubowitz L, Dubowitz V, Goldberg C. A comparison of neurological function in growthretarded and appropriate-sized full-term newborn infants in two ethnic groups. S Afr Med J 1982;61:1003-1007.

Erkinjuntti M. Body movements during sleep in healthy and neurologically damaged infants. Early Hum Dev 1988;16:283-292.

Escardo F, de Coriat LF. Development of postural and tonic patterns in the newborn infant. Pediatric clinics of North America 1960;7:511-525.

Ferrari F, Cioni G, Prechtl HFR. Qualitative changes of general movements in preterm infants with brainlesions. Early Hum Dev 1990;23:193-231.

Fitzhardinge PM, Steven EM. The small for date infant. II. Neurological and intellectual sequelae. Pediatrics 1972;50(1):50-57.

Frederickson WT, Brown JV. Gripping and Moro responses: Differences between small-forgestational age and normal weight term newborns. Early Hum Dev 1980;4(1):69-77.

Gesell A. The tonic neck reflex in the human infant. J Pediat 1938;13(4):455-464.

Gesell A, Halverson HM. The daily maturation of infant behavior: a cinerna study of postures, movements, and laterality. J Genet Psychol 1942;61:3-32.

Gesell A, Amatruda CS. The embryology of behaviour. New York: Harper, 1945.

Gils van JF. Postnatal growth and development in small-for-date babies. Normal and abnormal development of brain and behaviour. Stoelinga GBA., van der Werf-ten Bosch J.J (Eds) Leiden University Press 1971:53-69.

Gould JB, Gluck L, Kulovich MV. The relationship between accelerated pulmonary maturity and accelerated neurological maturity in certain chronically stressed pregnancies. Am J Obstet Gynecol 1977;127:181-186.

Graziani LJ, Korberly B, d'Amato G. Brain and behavior in the neonatal period. Topics in Child neurology. Spectrum publications 1977.

Gross TL, Sokol RJ. Intrauterine growth retardation. A practical approach. Year book medical publishers inc. Chicago, London, Bocaraton 1989.

Gruenwald P. Chronic fetal distress and placental insufficiency. Biol. Neonat. 1963;5:215-265. 
Gruenwald P. The relation of deprivation to perinatal pathology and late sequels. In: Gruenwald $P(E d)$. The placenta and its maternal supply line. Effects of insufficiency on the fetus. Lancaster, England: MTP press Itd 1975:335-356.

Hadders-Algra M, Huisjes HJ, Touwen BCL. Preterm or small-for-gestational age infants. Neurological and behavioural development at the age of 6 years. Eur J Pediat 1988:147;460-467.

Hadders-Algra M, Prechtl HFR. Developmental course of general movements in early infancy. I. Descriptive analysis of change in form. Early Hum Dev 1992;28:201-213.

Harvey D, Prince J, Bunton J, Parkinson C, Campbell S. Abilities of children who were small-for-gestational-age babies. Pediatrics 1982; 69(3):296-300.

Hawdon JM, Hey E, Kolvin I, Fundudis T. Born too small. Is outcome still affected? Dev Med Child Neurol 1990;32:943-953.

Herschkowitz N. Brain development in the fetus, neonate and infant. Biol Neonate 1988;54:119.

Herschkowitz N. Brain development and nutrition. In: Evrard P and Minkowski A. Developmental Neurobiology. Nestle nutrition workshop series. New York: Nestec Itd, Raven Press Itd, 1989 vol 12.

Hill RM, Verniaud WM, Deter RL, Tennyson LM, Rettig GM, Zion TE, Vorderman AL, Helms PG, McCulley LB, Hill LL. The effect of intrauterine malnutrition on the term infant. A 14-year progressive study. Acta Paediatr Scand 1984;73:482-487.

Hopkins B, Prechtl HFR. A qualitative approach to the development of movements during early infancy. Clinics in developmental medicine. London: S.I.M.P. 1984;94:179-197.

Hopkins B, Lems W, Janssens B, Butterworth G. Postural and motor asymmetries in newlyborns. Hum Neurobiol 1987;6:153-156.

Jones RAK, Roberton NRC. Problems of the small-for-dates baby. Clin Obstet Gynaecol 1984;11(2):499-524.

Jurgens-van der Zee AD, Bierman-van Eendenburg MEC, Fidler VJ, Olinga AA, Touwen BLC, Huisjes HJ. Preterm birth, growth retardation and acidemia in relation to neurological abnormality of the newborn. Early Hum Dev 1979;3(2):141-154.

Keirse MJNC. Epidemiology and Aetiology of the growth retarded baby. Clin Obstet Gynaecol 1984;11(2);415-436.

Kloosterman GJ. On intrauterine growth. The significance of prenatal care. Int J Gynaecol Obstet 1970;8:895-912.

Kloosterman GJ. De voortplanting van de mens. Bussum, the Netherlands: Centen 1983:380383.

Kramer MS, McLean FH, Olivier M, Willis DM, Usher RH Body proportionality and Head and Length 'sparing' in Growth-retarded neonates: a critical reappraisal. Pediatrics 1989;84(4):717-723.

Landis JR, Koch GG. The measurement of observer agreement for categorical data. Biometrics 1977;33:159-174.

Leijon I, Billstrom G, Lind I. An 18-month follow-up study of growth-retarded neonates. Relation to biochemical tests of placental function in late pregnancy and neurobehavioural condition in the newborn period. Early Hum Dev 1980;4(3):271-285.

Lin C., Sheikh Z., Lopata R. The association between oligohydramnios and intrauterine growth retardation. Obstet Gynecol 1990;76:1100-1104.

Low JA, Galbraith RS, Muir B, Killen H, Karchmar J, Campbell D. Intrauterine growthretardation: a preliminary report of long-term monbidity. Am J Obstet Gynecol 1987;30(5):534-545.

Low JA, Galbraith RS, Muir D, Killen H, Pater B, Karchmar J. Intrauterine growth retardation: A study of long-term morbidity. Am J Obstet Gynecol 1982;142:670-677.

Lubchenco LO. The high-risk infant. Major problems in clinical pediatrics 1976;XIV. 
Lubchenco LO. Intrauterine growth as estimated from liveborn birth-weight data at 24-42 weeks of gestation. Pediatrics 1963;32:793.

Magnus R. Körperstellung. Berlin: J Springer, 1924.

Magnus $\mathbf{R}$, de Kleyn A. Die abhängigkeit der tonus der extremitätenmuskeln von der kopfstellung. Pflüger's Arch 1912;145:455-548.

Meulen van der BF, Smirkovsky M. 'BOS2-30 Bayley ontwikkelingsschalen, Lisse: Swets and Zeitlinger B.V. 1982.

Michaelis R, Schulte FJ, Nolte R. Motorbehaviour of small-for-gestational age newborn infants. J Pediat 1970;76(2):208-213.

Miller HC, Hassanein K. Fetal malnutrition in white newborn infants: Maternal factors. Pediatrics 1973-52(4):504-512.

Muhiudeen HA, Melville-Thomas G, Ferguson SD, Mohan P. The postures exhibited by 3-day-old fullterm neonates Early Hum Dev 1984;10:57-66.

Ounsted M, Moar V, Scott WA. Perinatal morbidity and mortality in small-for-dates babies: the relative importance of some maternal factors. Early Hum Dev 1981;5:367-375.

Ounsted M, Moar VA, Scott A. Neurological development of small-for-gestational age babies during the first year of life. Early Hum Dev 1988;16:163-172.

Pacella BL, Barrera SE. Postural reflexes and grasp phenomena in infants. J Neurophysiol 1940;3:213-218.

Paine RS, Brazelton TB, Donovan DE, Drorbaugh JE, Hubbell JP, Manning Sears E. Evolution of postural reflexes in normal infants and in the presence of chronic brain syndromes. Neurology 1964;14:1036-1048.

Pearce JM, Campbell S. Intrauterine growth retardation. Birth defects: original article series, 1985;21(5):109-130.

Prechtl HFR. The neurological examination of the full-term newborn infant. Clinics in Developmental Medicine 1979;63. Spastics International Medical Publications. Heinemann Medical Books Itd.

Prechtl HFR. Ultrasound studies of human fetal behaviour. Early Hum Dev 1985;12:91-98.

Prechtl HFR. Developmental neurology of the fetus. Balliere Clin Obstet Gyn 1988;2(1).

Prechtl HFR. Qualitative changes of spontaneous movements in fetus and preterm infant are a marker of neurological dysfunction. Early Hum Dev 1990;23:151-158.

Prechtl HFR, Beintema DJ. Die neurologische untersuchung des reifen neugeborenen. Stuttgart: Thiemen, 1976:40-41.

Prechtl HFR, Fargel JW, Weinmann HM, Bakker HH. Postures, motility and respiration of low risk pre-term infants. Dev Med Child Neurol 1979;21:3-27.

Prechtl HFR, Hopkins B. Developmental transformations of spontaneous movements in early infancy. Early Hum Dev 1986;14:233-238.

Rees S, Bocking AD, Harding R. Structure of the fetal sheep brain in experimental growth retardation. J. Dev. Phys. 1988; 10:211-224.

Sacket DL, Hayness RB, Tugwell P. Clinical epidemiology. A basic science for clinical medicine. Boston, Toronto: Little, Brown and Company, 1985:17-45.

Saint-Anne Dargassies S. Neurological development in the full-term and premature neonate. Amsterdam, London, New York: Excerpta medica $19: 7$.

Sarma MKJ, Rao KS. Biochemical composition of different regions in brains of small-for-date infants. J Neurochem 1974;22:671-677.

Schouten HJA. Measuring pairwise interobserver agreement when all subjects are judged by the same observers. Statistica Neerlandica 19:2;36:45-61.

Scott KE, Usher F. Fetal malnutrition: its incidence, causes and effects. Ann J Obstet Gynecol $1966 ; 94: 951-963$. 
Shirataki S. Neurobehavioral development in high-risk young infants: Wakefulness and its implication for a future development. In: Yabuuchi $\mathrm{H}$ and Watanabe $\mathrm{K}$ (Eds) Neonatal brain and behaviour. Japan: The University of Nagoya Press 1987.

Sijmons EA. On screening for intrauterine growth retardation. Thesis 1989, Utrecht.

Sival DA, Visser GHA, Prechlt HFR. The effect of intrauterine growth retardation on the quality of general movements in the human fetus. Early Hum Dev 1992;28:119-132.

Teberg AJ, Walther FJ, Pena IC. Mortality, morbidity and outcome of the small-for-gestational age infant. Semin Perinatol 1988;12(1):84-94.

Thomas YM, Bedi KS, Davies CA, Dobbing J. A stereological analysis of the neuronal and synaptic content of the frontal and cerebellar cortex of weanling rats undernourished from birth. Early Hum Dev 1979;3/2:109-126.

Thomson AM, Billwicz WZ, Hytten FE. The assessment of fetal growth. JObstet Gynaec Brit Cwlth 1968;75:903-916.

Touwen BCL. De neurologische ontwikkeling van de zuigeling. Ontwikkelingsgang en samenhang van de onderdelen van het neurologisch onderzoek. The Netherlands: Bohn, Scheltema \& Holkema 1984.

Touwen BCL. Variability and stereotypy of spontaneous motility as a predictor of neurological development of preterm infants. Dev Med Child Neurol 1990;32:501-508.

Turkewitz G, Creighton S. Changes in lateral differentiation in the human infant. Ann NY Acad Sci 1974;299:309-318.

Usher R, McLean F. Intrauterine growth of live-born Caucasian infants at sea level: Standards obtained from measurements in 7 dimensions of infants born between 25 and 44 weeks of gestation. J Pediat 1969;74:901.

Usher RH. Clinical and therapeutic aspects of fetal malnutrition. Pediatr. Clin. North. Am. 1970;17: 169-183.

Vasella F, Karlsson B. Asymmetric tonic neck reflex; a review of the literature and a study of its presence in the neonatal period. Dev Med Child Neurol 1962;4:363-369.

Versluys C. Keuze van voor Nederland bruikbare perinatale groeicurven T. Kindergeneesk. 1980;48(6):158-167.

Villar J, Smeriglio V, Martorell R, Brown CH, Klein RE. Heterogeneous growth and mental development of intrauterine growth-retarded infants during the first 3 years of life. Pediatrics 1984;74(5):783-791.

Visser GHA, Laurini RN, de Vries JIP, Bekedam D\}, Prechtl HFR Abnormal motor behaviour in anencephalic fetuses. Early Hum Dev 1985;12:173-182.

Vles JSH. Spontaneous behaviour in preterm infants. Thesis 1988.

Vles JSH, van Oostenbrugge $\mathbf{R}$, Kingma $\mathbf{H}$, Caberg $\mathbf{H}$, Casaer $\mathbf{P}$. Influence of head position and head position change on body posture in pre-term infants. Neuropediatrics 1988a;19:96-100.

Vles JSH, van Oostenbrugge $\mathbf{R}$, Kingma $\mathbf{H}$, Caberg $\mathbf{H}$, Casaer P. Posture during head tuming in pre-term infants: a longitudinal study of 15 low-risk infants of 32-36 weeks of postconceptional age. Neuropediatrics 1988b;20:25-29.

Vles JSH, van Oostenbrugge $\mathbf{R}$, Kingma H, Caberg H, Casaer P. Head position in low-risk premature infants. Biol neonate 1988c;54:307-313.

Vles JSH, Kingma H, Caberg $\mathbf{H}$, Daniels $\mathbf{H}$ Casaer P. Posture of low-risk pre-term infants: a study from 32-36 weeks of postconceptional age. Dev Med Child Neurol 1989:31:191195.

Vles J, van Zutphen S, Hasaart T, Dassen W, Lodder J. Supine and prone head orientation preference in term infants. Brain Dev 1991;13:87-90.

Vles JSH, van Oostenbrugge RJ, Hasaart THM, Caberg H, Kingma H, Casaex PJM, Blanco CE. State profile in low-risk pre-term infants: $A$ longitudinal study of 7 infants from 32-36 weeks of postmenstrual age. Brain Dev 1992;14:12-7. 
Volpe JJ. Neurology of the newborn. Major problems in clinical pediatrics. WB Saunders Company, vol. 22, 2nd edition, 1987:33-68.

Vries de JIP, Visser GHA, Prechtl HFR. The emergence of fetal behaviour. I. Qualitative aspects. Early Hum Dev 1982;7:301-322.

Vries de JIP, Visser GHA, Prechtl HFR. The emergence of fetal behaviour. II. Quantitative aspects. Early Hum Dev 1985;12:99-120.

Walther FJ. Intrauterine malnutrition: Neonatal and early childhood morbidity. Thesis 1982.

Walther FJ, Ramaekers LHJ. Developmental aspects of subacute fetal distress: behaviour problems and neurological dysfunction. Early Hum Dev 1982;6:1-10.

Warshaw JB. Intrauterine growth retardation: Adaptation or pathology. Pediatrics 1985; 76(6):998-999.

Westwood M, Kramer MS, Munz D, Lorett JM. Watters GV. Growth and development of full-term nonasphyxiated small-for-gestational age newborns: follow-up through adolescence. Pediatrics 1983;71(3):376-382.

W.H.O. Public Health aspects of low birth weight. World Health Organization technical Report, 1961, Series 217.

Winick M. Fetal malnutrition and brain development. J Pediat gastroenterol nutr 1983;2 (suppl.1):68-72. 


\section{Appendix I \\ Exclusion criteria (adapted from Kloosterman 1983)}

A. Diseases influencing or influenced by pregnancy:

- neurological diseases: epilepsy, subarachnoidal haemorrhage, multiple sclerosis, brain tumour, psychiatric disorders;

- internal diseases: active tuberculosis, severe chronic obstructive pulmonary disease (COPD), cardiovascular diseases, M. Addison, hypo- and hyperthyroidism, thrombosis and embolism;

- essential hypertension, diabetes mellitus, renal disease, active rhesus antagonism.

\section{B. Obstetrical complications:}

- hypertension (blood pressure $>90 \mathrm{mmHg}$ diastolic);

- severe vaginal blood loss during pregnancy;

- hyperemesis gravidarum with acetonuria;

- adnex tumour requiring treatment;

- severe pregnancy-induced hypertension (PIH), defined as a condition with blood pressure (BP) higher than $150 / 95$ or diastolic persistent 90 , measured on two independent occasions;

- preeclampsia defined as PIH complicated by proteinuria of at least 100 $\mathrm{mg} / 24$ hours;

- eclampsia;

- Hemolysis, Elevated Liver function tests, Low Platelet counts (HELLP) syndrome;

- delivery between the 22nd and 37th week of pregnancy;

- prolonged ruptured membranes ( $>24 \mathrm{~h}$ );

- clinically significant hydramnion;

- pyelitis;

- fetal abnormalities, demonstrated or suspected by antenatal diagnostics;

- multiple pregnancy;

- rhesus sensibilisation;

- laparotomy after the 26th week;

- all mechanical problems leading to operative delivery; 
Appendix Ila Maternal and infant data of AGA infants

\begin{tabular}{|c|c|c|c|c|c|c|c|c|c|c|c|c|c|c|c|c|}
\hline Data & $\begin{array}{l}\text { Infant } \\
\text { Characteristic }\end{array}$ & 1 & 2 & 3 & 4 & 5 & 6 & 7 & 8 & 9 & 10 & 11 & 12 & 13 & 14 & 15 \\
\hline \multirow[t]{3}{*}{ Mabmal } & Age & 32 & 32 & 32 & 26 & 31 & 25 & 32 & 27 & 34 & 35 & 33 & 33 & 33 & 37 & 31 \\
\hline & G/P/A & $1 / 0 / 0$ & $1 / 0 / 0$ & $2 / 10$ & $2 / 1 / 0$ & $3 / 20$ & $1 / 010$ & $2 / 0 / 1$ & $1 / 000$ & $3 / 20$ & 2110 & 1000 & $5 / 3 / 1$ & $1 / 0 / 0$ & $4 / 3 / 0$ & $2 / 10$ \\
\hline & Max. diastolic BP & 90 & 70 & 85 & 75 & 80 & 85 & 80 & 75 & 80 & 75 & $-2=$ & 80 & 90 & 75 & 70 \\
\hline \multirow[t]{9}{*}{ Infant } & Sex & $m$ & 1 & 1 & $f$ & $f$ & m & m & f & m & 1 & m & m & 1 & m & m \\
\hline & Cestational ago & 40w 6d & $40 \mathrm{~m} 6 \mathrm{~d}$ & $38 w 2 d$ & $39 w$ & $38 w 3 d$ & $39 w 2 d$ & $40 w 6 d$ & $40 w$ & $39 w 5 d$ & $40 \mathrm{w} 5 \mathrm{~d}$ & $39 w 5 d$ & $39 w 5 d$ & $37 w 4 d$ & $40 w 5 d$ & $39 w 3 d$ \\
\hline & Birth weight & 3440 & 4100 & 2750 & 3630 & 2800 & 3580 & 3440 & 3210 & 3050 & 3920 & 3620 & 3210 & 2900 & 3420 & 3805 \\
\hline & Birth length & 50.0 & 53.0 & 52.0 & 50.0 & 47.5 & 49.0 & 52.0 & 50.0 & 47.0 & 50.0 & 50.0 & 49.0 & 48.0 & 50.5 & 50.5 \\
\hline & Ponderal index & 2.75 & 2.70 & 1.96 & 2.90 & 2.60 & 3.04 & 2.44 & 2.57 & 2.94 & 3.14 & 2.90 & 2.73 & 2.62 & 2.66 & 2.95 \\
\hline & Head circumference & 35.5 & - & 34.0 & 35.0 & 34.0 & 33.0 & 32.0 & 34.0 & 34.5 & 35.5 & 35.5 & 34.0 & - & 35.0 & 36.5 \\
\hline & Apgar 1' & 8 & 9 & 10 & 9 & 8 & 7 & 8 & 7 & 9 & 9 & 9 & 9 & - & 9 & 9 \\
\hline & Apgar $5^{\prime}$ & 10 & 10 & 10 & 10 & 10 & 9 & 10 & 9 & 10 & 10 & 10 & 10 & 10 & 10 & 10 \\
\hline & Ph umbilical artory & 7.30 & - & - & 7.29 & 7.23 & 7.16 & 7.16 & 7.15 & 7.16 & 7.21 & 7.34 & 7.48 & - & 7.33 & - \\
\hline
\end{tabular}

$G / P / A=$ Gravida $/$ Para $/$ Abortions; Max. diastolic $B P=$ Maximum diastolic blood pressure; $m=$ male; $f=f e m a l e ; ~ w=w e e k s ; d=$ days 
Appendix Ilb Maternal and infant data of SGA infants

\begin{tabular}{|c|c|c|c|c|c|c|c|c|c|c|c|c|c|c|c|c|}
\hline Data & $\begin{array}{l}\text { Intant } \\
\text { Characteristic }\end{array}$ & 1 & 2 & 3 & 4 & 5 & 6 & 7 & 8 & 9 & 10 & 11 & 12 & 13 & 14 & 15 \\
\hline \multirow[t]{3}{*}{ Matemal } & Age & 29 & 31 & 34 & 37 & 22 & 29 & 26 & 34 & 19 & 32 & 31 & 27 & 28 & 24 & 42 \\
\hline & GIPIA & 430 & $1 / 00$ & $3 / 20$ & $3 / 1 / 1$ & $3 / 1 / 1$ & $2 / 1 / 0$ & $1 / 000$ & $5 / 1 / 3$ & 100 & 1000 & $2 / 10$ & 100 & $4 / 1 / 2$ & 201 & $20 / 1$ \\
\hline & Max, diastolic: BP & 80 & 80 & 75 & 65 & 60 & 75 & 70 & 90 & 80 & 70 & 65 & 85 & 80 & $\cdot$ & 70 \\
\hline \multirow[t]{9}{*}{ Intant } & Sex & 1 & m & $t$ & f & 1 & 1 & f & m & 1 & 1 & m & I & 1 & 1 & 1 \\
\hline & Gestational ago & $38 \mathrm{w} 3 \mathrm{~d}$ & $38 w 2 d$ & $37 w 6 d$ & $41 w$ & $39 w 2 d$ & $37 w 5 d$ & $40 w 3 d$ & $38 w$ & $40 w 5 d$ & $39 w$ & $39 \times 1 d$ & $40 m 1 d$ & $41 w$ & $40 w 6 d$ & $39 w 3 d$ \\
\hline & Birth weighth & 1580 & 2270 & 2110 & 2480 & 2450 & 1960 & 2240 & 2280 & 2230 & 2300 & 2410 & 2060 & 2720 & 2270 & 2200 \\
\hline & Birth length & 39.5 & 46.0 & 4.5 & 45.0 & 45.0 & 44.4 & 45.0 & 44.0 & 45.0 & 46.5 & 47.5 & 4.0 & 48.0 & 44.0 & 46.5 \\
\hline & Ponderal indax & 2.56 & 2.33 & 2.40 & 2.72 & 2.70 & 2.25 & 2.46 & 2.67 & 2.45 & 229 & 225 & 242 & 2.46 & 2.66 & 2.19 \\
\hline & Head circumferance & 32.0 & 30.5 & 31.4 & 33.0 & 33.0 & 33.0 & 31.5 & 33.0 & 332 & 32.0 & 33.4 & 31.5 & $\cdot$ & 30.5 & 32.2 \\
\hline & Apgar 11 & 9 & 9 & 9 & 9 & 9 & 6 & 9 & 9 & 8 & $B$ & 8 & 9 & 8 & 8 & 9 \\
\hline & Apgar $5^{\prime}$ & 10 & 9 & 10 & 10 & 10 & 8 & 10 & 10 & 9 & 9 & 10 & 10 & 9 & 9 & 10 \\
\hline & Ph umbilical artery & 7.30 & 7.34 & 727 & 7.30 & 727 & 7.18 & 7.30 & 729 & 727 & 7.33 & 727 & - & 7.30 & 7.14 & 7.20 \\
\hline
\end{tabular}

$G / P / A=$ Gravida $/$ Para $/$ Abortions; Max. diastolic $B P=$ Maximum diastolic blood pressure; $m=$ male; $f=f e m a l e ; ~ w=w e e k s ; d=d a y s$ 


\section{Appendix III Quality Score of General Movements}

Registration number

GM number

Tape position

State

Item

Categories

Score

1. Onset of movement

1 =abrupt $/ 2$ =smooth

[ ]

2. Variability in speed

$1=$ absent $/ 2$ =present

[ ]

3. Overall speed

$1=$ predominantly fast

$2=$ predominantly slow

[ ]

4. Speed of arms compared to legs

$1=$ higher

$2=$ lower

$3=$ equal

[ ]

5. Force against gravity

$1=$ absent $/ 2=$ present

[ ]

6. Variability in amplitude

$1=$ absent $/ 2$ = present

7. Overall amplitude

$1=$ predominantly large

$2=$ predominantly small

8. Amplitude arms compared to legs $1=$ larger

$2=$ smaller

$3=$ equal

9. Fluency

$1=$ not fluent:

$a=$ tremulous

$\mathrm{b}=$ flapping

$c=$ abrupt, jerky

2 = fluent

10. Variability in movement pattern

$1=$ absent $/ 2=$ present

11. Variability in arm patterns

$1=$ absent $/ 2=$ present

12. Variability in leg patterns

$1=$ absent $/ 2=$ present

13. Fine distal movements

$1=$ absent $/ 2=$ present

14. End of movement

$1=$ abrupt $/ 2$ = smooth

15. Global judgement

$1=$ abnormal $/ 2=$ normal 


\section{Appendix IV}

Explanations of terms used in the quality score of general movements. Several items are not mentioned here as they do not need any further explanation.

\section{Onset of movement:}

the item is judged as "smooth" if the movement has a gradual onset, beginning in one limb and spreading slowly to the other limbs, with a gradual increase in intensity. The item is scored "abrupt" if the movement begins with a sudden movement of one or more limbs and with a high intensity.

\section{Speed:}

the item is judged to be "predominantly fast" if most of the components of the movement have a high speed, and "predominantly slow" if most components have low speed. The observer has to give his own interpretation concerning "high" and "low" speed.

Speed of arms compared to legs:

judged as "equal" if arms and legs have the same speed, "lower" if the arms move more slowly than the legs, "higher" if the arms move faster than the legs.

\section{Amplitude:}

the amplitude of the general movement is judged to be "predominantly large" if most of the movements of arms and legs have a large amplitude, i.e. if the movements in respectively elbow and/or shoulder or knee and/or hip have an amplitude which is equal to or larger than $50 \%$ of the maximal amplitude. Otherwise the amplitude of the general movement is judged to be "predominantly small".

Amplitude of arms compared to legs:

judged as "equal", "larger" or "smaller" if the movements of the arms have respectively the same, a larger or a smaller amplitude than the movements of the legs.

\section{Fluency:}

The movement is judged to be "fluent" if it is continuous with gradual accelerations and decelerations, without tremulous components. The move- 
ment is judged as "not fluent" if it is tremulous or abrupt and jerky with sudden accelerations and decelerations (Touwen 1990).

Variability in movement pattern, arm patterns, leg patterns:

Judged to be "present" if various patterns are present in the total general movement, in the movements of the arms and in the movements of the legs. Otherwise the items are scored as "absent".

Global judgement:

the quality of the general movement is judged as "normal" or "abnormal" according to the general impression and interpretation of the observer. 


\section{Publications}

INTER-AND INTRA-OBSERVER AGREEMENT IN THE ASSESSMENT OF THE QUALITY OF SPONTANEOUS MOVEMENTS IN THE NEWBORN.

Vivianne van Kranen-Mastenbroek, Robert van Oostenbrugge, Liesbeth Palmans, Anita Stevens, Herman Kingma, Carlos Blanco, Tom Hasaart, Johan Vles.

Brain \& Development 1992;14:289-93

POSTURAL BEHAVIOUR OF TERM SGA AND AGA NEWBORN INFANTS.

V.H.J.M. van Kranen-Mastenbroek, K.B. Folmer, H. Kingma, H. Caberg, C.E. Blanco, T.H.M. Hasaart, J.S.H. Vles.

Developmental Medicine and Child Neurology 1993;35:516-524

QUALITY OF SPONTANEOUS GENERAL MOVEMENTS IN FULL-TERM SMALL FOR GESTATIONAL AGE AND APPROPRIATE FOR GESTATIONAL AGE NEWBORN INFANTS.

V.H.J.M. van Kranen-Mastenbroek, H. Kingma, H.B. Caberg, A. Ghys, C.E. Blanco, T.H.M. Hasaart, J.S.H. Vles.

Accepted for publication in Neuropediatrics. 


\section{Dankwoord}

Vele handen maken licht werk. Hoewel "licht" in deze zin een understatement is, zou dit boekje er zonder de hulp van velen er misschien nooit, maar zeker nú nog niet, gekomen zijn. Ik wil iedereen die op een of andere manier aan de totstandkoming van dit boekje heeft bijgedragen, hetzij door mijn klaagzangen of juist mijn jubelzangen aan te horen, door te lezen en te corrigeren, mee te denken, interesse te tonen of er gewoon maar te zijn, heel hartelijk bedanken. Enkelen wil ik hier met name noemen.

Allereerst, mijn "baas" en vriend Dr. J.S.H. Vles. Beste Hans, hoewel je bij de publikaties als belangrijkste man steeds achteraan wilde staan, durf $i \mathrm{k}$ het nu aan je als eerste te noemen. Ondanks het feit dat wij het niet altijd evenzeer met elkaar eens waren, weet ik niet of dit boekje zonder jouw begeleiding nu al voor mij gelegen had. Ik hoop dat deze eerste "mijlpaal" het begin is van een langdurige samenwerking op wetenschappelijk en vriendschappelijk vlak.

Prof. Dr. C.E. Blanco, beste Carlos, jouw altijd enthousiaste begroeting met het bekende "Vivi", met direct daar achteraan steeds weer de vraag waar de volgende tekst toch bleef, heeft er telkens voor gezorgd dat ik elke nieuwe "deadline" op het nippertje haalde. Daar jij altijd gezegd hebt dat een proefschrift niet het eind van mijn wetenschap is, maar slechts het begin, hoop ik dat ik nog vaak op je steun mag rekenen.

Prof. Dr. J. Troost, beste Jaap, jou wil ik hartelijk bedanken voor de manier waarop je je, vanaf de eerste dag in Maastricht, hebt ingezet om de laatste loodjes niet al te zwaar te laten wegen. Je begrip voor de moeilijke combinatie van kliniek en wetenschap, in combinatie met je vermogen om de dingen te relativeren, hebben er zeer toe bijgedragen dat de gemaakte tijdsplanning ook werkelijkheid geworden is.

Dr. T.H.M. Hasaart, beste Tom, bedankt voor je enthousiasme en je eeuwige bereidheid om iets wat liever gisteren dan vandaag de deur uit moest snel, maar zeer nauwkeurig te lezen en te bekritiseren.

Dr. H. Kingma, beste Herman, jij hebt me geleerd om wetenschappelijk, maar vooral logisch te denken. Je hebt me wegwijs gemaakt in de wirwar van statistische bewerkingen, en tot op het laatste moment alle ideeën bekritiseerd. Het is er nooit slechter op geworden! Bedankt.

Dhr. H. Caberg, beste Bèr, bedankt voor de manier waarop je altijd de race tegen de klok bent aangegaan om de computerprogrammatuur niet alleen op 
tijd, maar ook nog zeer gebruikersvriendelijk te maken. Het heeft jou heel wat vrije uurtjes gekost en mij er des te meer bespaard!

Katinka Folmer, lieve Katinka, ontzettend bedankt voor alle uren die je, soms tot vervelens toe, voor de video hebt doorgebracht. Ik hoop dat je met even veel volharding je studie beëindigt en misschien kan ik dan ooit terugdoen wat jij voor mij gedaan hebt.

Robert van Oostenbrugge, Liesbeth Palmans en Anita Stevens bedank ik voor hun inzet bij het totstandkomen van hoofdstuk 4.

Alle verpleegkundigen van de kraamafdeling, die mij gewaarschuwd hebben wanneer er een gezonde zuigeling op hun afdeling verbleef, en de verpleegkundigen van de neonatologie, die altijd bereid waren te helpen bij de video-opnamen, en natuurlijk Annemiek, die mij leerde zo efficiënt mogelijk de gebruikte couveuse te poetsen, en die het mij zo vaak uit handen nam.

Alle ouders van de kinderen die hun kind na enkele dagen al voor enige uren "uitleenden", en er soms in hun kraamdagen speciaal voor naar het ziekenhuis kwamen.

Alle AIO's en niet-AIO's van de vrijdagmiddag meiden groep, waarin met veel plezier heel wat gal gespuugd werd en keiharde kritiek geleverd werd. Ik hoop dat er nog vele promotie-feesten uit voortvloeien. Irene, ik zal jouw boekje straks ook met plezier "muggeziften"!

Lisette Heuts-van Raak, beste Lisette, bedankt voor het delen van alle smart en je veelvuldige computerkundige Eerste Hulp Bij Ongelukken.

Alle collega-assistenten neurologie die altijd bereid waren om even het sein over te nemen als ik weer eens iets te bespreken had, en die mijn taak hebben overgenomen in de tijd die ik kreeg om dit proefschrift af te ronden.

De secretaresses van de Neurologie wil ik hier bedanken voor het feit dat zij altijd bereid waren te helpen en nooit mopperden als ik weer eens langdurig een van de computers in beslag nam. Thera, bedankt voor de "laatste" correcties.

De medewerkers van de AV-dienst bedank ik voor hun zeer gewaardeerde en veel gevraagde audio-visuele bijstand.

Ook Drs. V. Nanninga-van den Neste en Dr. O. van Nieuwenhuizen mogen in dit dankwoord niet ontbreken. Zij hebben nog tijdens mijn studie de eerste steen voor mijn kinderneurologische en wetenschappelijke interesse gelegd.

Mijn ouders bedank ik voor de manier waarop zij mij altijd gestimuleerd hebben om dat te gaan doen wat ik zelf het liefst wilde, en voor hun nooit aflatende interesse in alles waar ik mee bezig ben.

Lieve Wouter, bedankt voor de vele "harten" die jij me onder de riem stak als het niet ging zoals ik het wilde, voor de manier waarop je al die jaren mijn onderzoeks-enthousiasme deelde en voor het feit dat je er gewoon altijd was. 
tha

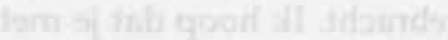

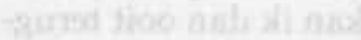

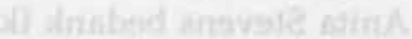

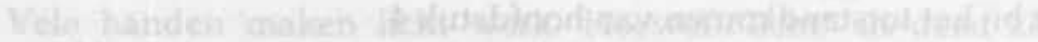

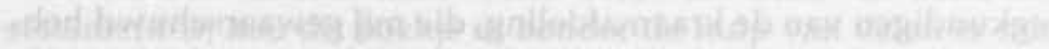

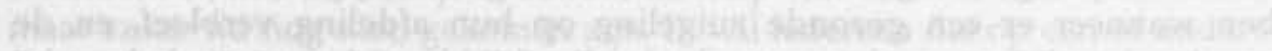

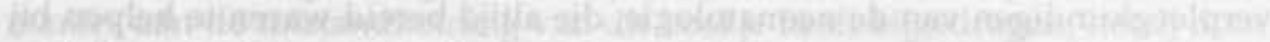

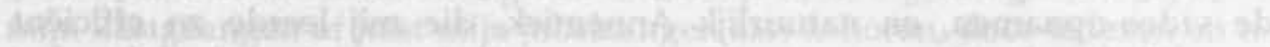

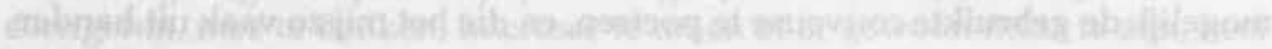

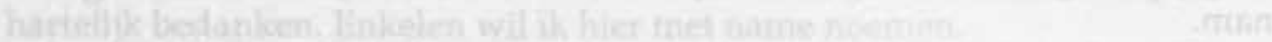

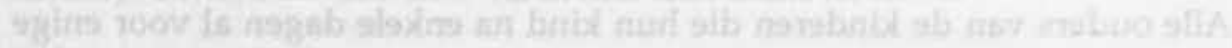

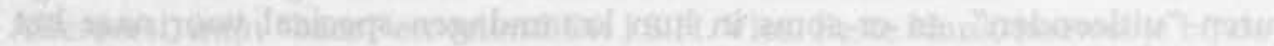

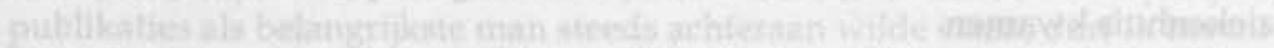

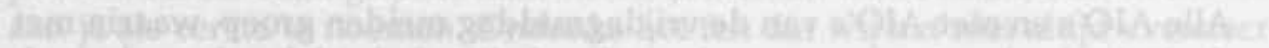

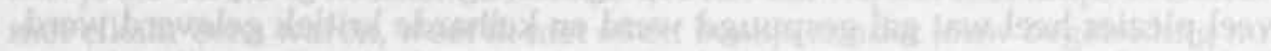

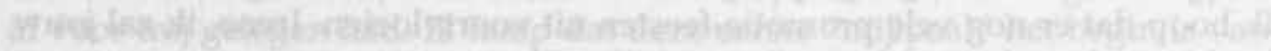

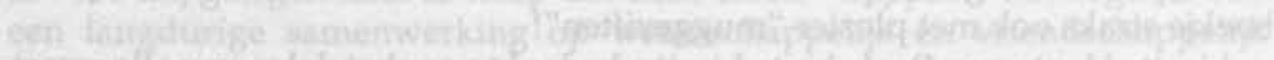

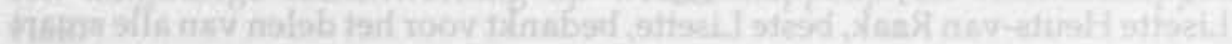

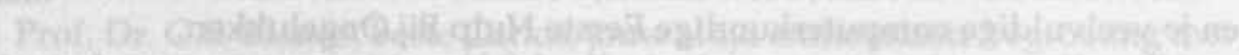

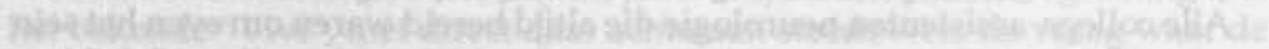

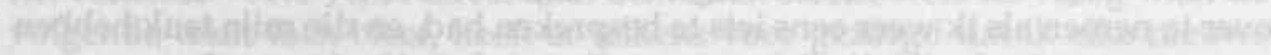

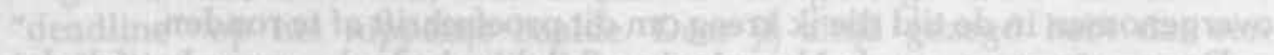

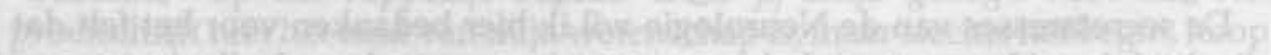

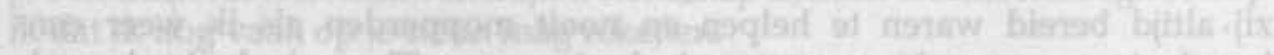

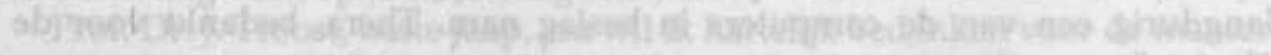

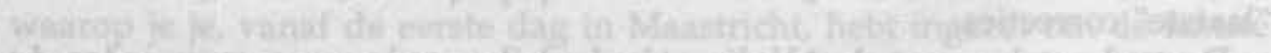

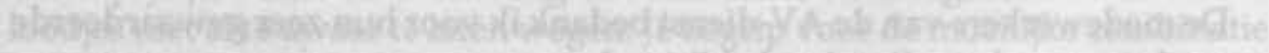

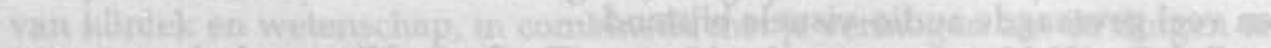

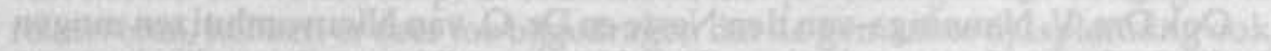

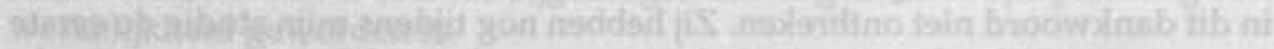

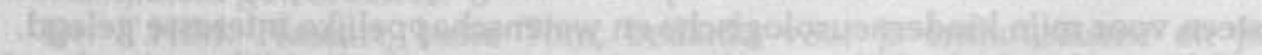

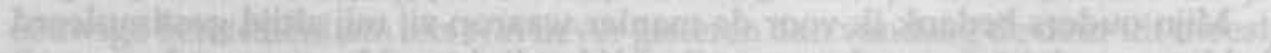

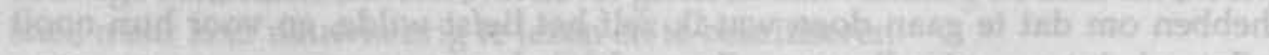

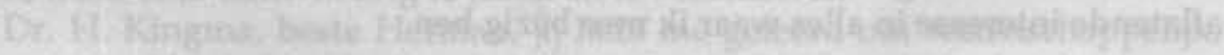

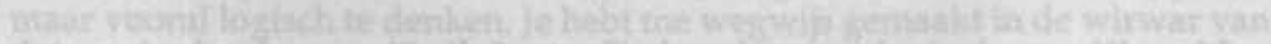

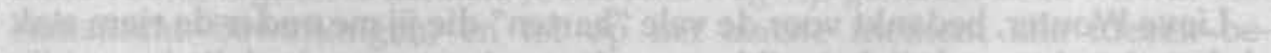

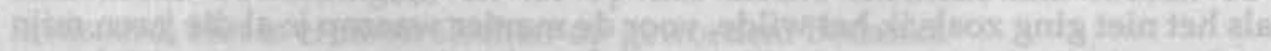

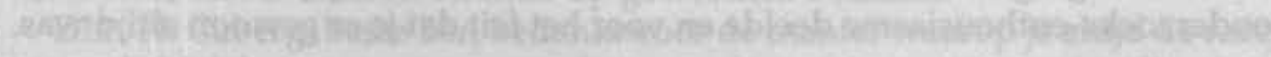

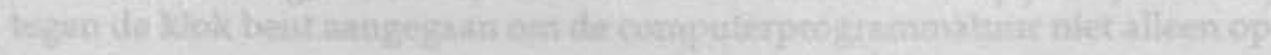




\section{Curriculum Vitae}

The author of this thesis was born on the November 6, 1962, in Geleen, The Netherlands. She attended secondary school (Atheneum B) and graduated in 1981. After studying Physiotherapy for one year she started medical training at the University of Utrecht in august 1982. After graduation in october 1989 she became a research fellow at the department of Neurology of the University Hospital Maastricht (Prof. dr. P.J.M. van der Lugt). In November 1992 she started her specialist training in neurology at the Department of Neurology of the University Hospital Maastricht (Prof. dr. J. Troost). 
